ISSN 2414-987X
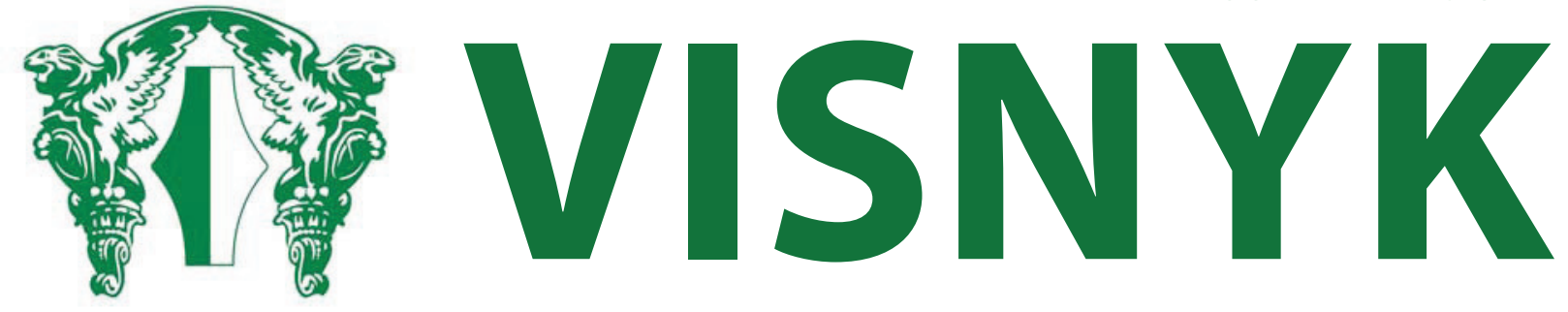

OF THE NATIONAL BANK OF UKRAINE

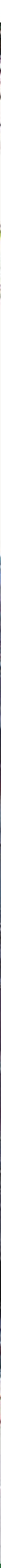

QUARTERLY RESEARCH

JOURNAL OF THE NATIONAL BANK OF UKRAINE

№ 239 March 2017 
Quarterly research Journal

of the National Bank of Ukraine

Published since March 1995

\section{Editorial Board}

\section{Dmytro Sologub}

Chairman of the Editorial Board, Deputy Governor,

the National Bank of Ukraine

\section{Vitaliy Vavryshchuk}

Director of Financial Stability Department, the National Bank of Ukraine

\section{Yuriy Gorodnichenko}

Associate Professor, University

of California, Berkeley, PhD

\section{Oleksandr Petryk}

Doctor of Economics,

Professor

\section{Inna Spivak}

Head of International Economy Analysis Unit of Monetary Policy and Economic Analysis

Department, the National Bank of Ukraine, Doctor of Economics

\section{Sergiy Nikolaychuk}

Deputy Chairman, Director

of Monetary Policy and Economic

Analysis Department, the National Bank of Ukraine, PhD

\section{Oleksiy Kryvtsov}

Director in the International Economic Analysis Department, Bank of Canada, PhD

\section{Tom Coupe}

Associate Professor,

University of Canterbury, PhD

\section{Viktor Koziuk}

Head of Economics Department at Ternopil National Economic University, Member of Council of NBU,

Doctor of Economics, Professor

\section{Andriy Tsapin}

Deputy Head of Research Unit of Monetary Policy and Economic Analysis Department, the National Bank of Ukraine, PhD

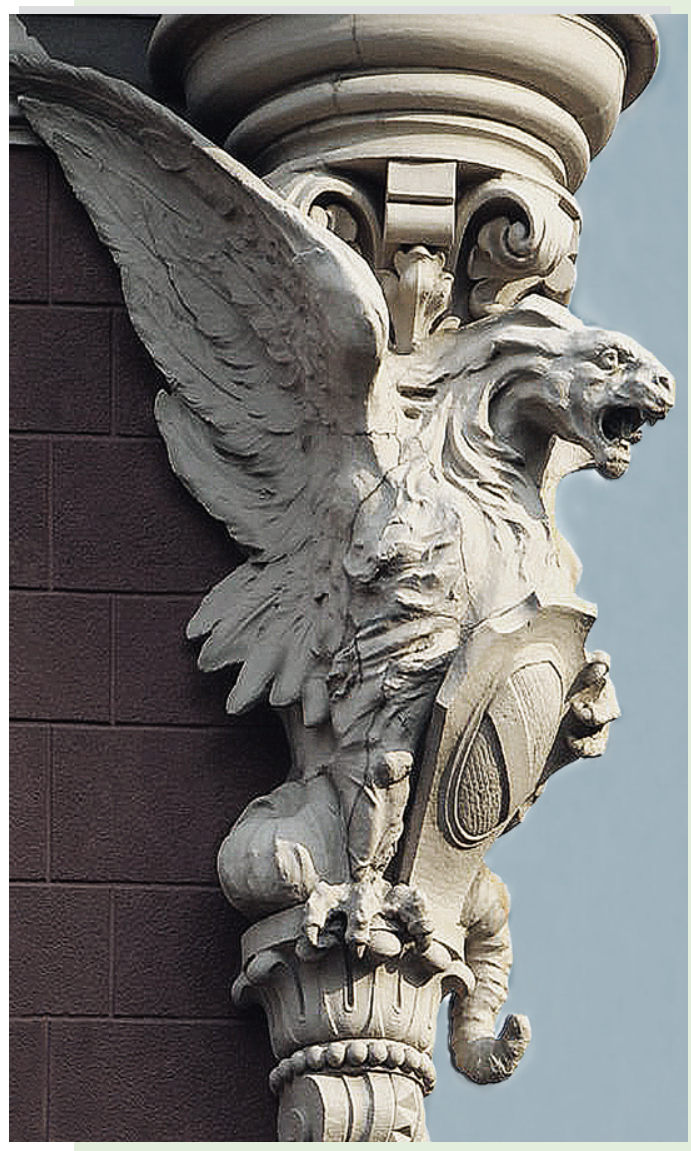

Founder and publisher:

National Bank of Ukraine

Editorial Board ensures compliance with ethical standards of publishing

For reprinting materials published herein the reference to the journal "Visnyk of the National Bank of Ukraine" is compulsory

The Editorial Board can publish materials being under discussion, not sharing the author's opinion

The author bears responsibility for the accuracy of the materials 


\section{PREFACE OF THE CHAIRMAN OF THE EDITORIAL BOARD}

\section{Dear readers,}

The current issue contains articles that address important aspects of a central bank's regulatory activity, study the specific behavior of economic agents, as well as model and estimate how non-performing loans influence the performance of banks and their borrowers.

This issue starts with an article by Viktor Koziuk Central Bank Independence and Financial Stability: Orthodox and Heterodox Approaches, which explores the conditions when a central bank's independence allows it to deliver financial stability. The author argues that post-crisis discussions about a central bank's independence are more about the relation between the bank's independence and mandate in financial stability rather than being about a choice of a level of independence. The article examines two approaches to a central bank's independence: the orthodox approach and the heterodox one. The author believes that the orthodox view is contradictory in its nature since a central bank's independence may have negative implications for the bank's responsibility - too much interference in the financial cycle may impair transparency, with deflation risks being in conflict with price stability principles. The heterodox approach implies that a central bank's greater responsibility for delivering financial stability requires a healthy institutional environment and a higher level of independence to give the central bank the right to interfere into the financial cycle, and to tighten its regulatory policy. The author argues that the price stability mandate should remain first priority, and financial stability issues should be institutionalized in a clearer way to secure independence.

The article Behavioral Finance: History and Foundations by Pavlo Illiashenko argues that economic research may be influenced by ideologies and have a bearing on economic agent decisions. The focus of the research is on studying the development and psychological foundations of the behavioral finance theory. The article provides a convincing case for a dichotomy between behavioral and classical finance.

The article Stock-Flow Consistent Modeling of Default Events Sequence in a Closed Economy by Ihor Voloshyn shows the entire chain of events from the default of firms through the fire-sale of goods to repay NPLs to the write-off of such loans. The author constructs a matrix of financial transactions, which is incorporated in the transactions-flows matrix. Ihor Voloshyn develops a stock-flow consistent model of a closed economy on the basis of the balance sheet and transactions-flows matrices. This model helps track economic dynamics and study the influence of such key parameters as the probability of default, the rate of fire-sales, the recovery rate, and interest rates on loans and deposits on the performance of banks and firms. 
We hope that the articles published in this issue will be useful for experts in finance, banking, monetary policy and macroeconomics. Researchers and scholars are invited to join professional discussions about relevant issues related to a central bank's regulatory activity, as well as other relevant issues related to the operation of the financial sector. Authors can submit their articles to the Visnyk of the National Bank of Ukraine at journal@bank.gov.ua.

Best regards,

Dmytro Sologub 


\section{CONTENTS}

\section{Viktor Koziuk}

Central Bank Independence and Financial Stability:

Orthodox and Heterodox Approaches

\section{Pavlo Illiashenko}

Behavioral Finance: History and Foundations

Ihor Voloshyn

Stock-Flow Consistent Modeling of Default Events

Sequence in a Closed Economy 


\title{
CENTRAL BANK INDEPENDENCE AND FINANCIAL STABILITY: ORTHODOX AND HETERODOX APPROACHES
}

\author{
Viktor Koziuk \\ Ternopil National Economic University \\ E-mail:viktorkoziuk@tneu.edu.ua
}

\begin{abstract}
This study argues that post-crisis discussions on central bank independence are less about a choice of a level of independence but more about a relation between the independence and the central bank mandate in financial stability. An offered hypothesis states that an increasing role of financial factors in the macroeconomic policy agenda has led to emerging of two approaches to the central bank independence. Within the orthodox approach, responsibility for the financial stability is a challenge to the accepted model: one mandate - one goal - one instrument. Interference into the financial cycle impairs transparency and distorts responsibility, while deflation bias risks get in conflict with price stability principles, adherence to which is exactly what central banks are granted independence for. In terms of the heterodox approach, a wider responsibility of central banks for financial stability requires more independence to protect the legitimacy of interference into the financial cycle and implementation of a more prudent regulatory regime. Orthodox view is contradictory in its nature, while the vulnerability of the second approach lies in quality of institutional environment. Price stability mandate is argued to remain the first priority, while the financial stability issues should be institutionalized in a clearer way to secure independence.
\end{abstract}

\section{JEL Codes: E02, E44, E58}

Keywords: central bank independence, financial stability, price stability, macroprudential regulation, financial cycle, dynamic inconsistency

\section{INTRODUCTION}

New macroeconomic phenomena and financial turbulence after the global crisis have long been calling for concentration of researchers' attention to the role of central banks in the "new" context. At the moment, the established "new normal" phenomenon following the rethinking macroeconomic policy leaves the question open on a desirable institutional functioning of monetary authorities. Implementation of nonconventional monetary policy programs has had an impact on changes in its operational design which resulted in further actualization of question how new features of central banks' operation and environment correlate with the central bank status. At the same time, post-crisis developments in central banking and emergence of new responsibilities only emphasize that traditional challenges do not go away but instead are reinforced with the new ones. In post-crisis reality discussions on central bank independence become more pronounced, with financial stability being their integral expression.

The problem of defining a role of central bank independence in the area of financial stability is attributed, to a large extent, to the fact that achievements of price stability and financial stability are not always the same thing. Deficiency of the quantitative basis for the latter, lack of tool-kits for achievement of predictable results, discrepancies in the policies are only a few items on the long list of their differences. Despite huge differences between the substance of the two, however, they still have a wide range of issues in common. Among those common grounds are, in particular, the problems of political pressure, dynamic inconsistency, and quality of institutions.

In light of the established views in the publications on the problem of independence and critical thinking on the subject in the context of the new reality of central banking after the crisis, the author offers a hypothesis on existence of two basic 
approaches: the orthodox one where responsibility for the financial stability is a challenge to the classical central bank independence model: one mandate - one goal - one instrument; and the heterodox approach under which the principle of central bank independence should be applied to the financial stability tools in a similar way to its use for the price stability purposes. Therefore, this article is an attempt to systematize any disputable questions on connection between financial stability and central bank independence with the aim to deepen the theoretical understanding of such connection. This deepening is structured in the following ways: comparative analysis of price and financial stability in the context of tool-kit for central bank independence analysis; problem of dynamic inconsistency in financial stability; issue of proactive and reactive policies in light of monetary authorities' status; optimal design of macroprudential regulation. The above areas are studied for correlation between quality of institutions and financial stability etc.

The article is structured as follows. Section II offers analysis of publication sources that have been used as the basis for separation of the pre-crisis dominants from the post-crisis ones in analysis of connection between central bank independence and financial stability. Section III focuses on differences between price stability and financial stability, potential conflicts in achieving them, and their consequences for monetary policy and central bank independence. Section IV covers the topic of dynamic inconsistency in the area of financial stability policy and the respective institutional design of central banks. Section $\mathrm{V}$ deals with institutional design of macroprudential policy and summary on orthodox and heterodox views on independence of central banks in the area of financial stability.

\section{CENTRAL BANK INDEPENDENCE, FINANCIAL SHOCKS, AND MONETARY RESPONSE: PUBLICATIONS OVERVIEW}

\section{Underlying view on the problem}

The well-documented empirical correlation between the level of central bank independence and inflation Grilli et al. (1991), Cukierman (2008), Crowe and Meade (2008), Arnone et al. (2006), Arnone et al. (2008) co-existed with an equally early opinion that exercise of functions beyond monetary policy scales down their autonomy. It stands to reason that when calculating the canonic GMT-index, endowing central bank with banking supervision functions was considered good enough grounds to reduce the index figure Grilli et al. (1991). The rationale is as follows. Inclusive information on the banking system conditions generated during exercise of the supervisory functions is an incentive to perform the role of the lender of last resort in contradiction to the inflation targets. Extending political pressure to the central bank has also been offered as a reasoning. Such political pressure is associated with "lobbying" certain banks. It is also caused by perception of the banking regulation burden, which, by strengthening financial stability due to certain macroprudential procedures may, however, reduce the profitability of the banking business because of the tougher requirements to lending standards. The main conclusion based on the above comes to the point that wide functions of central banks in the area of financial stability restrict their independence and constitute a threat of a higher inflation level.

At the same time, this conclusion adopted as the principle of building independence indices has opened a way to a wider discussion which can be tentatively divided into three parts: connection between price stability and financial stability; empirical analysis of functions of central banks' reaction to financial shocks; empirical analysis of correlation between the independence level and the financial stability.

As regards the connection between price stability and financial stability, different views can be clearly distinguished. According to Smets (2014) they are the following: price stability and financial stability are identic; advanced achievement of financial targets is a trigger of macroeconomic volatility; price stability and financial stability are in conflict with each other. Based on such approaches one can see two basic modalities of monetary policy participation in ensuring financial stability: clearing the market through increase of liquidity supply after a financial shock; raising the rates "to prickle the bubble" before it to avoid macroeconomic deterioration in future (IMF, 2015). The two mentioned policies have been called reactive and proactive approaches, respectively, to central bank's reaction to financial instability with the help of monetary instruments (as a reminder, macroprudential instruments had not been actively discussed before the crisis).

Empirical researches of the reaction function also produce ambiguous results. One can observe a general tendency that central banks react to financial stress by lowering the rates compared with the ones that could have been considered optimal based on the Taylor's rule calculations. The outcome of this is a higher level of inflation after the crisis (Bauducco et al., 2008). Cecchetti and Li (2005) emphasizes the importance of the cycle phase and the procyclical effects of microprudential regulation, however, they confirm the rates' undervaluation. Bulir and Cihak (2007) also point to lower rates as a reaction to a financial shock but at the same time stress the importance of the economy's structural features. Reactive policy is more typical for closed economies. Borio and Lowe (2004) reveal the dominance of the reactive policy. Although, this does not directly prove that "supervisory functions reduce the independence level, and exclusive information about the banking system conditions induces a softer policy which results in higher inflation". However, it is the description that was given in a later publication (Cihak, 2010). 
Contrary to the analysis of reaction function, the results of which can be classified as indirect confirmation (built on logical conclusions) of the hypothesis that cases of financial instability and dealing with its consequences have an impact on reduction of monetary autonomy, while empirical researches of correlation between the independence index of central banks and such instability show a different picture. For example, researches by Garcia Herrero and Del Rio (2003) and Cihak (2007) ascertain a direct relation between a chosen independence index and financial stability. In both cases the latter is associated with banking stability and the respective variable is used in panel regression. Klomp and de Haan (2009) reveal the inverse relation between the independence index and financial instability for 1985 - 2005 period for a wide selection of countries. Their research is characterized by the use of several specifications of independence index and a wide range of financial instability indicators. Thus, their understanding of the latter implies the use of variables that characterize both banking and much wider financial crises. The most important result of their research is the conclusion that financial instability is closer inversely correlated with political independence of central banks than with the economic one. This can be interpreted as the central bank ability to withstand political pressure that could lead to a policy incompatible with financial stability. Such conclusion contrasts with the research line started by Debelle and Fischer (1994) who state that for maintaining price stability the role of instrumental (economic) independence is more substantial.

At the same time, the conclusion made by Klomp and de Haan (2009) has several fundamental political and economic consequences. The authors indirectly point to the quality of institutions and the ability to withstand political pressure as well as self-responsibility of a central bank with a strong autonomous status. Here the conflict between price stability and financial stability is also removed because the independence level has a positive impact on the both over the long term. This conclusion should be considered as more institutional. The key role of political independence in the area of financial stability indirectly correlates with conclusions of the second generation research of the relation between monetary autonomy and inflation where the main emphasis is laid on quality of institutions and democracy level as drivers of public choice in favor of more independent central banks (review of the problem is offered in researches by Bodea and Hicks (2012), Dincer and Eichengreen (2014), and Koziuk (2016).

\section{Post-crisis experience: an increasing lack of theoretical consensus}

The global financial crisis has prompted the revision of probably one of the most strongly established views about distribution of roles in achieving price and financial stability, whereby monetary policy ensures the achievement of the first goal, while microprudential policy through supervision of individual financial institutions safeguards the financial stability goal. Following of the Tinbergen Rule has "conveniently" suited to the conceptual view of central bank independence because it opened a way to the orthodox approach of "one mandate - one goal - one instrument". However, precisely the review of such an approach and the necessity to introduce policy instruments addressing systemic risks, which is being emphasized in a number of wellknown papers of Blanchard et al. (2010, 2013), Eichengreen et al. (2011), Bayoumi et al. (2014), was the starting point for the post-crisis debate about the role of central bank independence in financial stability.

The analysis of relevant literature on the topic enables to pinpoint important issues in view of the fact that the traditional orthodoxy is being revised. Even if maintaining within the boundaries of the traditional mandate is acceptable, the operational expansion across those boundaries is already an accomplished fact (Caruana, 2013), Koziuk (2015). Reflections upon the consequences of the global financial crisis and emergence of a "new normality" have centered around the following ideas.

First, it is the financial crises that are driving forces behind a change of mandates of monetary authorities. Such events are fostering a sense of responsibility for financial stability within the mandate, which specific definitions vary in time (Reinhart and Rogoff, 2013). The survey of central banks' officials have confirmed this viewpoint. The role of financial stability in macrostrategies and in empirical focus of monetary authorities' activity has strengthened significantly, even in the absence of actual changes in the mandate (Carre, 2012). On the other hand, exaggerated expectations of society and key economic actors regarding central banks' "almightiness" make the former extremely vulnerable to political pressure. Aggressive stimulating steps with their long-term repercussions, being either dubious or destructive in nature, are posing a threat Blinder (2012), Cecchetti (2013), Caruana (2013), Orphanides (2013), Rossi (2013).

Second, the issue whether a central bank's mandate should explicitly pursue a goal of ensuring financial stability is relevant not only to the interpretation of an analytical framework of the independence concept, but also from the perspective of finding the correlation between price and financial stability. It is precisely this aspect that is being fervently debated. The differences between price and financial stability in the extrapolation of political interpretation of the mandate and the results for political assessments of central bank performance make the search for theoretical consensus more difficult. In this regard, it is possible to single out the following alternatives:

- safeguarding the price and financial stability has to be the prerogative of separate independent bodies Svensson (2012, 2016); 
- the financial stability has to be explicitly included into the mandate of a central bank, with the former enjoying a sufficient level of independence, transparency and accountability (Eichengreen et al., 2011);

- financial stability may not be explicitly defined. What matters is the ability of central banks to pursue a proactive policy while preventing the anti-crisis measures from being viewed as wealth distribution and subjection to fiscal targets (Koziuk, 2015);

- in a deflationary environment, the mandate issue is not a matter of principle (Does Central Bank Independence Still Matter, 2008). Increasing inflation targets may be viewed advisable for broadening a zone of lower rates necessary for an effective stabilization (Blanchard et al., 2010).

Third, the issue of organizational design is becoming crucial regardless of whether financial stability is an explicit element of the mandate, or it implicitly impacts a central bank's decisions amid considerations about how financial shocks affect deviations of inflation and GDP gaps from target levels. There is a lack of consensus in scientific papers that place emphasis on the organizational design, that is whether the macro-prudential supervision should be included into a central bank's competence or delegated to a separate body. In the absence of coordination breakdown, and provided there is a flexible exchange of information about aggregated risks and system vulnerability, the architecture of bodies responsible for financial stability is not a matter of principle. However, in the event of institutional imperfections with regard to the coordination process, the best approach is the consolidation of functions within a central bank (Bayoumi et al., 2014). An alternative approach envisages a quasi-fiscal nature of instruments of the macro-prudential regulation, therefore, the best choice will be to delegate financial stability functions to a separate body that would be closely cooperating with the Ministry of Finance (Georgsson, 2015). Such an approach toward the organizational design correlates with a view outlined in the paper of Svensson (2012, 2016). However, when it comes to delegation of the macro-prudential regulation powers to an independent central bank, political and economic arguments get to play an important role Eichengreen et al. (2011), BIS (2011), Acharya (2015). It shows the departure from a traditional orthodoxy "one mandate - one goal - one instrument" and the emergence of some sort of alternative in a theoretical analysis between independence of central banks and financial stability.

At the same time, authors Masciandro and Volpicella (2016) in their papers bring forward the empirical argument in support of a traditional approach. They do not play down the importance of macro-prudential regulation in the post-crisis economic architecture. However, whether a central bank would likely be granted such powers depends on the fact whether it is already performing micro-prudential regulation, and whether its mandate gives less political independence and less restrictions with regard to the monetary policy. The key issue here is that a lower level of political independence correlates with a higher probability of additional macroprudential regulation functions being delegated to a central bank. The same conclusion was made by Masciandro et al. (2008) arrive at the same conclusion as to the role of the quality of institutes and a level of independence of a central bank in financial supervision. They point to even a stronger correlation between the effective performance and more accountable supervision bodies. Ensuring independence of financial supervision does not itself guarantee better results, regardless whether it is performed by a central bank or a separate regulatory body.

Building on the findings about a positive relationship between the institutional quality, central banks' independence and transparency (Dincer and Eichengreen, 2014), findings of Masciandro et al. $(2008,2016)$ underscore a fundamental importance of institutional determinants concerning both price and financial stability. Although such findings speak in favor of the traditional orthodoxy. However, a higher level of inflation in the countries where a central bank is tasked with the micro-prudential regulation (Bayoumi et al., 2014), and an inverse correlation between central bank's independence index and the probability of financial stress (Cihak, 2010) expose vulnerabilities of the New-Keynesian approach to macroeconomic policy. Cihak (2010) also states that the central bank independence index is in an inverse correlation with crisis early warning indicators, but in direct correlation with an indicator reflecting the reliability and completeness of financial stability reports, as well as with the index of compliance with Basel Core Principles. Thus, the level of independence is important for ensuring financial stability. In other words, if the central bank functionality can (and must) be directed at financial stability, an issue of departing from the model "one mandate - one goal - one instrument" has to be theoretically analyzed more thoroughly.

The hypothesis about the existence of orthodox and heterodox approaches to the role of central banks' independence in financial stability will help structure more efficiently theoretical differences and polar proposals regarding the nature of the policy and its institutional support in the area of macrofinancial regulation. Accordingly, it is necessary to make understanding of the central bank status as regards to ensuring financial stability more profound in terms of comparative characteristics of price and financial stability, risk analysis of the dynamic inconsistency of the policy addressing financial stresses and systemic risks, the selection of proactive or reactive modality of monetary decisions, macro-prudential regulation, institutional determinants of pressure on the central bank and so on. 


\section{PRICE AND FINANCIAL STABILITY: NATURE OF CONFLICT, PROBLEM OF MANDATE INTERPRETATION, STATUS OF CENTRAL BANKS}

\section{Different views on macroeconomics}

Generalization of the experience of 1970-1990s shows that maintaining price stability was sufficient to ensure financial stability, at least theoretically. With the promotion of the rational expectations hypothesis, the nature of interpretation underwent some changes. According to the opinions set forth in the paper by Schwartz (1995), economic agents include the financial system conditions into a expected level of inflation, thus the additional control over financial variables is not required. Maintaining price stability is sufficient. One could assume that such state of affairs has created preconditions for a dominant position of the orthodoxy for a long time, according to which if a central bank best succeeds in curbing inflation, it will be the least sophisticated institutional solution aimed at ensuring financial stability.

However, in a low and persistent inflation environment, or even deflation, the situation looks differently. Downward deviations from the inflation target, accompanied by corresponding rate reduction and liquidity expansion, as well as the "search for yields" and "risk appetite" become a starting point of the dilemma of whether the monetary policy must be proactive or reactive. The same applies to an issue of intersection of monetary, macro- and micro-prudential policy functions. All can affect the aggregate loan dynamics in the economy and play an important role in sustaining such transmission channel of the monitory policy as risk-taking channel. The absence of a theoretical consensus concerning the modality and optimal coordination among those policies feeds discussions about the institutional format for ensuring price and financial stability, and therefore the independence of a central bank and its mandate, in particular, becomes a key focus of attention.

In this way, in accordance with the New-Keynesian approach set out in papers of Bernanke and Gertler (1999), as well as Svensson $(2012,2016)$ - any decisions made by central banks not in response to deviations of inflation and GDP from the target values result in their excessive variations sending misleading signals to economic agents. The loss caused by a proactive intervention will always be high, with monetary authorities' reputation being undermined. The reputation damage may be palpable, since a failure to identify a bubble in asset or credit markets in real time raises an issue about what has prompted a central bank's deviation from the declared policy goals. If independence is best ensured through a rigid price stability mandate, the determination of an inflation target and the use of an instrument, which relation to the target is foreseeable, then the deviation from the announced targets will come to be a serious argument regarding the monetary authorities' responsibility. If the reaction to financial imbalances is able to subject a central bank to greater political vulnerability, it is viewed as better either to delegate a correspondent instrument to a specialized body or differentiate "offices" within a central bank in a way that each of them will be pursuing relevant targets, applying specific instruments, thereby building up independent communication strategies and bearing independent responsibility.

It is easy to notice that a risk of losing a "part of economic growth" due to the reaction to a probable (and not necessarily inevitable) event in the future is transformed into the so called macroeconomic fetish. Paradoxically, but the traditional NewKeynesian rhetoric about the undesirability of reaction to the behavior of variables other than inflation and GDP, opens the way for a narrow vision on central bank independence. The orthodox approach "one mandate - one goal - one instrument" has been formulated from a dominant view of determinants of macroeconomic fluctuations, in which the financial sector is not given a critical role.

On the other hand, as the global financial crisis have demonstrated, the clean-up of the markets through pursuing unconventional monetary policy is a way out of traditional boundaries of this orthodoxy. Without a change in the mandate, the transformation of goals, as well as modification and expansion of instruments result in a situation when assessment of the level of independence of monetary authorities using a standard orthodox approach proves extremely difficult. Deflation risks prompt the search for sophisticated methods of influencing expectations (for example, forward guidance), encourage an unprecedented presence on the asset market, expansion of the scope of institutions at which the liquidity policy is being aimed. But this legitimizes a departure from the orthodox approach in terms of central bank independence, according to which financial stability concerns are not to be taken into consideration in monetary decision making. Underlining the importance of addressing the financial stability issue with the help of a special instrument helps only moderate the original position of the orthodox approach, but does not solve the issue of its intertemporal vulnerability. In other words, on a long-term horizon with an unequally distributed risk of the systemic financial stress, the orthodox view on the central bank independence undergoes dynamic inconsistencies.

Alternative to the New-Keynesian orthodoxy are the views of representatives of the Bank of International Settlements. A policy of response to unwinding a spiral of financial imbalances (commonly known as "lean against the wind") has a significant advantage in the sense that it prevents the transformation of a bubble into the crises, the effects of which have to be overcome with unconventional approaches, which are regarded as part of the problem or its source, rather than a solution. Apologetics concerning the market clean-up disregard the fiscal losses and structural distortions in financial behavior focusing on the central bank's ability to tackle most of the issues within the framework of a liquidity proposition at an extraordinary scale. It is namely due to criticism of dominant views on the reactive nature of monetary policy as an acceptable one, that the revision becomes possible of perceptions regarding central banks' arsenal and their response function, thereby laying the foundation for a broader look at their independence. 
At this, perceptions have evolved as to the instrumental formulation of policies of connecting price and financial stability. For example, Borio et al. $(2003,2004)$ first underlined the importance of monetary responses. Interest rate hike was expected to restrict liquidity expansion and financial imbalances build-up. Later, the focus shifted onto a specialized set of instruments aimed at the systemic financial vulnerability which is called macroprudential regulation (Borio, 2006). However, later Borio (2014) proposed a more integrated model (BIS, 2016), whereby monetary, macro- and microprudential policies combined with the fiscal policy need to be operating on a long-term horizon and in a coordinated manner so that to minimize pro-cyclical and destabilizing effects of each of them.

If within the orthodox approach there can be revealed an apology of the standard approach toward central banks' independence and the possibility of going beyond the boundaries of "one mandate - one goal - one instrument" model under the pretext of counteracting deflation risks and deepening of a negative GDP gap, then the assessment of BIS approach will not be straightforward. When remaining within the framework of the categorical apparatus of the orthodox approach, the coordination of at least four economic policies poses a challenge to independence and creates a prerequisite for the enhanced central bank's vulnerability in communication domain. Expanding a range of possible political interpretations of its actions can provoke a risk of an arbitrary manipulation of efficiency assessments with regard to measures taken and the relevance of set targets. Similarly, one can see that a principal role assigned to financial stability can be interpreted as an emergence of "financial dominance" (along with an "expectations dominance" phenomenon within the framework of unconventional policy implementation) to which monetary, regulatory and fiscal targets are subordinated. On the other hand, a central bank's extended functionality does not rule out that new responsibility areas must fall under the ambit of independence principles. An ever increasing role of the coordination approach toward ensuring financial stability does not necessarily mean that a central bank deviates from the targets it has set, rather to the contrary, it speaks to the strengthening of a central bank position's in cooperative architecture. It can be formulated in the following manner. If a government (and its stakeholders) is not interested in short-term risks of recession in response to a stricter monetary and regulation reaction addressing the pro-cyclical nature of the financial system and its systemic vulnerability, then its propensity for taking into consideration these risks while determining the optimal trajectory of the primary budget balance would be expected to enhance. Certainly, it does not mean that the government that has no formal commitments to financial stability is ready to deviate from its fiscal targets, which do not cover macro-financial risks, at least for reasons of electoral limitations. At the same time, a stronger position of central banks in the coordinated approach to ensuring financial stability deems possible provided its higher level of independence, and not on the contrary. At this, a higher level of political independence, and not only operational one, is implied, which corresponds to the logic of researches revealing empirically a positive correlation between the former and financial stability (Klomp and de Haan, 2009), Cihak (2010).

\section{Difficulties with interpreting elements of central banks' independence}

Although the connection between financial and price stability remains the issue of ongoing theoretical debates, when it comes to financial stability a conceptual view on central banks' independence is exposed to a number of limitations. Despite the validity of assumptions about the need to expand independence followed by functional expansion of central banks, there is a number of technical issues emerging when it comes to the mandate specification, its political interpretation, responsibility and transparency. If such an assumption is not valid, the issue of status, organizational design and responsibility becomes even more relevant. The urgency comes from the fact that central banks have actually expanded their responsibility for financial stability implicitly, while informal approval of policymakers have echoed the common interest in overcoming consequences of the crises and preventing deflation expectations from getting into the grip of secular recession. However, precisely the relativeness of unconventional policy results generates risks, either heading in the direction of enhancing responsibility for financial stability "in a wrong way", or conservation of an implicit "gray zone in the status quo". This is an institutional problem which becomes a determinant of central banks' architecture. A set of constituent elements of central bank's independence is suitably designed to counteract inflation. While a set of elements constituting central bank's independence in financial stability domain is either absent, non-determined or relative (Table 1). Most visibly it can be evidenced by a definition itself, a relevant policy goal, instruments, transparency model and responsibility (accountability).

\section{Table 1. Elements of central bank's independence and their relevance for price and financial stability}

Elements

Mandate (key objective) (political independence)

\section{Price Stability}

The higher level of its specification is as to conflict-free safeguarding of price stability, the better. The existence of equally important key tasks makes central banks vulnerable to a political pressure in terms of achieving any of them

\section{Financial Stability}

Explicit inclusion into the mandate expands not so much the scope of responsibility, but political interpretation of measures. Implicit inclusion, or non-equal importance with regard to the key task does not eliminate the problem of political pressure. On the other hand, both options strengthen a central bank's position when implementing unpopular regulatory measures 
Selection of final objective (political independence)

The procedure for appointing the management and its responsibility (political independence)

\section{Choice of instruments (operational independence) \\ Prohibition to finance budget deficit (operational independence)}

\section{Prohibition to purchase financial instruments other than state securities (op- erational independence)}

\section{Transparency}

Accountability

Provisioning under asset side operations (financial independence)

Covering loss using budget funds (financial independence)

\footnotetext{
Note. Prepared by the author.
}

Its delegation to the central bank improves financial stability prospects. In the event of distributed responsibility or delegating the achievement of an objective already set, the room for political maneuvers is narrowing, with the final objective becoming a subject of political compromise

The appointment of management for a term longer than an electoral cycle, as well as a clear procedure for defining responsibility for the policy, dismissal from the office, etc. foster prospects for implementing the price stability policy

It is essential for safeguarding price stability

This has a positive effect on price stability, thereby offsetting any fiscal dominance

This has a positive effect on price stability, thereby eliminating moral hazard

It is a key element in shaping relevant expectations and building confidence

It is a key element of ensuring a proper fulfilment of the mandate and eliminating a politically motivated pressure

Making a choice-of-instruments issue irrelevant, while, most importantly, reducing vulnerability to a potential possibility of transferring profit to the budget

It ensures that fiscal considerations will have no effect on the nature of policy relating to the mandate fulfilment
The quantitative determination is not easy to make, and therefore a central bank will always be susceptible to a political pressure, and so will it be able to call for the necessity to take financial stability into consideration in the current policy, regardless of the architecture of institutions tasked with ensuring such stability.

Appointing management for the term longer than an electoral cycle has similar effects. However, the non-availability of clear criteria for financial stability assessment makes a procedure for assessing performance and dismissing the management politically sensitive

Ensuring financial stability may be achieved through several policies at a time, and therefore to correlate the relevance of applied instruments and undefined targets deems very difficult. At this, it does not rule out the possibility for a central bank to operate based on the principle of structurally separated offices, enabled to select appropriate instruments and conduct independent communication policy

When a crisis escalates, the coupling of government debt position and the banking system performance diminishes possibilities of the policy aimed at supporting liquidity, which, however, conflict with the policy designed for price stability

Diminishing possibilities of supporting liquidity of specific markets or classes of financial instruments, although mitigating a contradiction with regard to inflation targets

Total transparency in financial stability domain is able to reinforce speculative or panic sentiments, although may contribute to improving assessments of systemic risks by private sector. Yet, the relevant assessment is possible given a fully-fledged financial system, effective institutions and trust

$A$ vague and interpretative nature of the financial stability definition, the absence of a clear quantitative objective and a specified operating framework makes an objective assessment of actions impossible. This weakens the central bank's independence making it politically vulnerable

Likewise. While the volume of provisions can be at such a level that reducing the amount of profit before transferring it to budget may give rise to fiscal and political conflicts

A level of loss may be significant, augmenting the central bank's vulnerability in terms of a fiscal and political conflict 
Thus, a definition of price stability is defined and consisting in maintaining a low and relatively stable level of inflation, measured through the consumer price index. The definition of financial stability provides for whole sets of options for definitions and, most importantly, the structure of the financial system itself does not always play a key role in generating systemic risks (i.e., the domination of banks in the financial system does not rule out that a source of instability may be a bubble in the real estate market, or substantial external borrowing of the real sector, etc.), but it remains important for a true understanding of those risks (for example, in the case of dollarization of liabilities, related party lending, etc.).

An issue regarding a policy goal is the continuation of the definition problem. If in the first case, the goal can be determined on a quantitative basis and the quantitative base itself is already an element of a specific operational framework, then, in the second case, no specific target or the quantitative base for its determination exist. There is a theoretical vision that a deviation of a financial variable from medium- or long-term trend may suggest imbalances, while a prolonged deviation that transforms into an exponential trend may herald a bubble. The situation looks even more complicated with regard to the term structure of interest rates or profitability indicators. The compression of spreads can occur relatively slowly, but their expansion may take place instantly. While profitability of the financial sector is peaking at times when systemic risks are getting most accumulated. The picking out of some indicator that best ascertains financial stability, or the analysis based on the financial conditions index is always an issue of interpretation.

The situation looks similar with regard to the instruments. Price stability is achieved through a traditional set of tools, whereas there is not any established set of tools addressing financial stability. Moreover, the latter can be ensured through a set of policies that can complement each other, but may as well conflict with each other. A possible "assignment" of policies to separated agencies also implies that a central bank is not a guarantor of financial stability of last resort.

A more serious situation with regard to responsibility is revealed. The absence of a defined objective results in a lack of the quantitative base, and a set of instruments allows for wide interpretations of the methodology for their use, with a political responsibility for financial stability being something rather relative. In countries with sound instruments, the scope of relativeness becomes narrower in the light of "debates in substance", while in other instances such a responsibility is instrumental in nature. Against this background, the relativeness in the definition of financial stability may easily transform into arbitrariness, which profile will be determined by political expediency.

It might be expected to help explain higher propensity of developed countries to include financial stability component into the mandate. The fact that it cannot be discerned in its pure form probably implies a stronger causality between price and financial stability, while in developed countries counterposing price and financial stability requires an adequate response from regulators. In other words, in the event of a politically expedient interpretation of the results of the policy, the nature of the mandate may be of secondary importance, while in the case of a political interpretation "in substance", the mandate issue becomes a part of an institutional design.

This problem can also be analyzed from another perspective. Those democracies that enjoy strong institutions will tend to seek a balance between independence, transparency and responsibility, which components become subject of political debates "by implication". Should financial stability conflict with price stability, a response on the part of institutional design will provide for full consideration of all possible risks and threats. A specific choice of a nature of the mandate and institutional design may turn out to be random in terms of countries. Its mixed character has been pointed to in the paper of Bayoumi et al. (2014). But behind it some specific traditions and political practices may stand (Masciandro et al., 2008). Two options may be used in the countries with weak institutions. A) A formal status is invariant. The most significant is actual control. In other words, the choice of institutional design will be determined by the fact to what extent it will enable the implementation of control over the financial system. B) The formal status may allow for a low level of independence whereby control can be exerted over the institution's policy. In both cases, financial and price stability will unlikely be antagonists, since the "capture" of the institution or manipulation of its policy will have a similar negative effect.

Similarly, the financial system structure may influence a political modesty of the central bank's status and design. Certain patterns may be singled out with regard to its policy. For example, during and in the aftermath of a crisis, a central bank may generate implicit subsidies to the financial sector through various unconventional measures or relaxation of regulatory requirements under the pretext of preventing the credit crunch shock. Amid the boom a central bank may be reluctant to take measures to curb the procyclicality of the financial system. As a result the overheated financial sector will be regarded as a source of rapid economic development. Market-based or banking-based models, and a level of their concentration will have a significant impact on a political and economic choice of politically exposed persons. In systems with dispersed ownership, as well as in systems with concentrated ownership, a motivation behind the regulation profile may differ. In the first case, monetary policy and financial regulation may be more distanced from each other. The opposite holds true in the second case. Concentrated ownership of the financial system will contribute to the fact that the regulation capture will generate lower transaction costs in the political process as a wide range of functions will be localized within the same structure. The higher will be the correspondence between weak institutions and concentrated ownership of the financial system, the more likely will be the concentration of powers relating to monetary policy and financial stability, which will encourage a tendency towards stronger control regardless of the formal status. 


\section{DYNAMIC INCONSISTENCY AND FINANCIAL STABILITY: DOES THE STRUCTURE OF MANDATE MATTER?}

\section{The nature of the conflicting objectives in the short and long term}

The conflicting objectives of the policy on the different time horizons (dynamic inconsistency) leads to its deterioration even before the start of its implementation. In case of the monetary policy it is an inflation bias (Kydland and Prescott, 1977). On the global monetary level this problem is also possible. In terms of expansion of liquidity the world is faced with a choice between faster growth of energy prices and greater financial vulnerability (Koziuk, 2009). In net extrapolation on financial stability, Cihak (2010) provides reasons why regulatory and anti-crisis aspects of the respective policies of the central bank fall under dynamic inconsistency. To this end, some assumptions are made. The growing level of financial instability generates expectations of crisis. Expectations of crisis generate the moral hazard problem. One cannot completely rely on the quality of the institutions, therefore a number of financial institutions activate the so-called "gamble for resurrection". The central bank affirms that it will be tough during crisis. However, economic agents do not trust the promises of the central bank supposing that instead of the promised toughness (publication of information about the real situation in the financial system, strict adherence to regulatory norms, the observance of all procedures of banking supervision, absence of supporting liquidity injections, etc.) it will be lenient. Such leniency means soft or flexible interpretation of the regulations, pumping of liquidity, shying away from the actual state of the financial system and connivance of risky business models etc. As a result, the lack of confidence in the central bank's tough policy in the area of financial stability will mean that during the crisis it will behave as expected. And this in its turn will allow a reasonable choice of moral hazard behavior which will result in accumulation of systemic vulnerability of the financial system. In the strategy game the central bank will always be a loser, except when its promises are trusted.

Cihak (2010) shows significant difference between dynamic inconsistency between price and financial stability. The monetary policy is a repetitive game which allows identifying the type of central bank behavior relatively quickly. Similarly, the game where the moves of participants are frequently repeated allows gaining trust quickly. Financial stability is time-expanded, and cases of crises are not frequently repetitive. In such circumstances it is difficult to track logic of central bank actions, and it is even more difficult to gain confidence, because it may be impossible to define how long it will take for economic agents to form such opinion.

For countries where financial instability is rare this issue is simpler. Usually, the sources of instability in such countries are inadequate macroeconomic policy and / or weak institutions. In such circumstances, the normalization of the situation goes hand in hand with a general trend towards an increased independence of the central bank and improved quality of institutions. At that, the latter is often the key to successful consolidation of the central bank status, and the first is a trigger for deeper reforms in other areas of public sector. However, strengthening of the central bank independence does not exclude the worsening situation, for example, in terms of public debt, if there are no parallel reforms in other parts of the institutional structure of the country (Acemoglu, 2008).

However, the dynamic nature of inconsistency in the area of financial stability is more complicated (see Table 2).

\section{Table 2. Comparative characteristics of dynamic inconsistency in terms of monetary, fiscal, and financial stability policies}

\begin{tabular}{|c|c|c|c|}
\hline $\begin{array}{c}\text { Elements of the } \\
\text { dynamic inconsistency } \\
\text { problem }\end{array}$ & Monetary policy & Fiscal policy & Financial Stability Policy \\
\hline $\begin{array}{l}\text { Socially optimal policy } \\
\text { in a long-term }\end{array}$ & Maintenance of price stability & Support of sovereign solvency & $\begin{array}{l}\text { Maintenance of the financial } \\
\text { system stability, elimination } \\
\text { of causes for accumulation of } \\
\text { systemic risks, counteraction to } \\
\text { the pro-cyclical behavior of the } \\
\text { financial sector, prevention of } \\
\text { financial imbalances, ensur- } \\
\text { ing of an adequate regulatory } \\
\text { environment }\end{array}$ \\
\hline $\begin{array}{l}\text { Socially optimal policy } \\
\text { in a short-term }\end{array}$ & $\begin{array}{l}\text { Creation of unexpected infla- } \\
\text { tion to stimulate employment }\end{array}$ & $\begin{array}{l}\text { Stabilizing response to a shock } \\
\text { or change in the preferences } \\
\text { on the structure and amount } \\
\text { of expenditures and taxes }\end{array}$ & $\begin{array}{l}\text { Support of the liquidity of } \\
\text { financial institutions and / or } \\
\text { flexible application of regula- } \\
\text { tory requirements }\end{array}$ \\
\hline
\end{tabular}




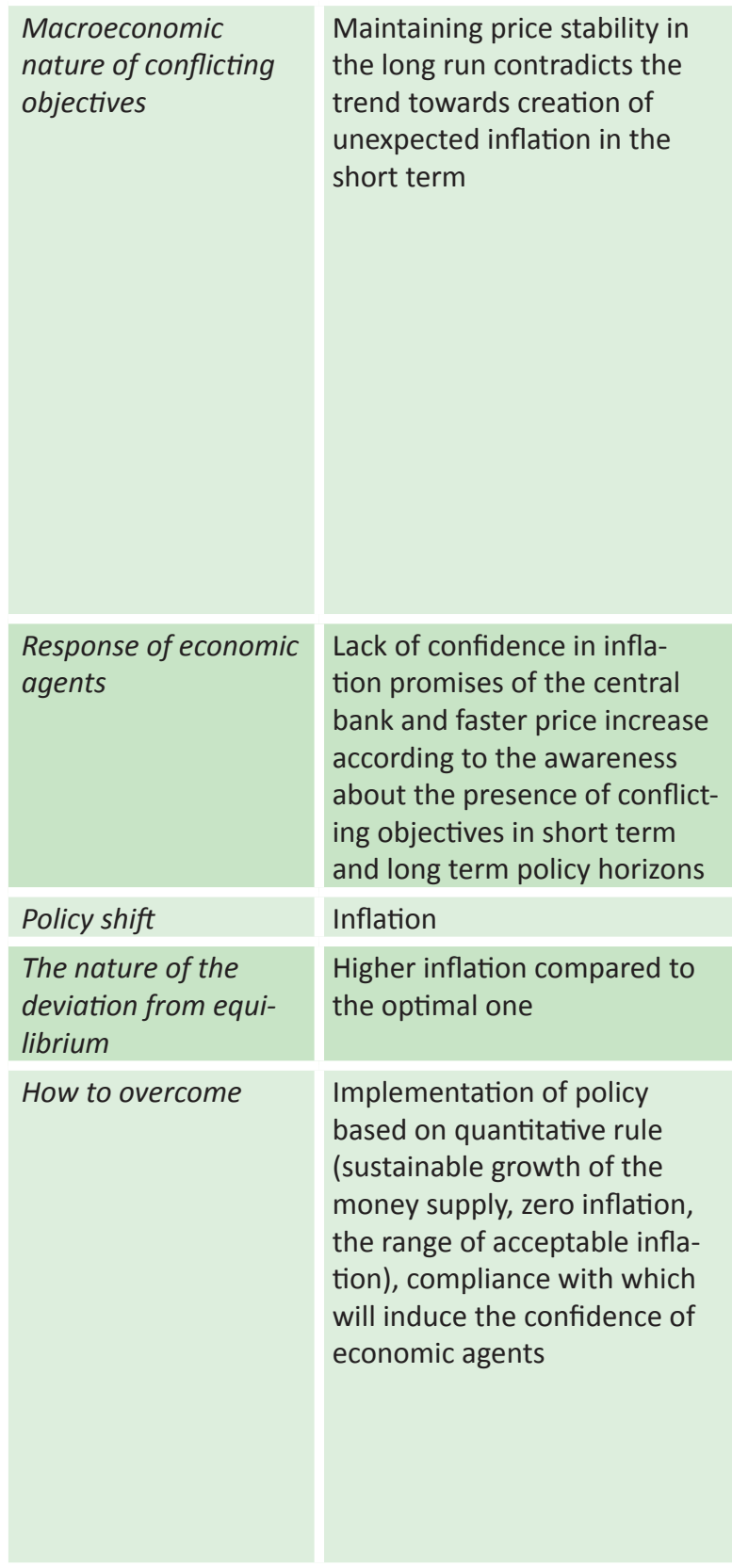

Activist policy or changing fiscal and redistributive preferences in the short term are contrary to maintaining debt sustainability and sovereign solvency in the long term

Lack of confidence in promises of a balanced budget and keeping from public debt increase according to the awareness about conflicting objectives in short term and long term policy horizons

Deficit

Higher budget deficit and, consequently, public debt, compared to the optimal ones Implementation of policy based on quantitative rule (balanced budget, quantitative limits on budget deficit/public debt), compliance with which will induce the confidence of economic agents
A) Monetary policy. Raising interest rates in the short term rather generates destabilizing effects, while in the long run the probability of crises and systemic risks lowers.

B) Macro- and microprudential policy. More strict requirements in the short term exacerbate procyclicality of the financial system, and in the long term they weaken it due to risk assessment, the nature of the response of loan supply (liquidity) to the regulatory requirements etc.

Lack of confidence in strict anti-crisis promises and / or the declared policy aimed to prevent moral hazard, coupled with expectations of liquidity injections

\section{Accommodative}

Higher levels of systemic risk, higher propensity to risky behavior, behavioral distortions

Rules of behavior at the time of crisis But it is difficult to define them. The independence of the authority responsible for financial stability. However, formal independence does not guarantee addressing the problem of dynamic inconsistency. Also, financial stability is not confined solely to one type of policy. This means that there is no conventional way to solve this problem

Note. Prepared by the author.

The variant presented in Cihak's research (2010) shows policy's details, which, except for liquidity injections, do not directly relate to monetary actions. In the light of the issue on whether / how the central bank should respond to financial imbalances via monetary instruments, dynamic inconsistency should be extended to the monetary policy problem from the standpoint of financial stability. In this context, the conflict between optimal monetary decisions over short and long periods is based on the difference in financial sector responses and, respectively, probability of transformation of vulnerability into disruption. In other words, in the short period, when the signs of imbalances accumulation have already appeared, after-effects of raising the rates, which is related to the monetary response to the problem of instability, are opposite to those in the long period, during which maintaining of the rates at an adequate level creates the fundamental precondition for financial stability (Table 3 ).

\section{Table 3. Differences in impacts of a rise in interest rate on macrofinancial processes in a short and long period}

\section{Effects of a rise in interest rates in a short period}

Enhancing of negative aspects of the balance-sheet effect

\section{Effects of a rise in interest rates in a long period}

Decreasing of a risk appetite and focusing on "good" investment 


\begin{tabular}{|c|c|}
\hline Tightening of lending conditions & \multirow{4}{*}{$\begin{array}{l}\text { Decreasing of a leverage level. Releasing decisions concern- } \\
\text { ing capital structure from expectations of a downward path } \\
\text { of interest rates. Forming a macroeconomically neutral } \\
\text { capital structure }\end{array}$} \\
\hline Increasing the burden of interest payments & \\
\hline Decreasing the banks' propensity to borrow & \\
\hline Shifting the portfolio structure towards less risky instruments & \\
\hline Expansion of spreads & $\begin{array}{l}\text { Forming more adequate risk and term interest rates struc- } \\
\text { ture }\end{array}$ \\
\hline Decreasing the distance to default & $\begin{array}{l}\text { Displacing behavioral distortions that are parasitic on } \\
\text { expectations of the accommodative policy and weakness of } \\
\text { regulating institutions }\end{array}$ \\
\hline
\end{tabular}

Note. Generalized by the author based on IMF (2015) and Bulir and Cihak (2008).

Naturally, in such conditions, non-conventional practices of central banks should have a logical endpoint. However, in the event that during carrying out of the non-conventional policy their status will change towards weakening of independence in response to transvalued results of actions beyond the scope of the mandate of maintaining price stability (for example, for carrying out such policy on a permanent basis), further actions on ensuring financial stability may face serious political opposition. As a result, the policy with respect to financial stability will be changed from the dynamically inconsistent policy into a consistent riskogenic one. Despite the fact that this is an extreme case, the question on how to limit the dynamic inconsistency of central banks in the area of financial stability is not trivial.

\section{Significance of a mandate}

Formulation of a mandate in the area of financial stability as a precondition for preventing dynamic inconsistency is quite problematic.

First, if you start from the logic of an orthodox view on central bank's independence, the fact of dynamic inconsistency in implementing the price stability policy is reasonable grounds for extending this principle to financial stability. However, an analogy between "one mandate - one goal - one instrument" cannot be deemed to be a benchmark for analysis. It derives from the fact that the issue on the mandate structure arises, whereas the goal in the financial stability area as well as a set of instruments cannot be clearly specified. In the context of an orthodox approach, the more dual is the mandate, the less independent is the central bank. At the same time, in the context of heterodox approach, going beyond the bounds of the dilemma: "expansion of the mandate narrows independence, whereas the policy in the area of financial stability needs it" looks more attractive. For example, Acharya (2015) describes this problem in the following way. The mandate for ensuring financial stability is required to overcome the political pressure in the event of proactive policy that restrains economy during the boom, and not to go beyond the bounds of an inflation target during the anti-crisis support to the financial sector after the crisis has already occurred.

At the same time, the standard expansion of the mandate will not appear to be an optimal decision, because, as it has been demonstrated, price and financial stability may be conflicting goals. In other words, the issue is related not to mandate expansion, but to finding such its specification that would make it impossible to combine a common principle of protection of central bank's independence with separation of actions and concerns regarding the monetary, macro- and microprudential policy. However, price stability should remain the central task for its crucial importance for healthy macroeconomic environment for financial sector functioning, its Pareto-neutral nature, and clear and recognized identification criteria.

Financial stability should be considered rather as a parallel goal than a subordinate one, taking into account warning about the fact that the basis of its achievement is implementation of several policies that need to be coordinated with each other, have separate offices and a reporting and communication system which does not exclude the possibility for integrated communication. This will make it possible to implement and explain proactive actions in response to financial sector overheating in a situation when, for example, given a great deflation shock of productivity, political actors and markets will wait for policy easing by a central bank. In light of the fact that the global integration changes inflation processes and increases its disinflation profile, the traditional orthodox model of central bank's independence may be functionally and politically vulnerable. Under disinflation provoked by global factors, policy easing may cause unwelcome processes of unwinding of the spiral of imbalances, whose transformation into a systemic crisis followed by deflation and recession will bring to life an interest in reducing central banks' independence to combat them.

Second, the risks of the direct and traditional inclusion of financial stability in the mandate, due to which the latter will be deemed to be dual, come down to a known set of nuances. Out of them one can find the following:

- a traditional conflict between price stability and lending of last resort, carried out as a part of the financial stability policy. This may not seem critical in the countries where the exchange rate and the balance of payment do not restrain the macroeconomic policy. This applies also to the countries with strong institutions and consistent financial regulation. However, for the countries that are vulnerable to exchange rate fluctuations and reverse processes in capital flows and face the challenges 
of institutional distortions, lending of last resort may become an additional factor of macrofinancial instability resulting in considerable reputational losses for a central bank;

- a difficulty to identify the financial stability and evidence of its antipode generate considerable difficulties in interpretation of central banks' actions and interpretation of the grounds for political responsibility. At that, financial instability determinants may change, requiring from a central bank the wide discretion to choose the instruments whose linkages with the goals are not always obvious or not always obvious in a short period. The same applies to the problem of a cross impact of the monetary, macro- and microprudential policy on the price and financial stability. An exchange rate is the most striking example. It influences the price stability via carryover effect, and the financial stability - via balance sheet effect. However, the rate itself very often depends on the factors outside the central bank's influence. Exogenous shocks that determine reallocation of global capital flows are an example of this;

- essential differences in the horizons of the price and financial stability policies, as well as a difference in a frequency of deviation from them, deepens the problem of confidence. In addition, during different time periods, confidence in one policy may increase confidence in another one. This does not preclude an extremely optimistic assessment of separate aspects of central bank's activities and drifting in assessment of factors that lead to deviation from the goals. For example, the financial stability may be taken for granted under price stability, and deflation may be assessed as a result of insufficient support for the financial sector during the stress. In the first case, confidence in one of the policies will generate positive externalities for another one, and in the second case - vice versa;

- concentration of power, where the result is achieved by separate policies and different instruments, may create a problem of instruments combining. For example, requirements for regulatory capital adequacy or requirements for provisioning under assetside operations may be reduced in reaction to heavy political pressure with respect to a decrease in interest rates. Meanwhile, this may have redistributive effects. Differences in the asset structure of different financial institutions imply that the ones will be in better conditions than the others. This will create political intentions regarding additional control over the central bank, because concentration of power will be considered by some groups as additional redistributive possibilities in the event of "capture of the regulator", whereas another groups will be interested in minimizing of selectivity, thereby creating pressure towards formation of institutional preconditions for rigorous monitoring with ambiguous political ways to use its results, etc.

Third, the problem of spillovers is very important. Growth of global cross-border capital flows shows to what extent unwinding of the spiral of imbalances in one country may be associated with global centric factors or with changes in the policy of one or another big country. Central banks should be always ready for such-like shocks, whereas the scale and speed of changes in global flows can make the measures to support the financial sector relative. This raises a question of whether the political responsibility for failure to achieve financial stability should be focused on the central bank's management, if the epicenter of its origin is abroad.

Forth, as already mentioned, the lags and frequency of events have very different duration in the event of the price and financial stability. In the first case, within even a half of tenure of central bank's management, one can discuss the specific effects of those actions, not to mention the cases when the effects of inflation actions make themselves evident, in a few months, whereas in the event of financial stability, the situation differs. Moreover, the differences can also be projected onto the monetary policy that was passive with respect to unwinding of the spiral of imbalances as well as onto macroand microprudential regulation. The effects of failures in the policy as regards the financial stability may become evident years later. The case of frustration of regulation, which results in appearing of institutional distortions, is typical. However, the situation when the policy regime changes will be highly problematic for the political responsibility of central bank's management. The response to such a change can cause not just the political opposition but a complicated multi-period game, in which stability of financial institutions will be only an episode of more complex strategic plan to return to the redistributive status quo. In other words, the change in the policy regime following the change in the central bank's management may be a precondition for addressing imputations to it concerning failure to reach financial stability just because a new policy changes the institutional equilibrium of rent distribution related to the activity withholding evident captive business models. It is clear that this is a situation of countries with weak institutions. However, even in developed countries, the opposition to all-encompassing regulation does not seem to be an exception, especially in the context of speculating on procyclical effects of stricter requirements for financial stability institutions. As these requirements are usually introduced after a crisis and may coincide with recession, a short-term shrinkage of credit supply is a typical example of manipulating interpretations about what is financial stability and how it should be achieved. The basic conclusion that one can make - the responsibility for financial stability should be based on an extended set of interpretations that would take into account a temporal problem and broadened policy horizon and in this way narrow the area of political interpretation of central bank's effectiveness.

Consequently, combating the dynamic inconsistency in the area of financial stability needs more independent regulator; however, a direct analogy with the orthodox approach with respect to the price stability is not relevant. The conflict with the latter is one of the reasons, while the dual mandate is politically vulnerable. More complex mandate structure with an allowance for maintaining a price stability status looks like some compromise, in terms of which the task concerning financial stability and responsibility for its achieving need additional interpretations separated from the key task. 


\section{FINANCIAL STABILITY AND INDEPENDENCE OF THE CENTRAL BANK: STYLIZED CASES}

\section{Independence and proactive versus reactive policy}

It is a well-known discussion (lean vs clean) on what is better: respond early to imbalances and pierce the bubble by rising rates (lean against the wind) or clean-up the market through the unlimited supply of liquidity (clean), lasts for about 20 years. Although it does not affect the status of central banks directly, it has an obvious institutional correlate. What design should be envisaged and maintained in order to have minimum losses from either proactive or reactive policy. At the same time, to speak theoretically, the situation is not so simple. We can assume that orthodox central bank the independence of which falls under strict specification "one mandate - one objective - one tool", will choose the option of the priority of target trajectory of inflation, complementing it with clean-up of markets if needed. But this points to the fact that orthodoxy is not a direct synonym of independence. The same applies to heterodox central bank, although, according to the orthodox approach it is a priori less independent.

Wagner and Kissmer (2013) point out that if financial stability is associated with smooth cycle in asset prices, central bank independence is contrary to it. The main reason for this is exactly in the orthodox interpretation of the independence itself. The central bank will evade from the response to the rising trend of asset prices. Also, the reason that pushes a central bank to neutral reaction to financial imbalances is a lower level of inflation after financial stress. In the same study, Wagner and Kissmer (2013) state that the independence of the central bank should relate not only to the fact of reaction to the asset prices behavior, but also to what profits and losses are brought by negative inflation gap after the episode of financial instability to the central bank itself. For more independent central bank it means inability to achieve inflation target, which finds itself above the actual one; for the less independent it is an opportunity to solve the problem of inflationary shift.

In its turn, Borio (2014) denies the link between formal status (or how mandate is worded) and the nature of the choice among proactive or reactive policies. The way the central bank acts is more important than its status. Mentioned in some works, namely Cihak (2010) and Klomp and de Haan (2009), tighter link between political independence and financial stability can be interpreted as a manifestation of the fact that exactly this type of central bank may go beyond the approach to definition of its independence in the traditional sense. In a situation like this, only a more independent central bank can "lean against the wind" (Koziuk, 2015).

However, these discussions indicate several issues, namely how price stability and financial stability correlate; what is central bank independence - a mechanical adherence to the mandate, or willingness to act and take responsibility in the political environment. This environment can be characterized by the domination of position envisaging monetary policy overload with objectives of economic recovery. And maybe by the domination of politically motivated intentions regarding the arbitrary interpretation of how a status correlates with macro financial environment of different actions, or lack thereof. One can draw some conclusions (aggregated in Table 4). First, it is necessary to combine two options in the analysis, namely: when maintaining the price stability conflicts with maintaining the financial stability, and when such opposition does not exist.

Second, it is important how the central bank integrates a financial content into macroeconomic model. In many cases it will define how narrowly or broadly it will interpret the mandate, even if the mandate is to define a single goal - price stability. In other words, the fact how strictly the new Keynesian model will be opposed to BIS approach to a large extent will define whether the independence will be measured using classic approach "one mandate - one objective - one instrument", or going beyond that limits will mean the willingness to be active and responsible.

Third, post-crisis inflation and the associated state of aggregate demand are important as they shape the profile of the central bank assessment by the political actors and, accordingly, how the latter will ask the central bank about the return to pre-crisis trajectory. More independent central bank in the orthodox sense can lean to reactive policies without regard to the risk that falling inflation and stagnation after the crisis will cause pressure on it. A less independent central bank, which also tends to pursue a reactive policy, may not resort to it, being aware of the risks of political pressure over the following periods. At the same time, a less independent central bank may not to be proactive as it will be under political pressure when trying to "prickle the bubble" because such policy is perceived as a challenge to faster economic growth.

Fourth, if the response to the unwinding financial imbalances does not depend on the status, it would hardly mean that its motivation is different. Similarly, if such response is analyzed in the light of the effects on inflation, the incentives to be proactive or reactive shift towards what method of interpretation and assessment of the actions of the central bank dominates and, respectively, the realization of its responsibilities. This means that in case of political preferences unevenly distributed in time, the incentives are also displaced in either direction, bringing back the issue of what constitutes independence of the central bank.

In this situation we can only note that the more the price and financial stability are antagonists and the less the principal (society, parliament, government) is prone to opportunistic behavior, the more the central bank can count on the adequacy of the orthodox approach. Otherwise, independence should be more comprehensive than the model "one mandate - one objective - one tool" assumes. That is why, in developed countries there is a strong link between operational independence 
and low inflation, and political independence is often lower than in emerging markets, whereas financial stability better corresponds to the political independence, as the examples of the large sample of countries show Debelle and Fischer (1994), Cihak (2010), Klomp and de Haan (2009), Dincer and Eichengreen (2014), Balls et al. (2016).

The case of emerging economies also suggests that a conflict between the price stability and the exchange rate stability could have serious secondary effects in the form of financial instability. Higher vulnerability to negative balance sheet effects of exchange rate fluctuations (excessive propensity to leverage amidst higher exchange rate, increase of debt burden as a result of lower exchange rate etc.), coupled by the problem of the regulatory institute quality questions the possibility to rely solely on the orthodox approach. Where the quality of institutions in terms of financial behavior is low, monetary and regulatory policies must take into account the risk of further political pressure on prudent response to imbalances or pressure toward redistributive design of incentives during markets clean-up. And price stability and financial stability policy should allow for the option of crossresponse, when the former or the latter will be under more pronounced pressure of opportunistically minded principal.

\section{Table 4. Incentives and response options for central banks, depending on the nature of the relation between price stability and financial stability}

Ideal type and incentives
for responses
Orthodox option "one
mandate - one objective -
one tool" (Ideal type)

Heterodox option: extended interpretation of mandate even if the latter envisages the price stability (ideal type)

The choice of more independent orthodox central bank

The choice of less inde-
pendent orthodox central
bank
bank

The choice of more independent heterodox central bank

\section{Price stability and financial stability are antagonists}

Independence is not considered in the context of financial stability, as the latter can be a part of other policies implemented by separate agencies. However, the response to financial instability undermines the ability to be independent after achieving price stability Independence allows responding within a wide macrofinancial range. Temporary deviations from the target trajectories of inflation and GDP are neither a challenge for interpretation nor the grounds for independence

With financial instability signs, reactive policy has more benefits. The apparent losses from future response to a probable event are always higher than the expected present benefits from the prevention of the likely event. Inflation target is a dominant. Post-crisis risk of deflation is not considered as a challenge to the current status. Example - the Riksbank The response to signs of financial instability is not considered appropriate because it is perceived as risky in this political environment. Clean-up of markets may be more aggressive because of the need to prevent political pressure in the respective area and because of likely need to prevent deflation. Example-Bank of England before expansion of macroprudential powers

Financial imbalances are a challenge to future macroeconomic stability and temporary problems of downward inflation deviation from the target is not a barrier to proactive responses. Downward deviation of inflation should not be considered as grounds for "liquidity injection" because it encourages a new financial cycle. Monetary policy and macro- and microprudential regulation should complement each other. Example is not yet defined

\section{Price stability and financial stability complement each other}

If there is no conflict between price stability and financial stability it is assumed that the traditional approach to independence is sufficient to guarantee them both

Independence is an important prerequisite for achieving price and financial stability, a means to neutralize political pressure, but solely monetary response may not be enough. Independence also enables the implementation of other types of macrofinancial stability policy, increasing efficiency of them all

In case of signs of financial instability monetary response should ensure neutralization of transformation of financial shock into price shock. However, when a crisis has already occurred, expansion of liquidity may be restricted to avoid triggering inflation. Example - ECB before 2012

Opting for a proactive policy can be complicated by political opposition to actions that could slow the economic growth. However, overcoming the effects of the financial crisis may be accompanied by higher inflation. Example - most southern EU countries before entering the euro area

Coordinated work of monetary policy and macro- and micro-prudential regulation will enable to better cover the area of macrofinancial instability. The reaction to financial imbalances is likely to be prudent, given the awareness of the risks of future dilemma: to support either price stability or financial stability in the event of a crisis. Example emerging markets with independent central banks 


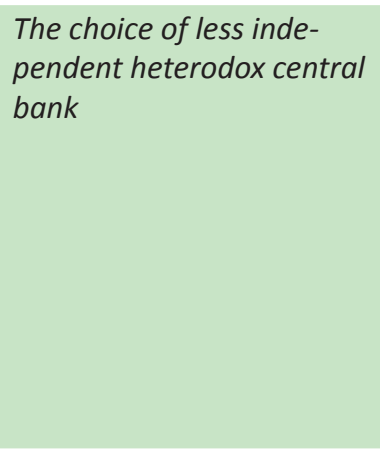

The response to signs of financial shock will occur on the basis of the instrument, for which the conflict with the dominant political forces is the least likely. The same applies to priority of price stability or financial stability in the event of a crisis. Example - emerging markets with moderate monetary autonomy and considerable financial openness
The response to signs of financial shock will allow the combination of tools so that its subsequent political pressure was graduated optimally. In the event of a financial stress, the response profile will be determined by the behavior of the principal prioritizing either price or financial stability in restoring them both in the future. Example - emerging markets with moderate monetary autonomy and vulnerability to fluctuations in the exchange rate and capital flows

Note. Prepared by the author.

From these generalizations one can conclude that the profile of proactive or reactive modalities of behavior is significantly influenced not only by the status itself, but also by the way the central bank generalizes macrofinancial economic model. Independence can be very useful in achieving both price and financial stability, while financial factors are seen as significant drivers of macro-instability. Its narrower interpretation can, on the contrary, lead to over-simplification of monetary policy environment, which, however, does not exclude more complex view to the "special" structures aimed at ensuring financial stability. The issue of optimal design accordingly moves the focus to the issue of independence, but does not deny it, as shown below.

\section{Independence of the central bank and macro- prudential competencies}

Once macroprudential regulation was recognized as a specialized type of policy aimed at financial stability, the question arose what should be optimal design of an agency that would pursue it. At the same time, it also raised the question of a degree of independence of an authority empowered to carry out macroprudential regulation. In the event when macroprudential regulation is delegated to the central bank, it should undergo institutional changes to incorporate the responsibility for financial stability, define anti-crisis functions and tools, and arrange cooperation with other agencies and policy makers. Those so-called "new functions" should be clearly manifested and be of justifiable nature, otherwise the issue of democratic control, accountability or concentration of power will inevitably arise (Balls et al. (2016), Achrya (2015), Bayoumi et al. (2015)).

However, the optimal design of the agency does not remove the issue of its independence. One can see that the definite difference between heterodox and orthodox approaches also covers the delegation of the central bank's mandate on macroprudential regulation. According to the first one, like in bank supervision, competence for which reduces the level of independence in accordance with the theoretical foundations of GMT-index construction, macroprudential regulation will narrow the central bank's independence. Most likely, it will be delegated to the central bank that already performs macroprudential regulation, and which has a lower level of political independence (Masciandro and Volpicella, 2016). In other words, under the "one mandate - one objective - one tool" model, expanding the central bank's functionality inevitably entails extension of political responsibility and therefore extension of political pressure. The combination of this model with responsibility for financial stability based on a strict split of functions in the field of monetary policy and macroprudential regulation allows "assimilating new functions", but at the cost of partial loss of independence.

However, such perception of the problem should be recognized as appropriate only when there is really an actual underlying conflict of objectives of maintaining price and financial stability. Failure to ensure that externalities of macro-prudential policy will not affect the area of responsibility for price stability, leads to a situation where more advanced view on the drivers of macro-financial instability conflicts with institutional choice of agency design. For example, restraining expansion of credit of strengthening macroprudential requirements may affect the compression of demand which will decline inflation down to the target area. Reduced rates as a response may, however, enhance propensity to risk. In both cases, the individual response is optimal, but it is so only in the narrowed interpretation of the mandate and assessment of risks of political pressure for no actions, the need for which is generated by the optimal response of the other policy. This example clearly indicates the limitations of the orthodox approach.

The example suggested by Ueda and Valencia (2012) is similar. They show that when a change in macroprudential instruments cannot be as fast as monetary ones, there will always be a risk of dynamic inconsistency. The central bank may tend to maintain the inflation target ex ante, but to deflate private debt through higher inflation ex-post. Moreover, a higher political independence here can play a negative role because "failure" of one policy can be offset by sub-optimal result of the other. However, the status of an "umbrella" for coverage of failures cannot be considered as optimal multiple-period strategy, because on the long-term horizon we will see actions on the political responsibility or actions aimed to change the status depending on which political and economic ideas and interests dominate in this or that time. And here the quality of institutions is especially important. Reduced independence may envisage increased control with redistributive purpose and the reason for this - failures in one of the policies, despite the fact that the other can demonstrate an adequate level of social optimality. 
Political and economic factors taken into account allow us to see a different picture. It is more consistent with the experience of institutional protect of the monetary policy from political pressures. The most typical examples here are situations of conflict between more strict measures in the area of financial stability and electoral considerations of political players. Such measures can be described in more details. If a central bank estimates increasing of systemic risk, the change of respective instruments may have a short-term deterrent effect. And it applies both to macroprudential and monetary instruments. Political opposition to such steps should be associated with direct deterrent effect and with the fact that opportunities to increase profits in the financial sector decrease. The latter does not exclude creation of certain lobbying movements oriented to criticize the central bank.

But, it may manifest most prominently in case of the change of regulation regime. Thus, the concept of financial regulation (especially banking) has not principally changed for a long time; therefore a kind of institutional balance was reached. Situation changed after the global financial crisis, which caused a change in the nature of regulation. The introduction of macro-prudential mechanisms of limiting the pro-cyclicality in conjunction with the Basel III approaches have in general increased regulatory burden of the banking business. By countries, the transition to more strict regulatory practices (risk assessment, requirements to the regulatory capital, liquidity buffers etc.) showed that it does not always goes smoothly. Political resistance to change is generated exactly basing on speculations about the short-term effects of compression of aggregated loan. Thus, low trajectory of lending resumption is often perceived as grounds for the reluctance to introduce stricter regulatory requirements within the framework of financial stability policy. Therefore, if a central bank does not have sufficient independence to change the regulatory regime, can it be responsible for financial stability at all? Reverse political pressure may aim to slower regulatory innovations, as well as it may relate to the creation of compensators in the form of lower rates and liquidity expansion. And this raises the question of whether the central bank will be able to achieve price stability. In both cases, no matter how mandate is specified and no matter how the responsibility for price and financial stability was distributed among structural subdivisions of the central bank itself, if both policies are not subject to joint protection of the fundamental principles of independence, their implementation will always be under pressure. Moreover, the possibility to cross-compensate the consequences of one policy with the measures of another one considerably undermines transparency and distorts responsibility. In this case, it is not about the optimal coordination. Not only aspects of policy change will be aspects of higher risk of political pressure. Without sufficient protection the risks of such pressure will always intensify following the electoral cycle or in response to stress, which can distort the electoral picture in the future.

Another example is a typical short-terminism. Financial cycle is longer than business cycle. Specification of instruments of the macroprudential policy and their nature may deviate from the business cycle, causing restrictions and political accusations. Global determinants of the internal financial cycle only deepen the problem. For example, implementation of macroprudential instruments aimed at limiting internal lending can be partially offset through external borrowings. In such circumstances, the question arises, either about the extension of macroprudential influence, or monetary response in the form of strengthening the exchange rate and / or increasing rates. It is clear that if such actions coincide in time with relatively stable inflation (better say coincide with politically neutral / acceptable level of inflation) prudent opinions of the central bank will not be supported by individual interest groups. Duration of policy horizon and duration of monitoring of the regulator's actions exercised by political actors will be different. Solely communication measures may not be enough to neutralize the pressure against the actions in response to the risks seen by the central bank, but not by others.

Another important issue is the trust in the asymmetric information environment. The central bank typically has a wider range of information than other market participants, and sometimes - than other agencies. This makes it a monopolist owner of aggregated information. It raises the issue of transparency in handling a monopolist status. In the area of financial stability the transparency is limited by the bank secrecy, on the one hand, and the risk to stir panic on the other. Given the lack of uniform access to aggregated information on financial stability, there is a question of overconfidence, transformation of which into credibility is based on actions which should be guaranteed by the independence.

Also the question of the perimeter of regulation is important. Where the central bank is competent to apply macroprudential tools only to a certain group of financial institutions, its ability to maintain financial stability decreases. However, it raises the question, to what extent the central bank can extend its macroprudential influence to certain financial institutions when they are not subject to macro-prudential supervision. On the one hand, in the case when there is a separate supervision of individual financial institutions, macro-prudential regulation can seem limited and therefore potentially ineffective. The example of so-called shadow banking system is classical. On the other hand, the concentration of supervisory functions solely to improve the efficiency of macroprudential regulation can also cause concerns. A compromise option may be expanding macroprudential powers and institutionalized enforcement of coordination within the anti-crisis policy. It stands to reason that modalities of changes in the central bank when implementing such a policy may require a separate specification in the legislation (Balls et al., 2016), Acharya (2015).

It brings a question whether it decreases the central bank independence. According to the orthodox approach - yes. However, when in case of crisis the central bank has to go beyond a single mandate, establishment of it may be accompanied by changes in the status that will be more dangerous. Yet, within the heterodox approach, the answer is likely to be somewhere 
in the middle. To protect actions in the area of financial stability, especially when they are at odds with the electoral process, reservations on the options of changes in the activity of the central bank may be more necessary. They can be seen as insurance against pressure, following of which could lead to the consequences, elimination of which will lead to the results though oriented to restoration of financial stability, yet be contrary to the price stability.

Also Acharya (2015) emphasizes the rules that would have settled the lending of last resort during systemic crises and prevented generation of moral hazard problem. On the one hand, the existence of rules is the easiest way to solve the problem of discretionary behavior limitation. Financial crises and relevant central bank's non-conventional practices open a wide space for actions that eventually are interpreted as non-transparent, selective and targeted at individual market participants. This creates a dangerous precedent for political pressure in terms of tightened control over the central bank in the area of financial stability. Naturally, the rules in case of anti-crisis measures will allow narrowing the range of actions on the grounds that they require status change for increased control. But, do they guarantee flexibility of operational ability to eliminate crisis adverse effects? On the other hand, the rules of behavior in the area of financial stability do not guarantee the central bank efficiency, especially when it is about dynamic deployment of stress that absorbs financial institutions one by one rather than all at once. In such circumstances, any ex ante design of rules will not be optimal ex post, which, in principle, is the familiar analogy with the debates about monetary rules.

One of the very dangerous aspects in cascade-like patterns of crisis deployment is a change of motivation of financial institution owners and managers, when each next stage of crisis changes the motivation whether to stay in the market or leave it. Institutional weakness of microprudential regulation will be here a problem trigger. Leaving the market through outsiders looting is possible through non-reflection of actual financial standing and erosion of risks through related operations. Time concentration of microprudential failures followed by changing motivation of owners and managers regarding the extension of the presence in the market generates a deep crisis and a crisis of confidence in the central bank. This raises the question of whether the rules of conduct in one segment of the anti-crisis policy can always help if there are institutional distortions in the other segment. Such asymmetries discredit the principle of independence. It can be used by the central bank as an "umbrella" so that positive aspects of right decisions in one segment of policy compensate the negative aspects of another one. But it also can be used by policy makers as a prerequisite for creating a new redistributive configuration rather than for improving the institutional environment for regulator. These examples show that responsibility and transparency should be the intentions of both the central bank and society. Otherwise, the interpretative nature of financial stability will always be a reason for the central bank independence to be in the midst of political and economic negotiations.

\section{Comparison of approaches to central bank independence and its outcome in Ukraine's context}

The conducted analysis has shown that an issue of central bank independence has gained new importance. Apart from theoretical approaches towards determinants of levels of independence, no less important is a central bank's own vision of macroeconomics. Without such a vision, it would be difficult to understand why it is necessary to ensure one or other level of independence for implementing a socially optimal policy. The complexity of the issue emanates from the fact that financial stability continues to be an interpretative category, and its connection with price stability remains a debating point. However, there are two approaches emerging that equally highlight the importance of a high level of independence of a central bank, yet suggesting different interpretations thereof, partially due to the interpretation of criteria and different views on the role of financial factors in macroeconomic instability. At this, there is no consensus on the dual nature of the mandate even among representatives emphasizing the need of a more active role played by a central bank in the financial stability domain. The comparison between such approaches, which we call the orthodox and the heterodox approach, is provided in Table 5. It does not look into the interpretation of independence elements (their consideration against the backdrop of the global financial crisis is provided by us (Koziuk, 2015) from a perspective of the approaches.

\section{Table 5. Central bank independence and financial stability: comparison of orthodox and heterodox approaches}

\section{Orthodox approach}

Basic macro-model
New Keynesian: stabilization policy effects amid confidence in the price stability policy; business fluctuations caused by stochastic shocks; financial frictions act similar to price inflexibilities; by narrowing down inflation variations a central bank minimizes GDP variations, and in some cases it combines this (over a longer policy horizon)

\section{Heterodox approach}

New Keynesian model should be supplemented with macrofinancial view: the financial system is pro-cyclical; accumulation of systemic risks and financial imbalances pose a threat to macroeconomic stability; the financial cycle and the business cycle are not the same; risk attitude is important; cross-border flows, financial sector gross positions, asset prices and credit dynamics are important indicators of systemic risks; expansion of liquidity unwinds imbalances rather than stimulates aggregate demand per se 
Basic model of central bank independence

Main options for expanding the basic model of independence

Interpretation of the
conflict between price
stability and financial
stability

\section{Interpretation}

of deflation and

deflation risks

\section{Position regarding lean vs clean}

Assessment of gains and losses of a proactive policy

\begin{tabular}{l|l}
$\begin{array}{l}\text { Assessment } \\
\text { of gains and losses } \\
\text { of a proactive policy }\end{array}$ & $\begin{array}{l}\text { The market clean-up will contribute to } \\
\text { the restoration of the financial sector, } \\
\text { and losses due to extending support for } \\
\text { it should be comparable with the loss of } \\
\text { GDP and employment in the conditions of } \\
\text { a proactive response }\end{array}$ \\
\hline $\begin{array}{l}\text { Role of political and } \\
\text { operational } \\
\text { independence }\end{array}$ & $\begin{array}{l}\text { Operational independence is more impor } \\
\text { tant for price stability }\end{array}$ \\
\hline $\begin{array}{l}\text { Macroprudential } \\
\text { functions and their } \\
\text { impact on } \\
\text { independence }\end{array}$ & $\begin{array}{l}\text { Influencing independence in a way that } \\
\text { it is narrowed. Complex organizational } \\
\text { models of separate reporting, communi- } \\
\text { cations and responsibilities designed to } \\
\text { delineate responsibilities for price and } \\
\text { financial stability so as they do not affect } \\
\text { one another due to the risk of political } \\
\text { interpretation with regard to the latter }\end{array}$ \\
\hline
\end{tabular}

A) Dualization of the mandate, enhancing responsibility for financial stability, the legalization of "new functions" (dealing with debt management, anti-crisis policy, etc.);

B) Functions of ensuring financial stability have to be taken out of scope of the institution responsible for price stability

\section{The conflict may arise:}

A) an implicit or explicit mandate for financial stability may encourage higher inflation as a result of overcoming consequences of the crisis (large-scale liquidity injections);

B) a lack of measures to bolster the financial sector may pose a threat in terms of a deflationary shift, which undermines financial stability

Deflation poses a higher risk than a temporal upward deviation of inflation lower bound become ineffective; secular stagnation; unemployment

\section{Market clean-up is better}

The benefits are questionable in the light of inability to identify bubbles on a realtime basis, while losses could be significant affecting GDP and employment
There must be a high level of independence, however:

A) there is a sufficient mandate for price stability, but actual steps to dampen the macrofinancial risks should be protected from external pressure;

B) the dual nature of the mandate is necessary to safeguard measures aimed at ensuring financial stability from the target. Major risk: rates at a zero

Legalizing authorities in the area of macroprudential regulation can be variable in terms of details

Price stability is not sufficient for ensuring financial stability, but the former is a fundamental precondition for the latter to materialize. Against the background of a significant decline in actual rates, price stability gives rise to the "paradox of confidence" and encourages higher risk appetite

Deflationary pressure should not be regarded as a precondition for a reckless expansion of liquidity. What matters is the cause of deflation, rather than a formal downward deviation of inflation from the target. Major risk: expansion of liquidity initiates a new financial cycle

Response toward unwinding of imbalances is better

Benefits are significant in view of the need to consider the "price" of the crises, risks of public debt growth and moral hazard. Losses are exaggerated. A more flexible economy adjusts to an increase in rates creating prerequisites for healthy investment

The market clean-up itself already evidences a "policy failure". It generates additional risks of extending in time the deleveraging process, but does not offer a solution for a search-for-yields issue

Political and operational independence both are essential. Political independence is, however, crucial for financial stability

Independence is increased due to the lack of opportunities to exert pressure on a central bank when it is tightening its macroprudential requirements contrary to political preferences of socially active persons 


\author{
Main vectors of a politi- \\ cal pressure
}

An issue of effective
institutions

Insufficient measures to overcome consequences of the crises which result in enhanced tendencies to deflation and recession

The effectiveness of the present model is ensured through efficient institutions. Amid institutional weaknesses, the pressure exerted on a central bank will mostly be about the scale of incentives for the economy
Excessive measures designed to ensure financial stability

\section{The present model needs efficient institutions.} Within weak institutions:

A) there is a mounting risk of "capture" of authorities with extended powers;

B) asymmetrical efficiency in price and financial stability encourages abusive practices with regard to interpreting performance of a central bank

Note. Prepared by the author.

The approaches provided in Table 5 may be regarded as certain ideal types. However, a tendency to establish bodies, responsible for systemic risks and macrofinancial stability (Bayoumi, 2015) that have a complex organizational design indicates that practical policies need a better understanding of both of them. Extrapolation of these approaches to domestic practices, however, have a number of reservations. First, post-crisis inflation rates in Ukraine show no indications of deflation shift. On the contrary, inflationary jump, flat disinflation trajectory and enhancing transmission effect demonstrate the existence of traditional threats to financial and price stability inherent in low- and middle-income economies. Second, in Ukraine, macrofinancial vulnerability to commodity prices and fluctuations in the global liquidity actualize the issue of a broader view on the domestic macroeconomics. The financial sector being sensitive not only to cross-border capital flows, but also to internal fluctuations in demand for safe assets (i.e. foreign currency cash) generates fundamental risks in those cases when a policy would disregard the credit cycle phenomenon and the linking between internal and external imbalances. Third, a low GDP per capita and a non-dynamic crisis-recovery trajectory against the background of continuing hostilities is regarded as a pretext for more expansionary policy conducted by the NBU. Given excessive institutional distortions in the domestic economy and its quasi-commodity nature, stimulating measures that lack confidence in them will result in even a greater crisis. It means that the NBU's independence is a key factor in ensuring price stability as a prerequisite for the restoration of economic potential based on healthy expectations. Structural reforms should reinforce the policy focus on price stability, otherwise it will be perceived as detached from macroeconomic fundamentals, thus causing permanent downward pressure on the level of regulator's independence. Forth, the banking supervision reform and implementation of macroprudential tools is perceived in connotation of a risk of a short-term aggregate credit crunch, while the scale of growth, such as car loans in 2016, points to the contrary. Accordingly, political independence of the central bank is a key prerequisite for financial stability, the idea that has actually been proved empirically by Klomp J., de Haan J. (2009). Fifth, considering a tight correlation between price and financial stability in Ukraine, the current mandate that the NBU has been provided with may be deemed as an optimal one. Progressing on the way of balancing between inflation targeting policy and macroprudential regulation will aim to more efficiently offset systemic risks, which are resonating with virtually each and every global or domestic distress amid institutional distortions. At this, the flexibility of inflation targeting regime in Ukraine and the introduction of macroprudential regulation necessitates further structural reforms and institutional renewal of the financial sector.

\section{CONCLUSIONS}

The global financial crisis affected the changes in the ideas about central banks' independence and the elements that determine it. At the same time, the bottom line of the discussion is not the choice between more or less independent central banks but correlation between such independence and explicit or implicit expansion of powers in the area of financial stability. A pre-crisis view on monetary authorities' autonomy foresaw that competences in the area of banking supervision weakened independence in achieving inflation targets. This view, being integrated in the neo-Keynesian macrotheory, became the basis for formation of the orthodox view that is central bank's independence. The "one mandate - one objective - one tool" model was found an institutional continuation of the neo-Keynesian macrotheoretical doctrine.

Such a model should be recognized as contradictory, because ignoring the problem of financial imbalances leads to the fact that the clean-up of the markets after the crisis may require unconventional policy to such an extent that it, by its sense, will come beyond the frames of the mentioned model, undermining its macroeconomic and institutional legitimacy. In the context of this model, the central bank prefers to abstain from intervening in the financial cycle and carry out monetary expansion in response to the shock by reason of the fact that such actions are in contradiction to the principle of correlation between the mandate on price stability, the inflation target, and the relevant monetary instrument. A deflation risk is considered to be essential with respect to macroeconomic losses of the economy, failure to achieve the inflation target, and political pressure on the score of more accommodative policy.

The heterodox approach assumes that financial factors are key drivers of macroeconomic instability; therefore, interventions in the financial cycle are the precondition for ensuring both price and financial stability. In the context of this approach, 
independence is taken as necessary institutional protection of the central bank whose shares in the financial stability area can conflict with political players' preferences. At the same time, this central bank is highly vulnerable to distortions in the institutional environment, because the "benefit of capture of the regulator" with extended powers increases, and the asymmetric effectiveness of the price stability and financial stability policies may be considered as a precondition for manipulative perception of responsibility.

The lack of consensus on reasonability of mandate dualization brings together both approaches. At the same time, maintaining the price stability mandate, as a key task, needs broader interpretation of competences, accountability, and responsibility for financial stability. This will make it possible to reduce the problem of political interpretation of asymmetries as regards the efficiency of ensuring of price and financial stability and narrow the possibilities of cross application (or the pressure concerning it) of the monetary and macroprudential (and/or even microprudential) instruments in opposition to socially optimal targets. The necessity of having higher level of central bank's independence results from the issue of dynamic inconsistency and elimination of pressure under substitution of the policy regime for the tighter one. However, difficulties with an optimal institutional design of the financial stability policy are still based on the fact that the latter is essentially interpretative. In many cases there is no matter of choosing between the orthodox and heterodox approaches. A crucial point is how the central bank envisages the macroeconomic model and identifies the role of financial factors in it.

Discussions in Ukraine as regards weakening of the NBU's independence have no grounds and contradict to the world best practices searching for balance between proactivity, transparency, and responsibility for financial stability that is not only seen on a short-term horizon, but is of intertemporal nature, and has a complicated relation to the price stability and its implementation.

\section{References}

- Acemoglu D., Johnson S., Querubin P., Robinson J. (2008). When Does Policy Reforms Works? The Case of Central Bank Independence. Working Paper, No. 14033, NBER, pp. 1-73. https://doi.org/10.3386/w14033

- Acharya V. (2015). Financial Stability in the Broader Mandate for Central Banks: A Political Economy Perspective. Hutchins Center on Fiscal and Monetary Policy at Brookings, Working Paper, No. 11. pp. 1-19.

- Arnone M., Laurence B., Segalotto J-F., Sommer M. (2007). Central Bank Autonomy: Lessons from Global Trends. Working Paper, No. 88, IMF, pp. 1-53.

- Arnone M., Laurens B., Segalotto J-F. (2006). The Measurement of Central Bank Autonomy: Survey of Models, Indicators, and Empirical Evidence. Working Paper, No. 227, IMF, pp. 1-56.

- Balls E., Howart J., Stansbury A. (2016). Central Bank Independence Revisited: After the Financial Crisis, What Should a Model Central Bank Look Like? Working Paper, No. 67, Mossavar-Rahmani Center for Business and Government, pp. 1-113.

- Bauducco S., Bulir A., Cihak M. (2008). Taylor Rule Under Financial Instability. Working Paper, No. 18, IMF, pp. 1-43.

- Bayoumi T., Dell'Ariccia G., Habermeier K. Mancini-Griffoli T., Valencia F. (2014). Monetary Policy in the New Normal. Staff Discussion Note, No. 3, IMF, pp. 1-48.

- Berger W., Kissmer F. (2013). Central Bank Independence and Financial Stability: A Tale of Perfect Harmony? European Journal of Political Economy, Vol. 31, pp. 109-118. https://doi.org/10.1016/j.ejpoleco.2013.04.004

- Bernanke B., Gertler M. (1999). Monetary Policy and Asset Prices Volatility. Federal Reserve Bank of Kansas City Economic Review. Issue QIV, pp. 17-51.

- BIS (2003). Monetary Stability, Financial Stability and the Business Cycle: Five Views. BIS Papers, No. 8, pp. 1-30.

- BIS. (2011). Central Bank Governance and Financial Stability. A Report of Study Group. Chair: S.Ingves, pp. 1-91.

- BIS. (2016). 86th Annual Report. Basel. pp. 7-119.

- Blanchard O., Dell’Ariccia G., Mauro P. (2010). Rethinking Macroeconomic Policy. Staff Discussion Note, No. 03, IMF, pp. 1-19.

- Blanchard O., Dell’Ariccia G., Mauro P. (2013). Rethinking Macroeconomic Policy II: Getting Granular. Staff Discussion Note, No. 03, IMF pp. 1-26.

- Blinder A. (2012). Central Bank Independence and Credibility During the Crisis. Working Paper, No. 229, Grisword Center for Economic Policy Studies, pp. 1-10.

- Bodea Cr., Hicks R. (2015). Price Stability and Central Bank Independence: Discipline, Credibility and Democratic Institutions. International Organization, Vol. 69, No. 1, pp.35-61. https://doi.org/10.1017/S0020818314000277 
- Bordo M. (2010). Central Bank Independence and Financial Crises in History. Oesterreichische Nationalbank 38th Economic Conference. Wiena, pp. 29-34.

- Borio C. (2006). Monetary and Prudential Policies at a Crossroads? New Challenges in the New Century. Working Paper, No. 193 , BIS pp. 2-28.

- Borio C. (2014). Monetary Policy and Financial Stability: What Role in Prevention and Recovery? Working Paper, No. 440, BIS, pp. 1-23.

- Borio C., Lowe Ph. (2004). Securing Sustainable Price Stability: Should Credit Come Back from the Wilderness? Working Paper, No. 157, BIS, pp. 1-51.

- Borio C., White W. (2004). Whither Monetary and Financial Stability? The Implications of Evolving Policy Regims. BIS Working Paper. \#147. pp.1-51.

- Bulir A., Cihak M. (2008). Central Bankers' Dilemma When Banks Are Vulnerable: To Tighten or not to Tighten? IMF. Mimeo

- Carre E., Pourroy M., Couppey-Soubeyran J., Plihon D. (2012). Central Banking After the Crisis: Brave New World or Back to the Future? University of Paris Centre d'Economie de Paris Nord Papers, pp. 1-22.

- Caruana J. (2013). The Changing Nature of Central Bank Independence. Panel remarks at Bank of Mexico International Conference on "Central Bank Independence - Progress and Challenges", Mexico City, 14-15 October 2013, pp. 1-4.

- Cecchetti St., Li L. (2005). Do Capital Adequacy Requirements Matter for Monetary Policy? Working Paper, No. 11830, NBER.

- Cihak M. (2007). Central Bank Independence and Financial Stability. IMF. Mimeo.

- Cihak M. (2010). Price Stability, Financial Stability, and Central Bank Independence. Oesterreichische Nationalbank 38th Economic Conference. Wiena, pp. 45-55.

- Crowe C., Meade E. (2008). Central Banks Independence and Transparency: Evolution and Effectiveness. Working Paper, No. 119, IMF, pp. 1-30.

- Cukierman A. (2008). Central Bank Independence and Monetary Policymaking Institutions: Past, Present, and Future. European Journal of Political Economy, Vol. 24, No. 4, pp. 722-736.

- Debelle G., Fischer St. (1994). How Independent Should a Central Bank Be? Goals, Guidelines, and Constraints Facing Monetary Policy. Federal Bank of Boston Conference Series, No. 38, pp. 195-221.

- Dincer N., Eichengreen B. (2014). Central Bank Transparency and Independence: Updates and New Measures. International Journal of Central Banking, Vol. 10, No. 1, pp. 189-253.

- Eichengreen B., El-Erian M., Fraga A., Ito T., Pisani-Ferry J., Prasad E., Rajan R., Ramos M., Reinhart C., Rey H., Rodrick D., Rogoff K., Song Shin H., Velasco A., WeMder di Mauro B., Yu Y. (2011). Rethinking Central Banking: Committee on International Economic Policy and Reform. Brookings. Wash. (D.C.).

- Garica Herrero A., Del Rio P. (2003). Financial Stability and the Design of Monetary Policy. Working Paper, No. 17, American University of Paris. https://doi.org/10.2139/ssrn.396980

- Georgsson M., Vredin A., Sommar P.A. (2015). The Modern Central Bank's Mandate and the Discussion Following the Financial Crisis. Sveriges Riksbank Economic Review, No. 1. pp. 7-42.

- Grilli V., Masciandro D., Tabellini G. (1991). Political and Monetary Institutions and Public Financial Policies in the Industrial Countries. Economic Policy, Vol. 6, No. 13, pp. 341-392.

- Haan J., Masciandro D., Quintyn M. (2008). Does Central Bank Independence Still Matter. European Journal of Political Economy, Vol. 24, No. 4, pp. 717-721. https://doi.org/10.1016/j.ejpoleco.2008.09.005

- IMF (2015). Monetary Policy and Financial Stability. Staff Report. Sept., pp. 1-66.

- Klomp J., de Haan J. (2009). Central Bank Independence and Financial Instability. Journal of Financial Stability. Vol. 5, No. 4, pp. 321-338. https://doi.org/10.1016/j.jfs.2008.10.001

- Koziuk V. (2009). Monetary Foundations for Global Financial Stability. Ternopil. TNEU, Scientific Thought. 
- Koziuk V. (2015). Central banks independence after the global financial crisis: "gray area of the status quo". Visnyk of the National Bank of Ukraine, No. 228, pp. 16-25.

- Koziuk V. (2015). Reserve Currencies: Perimeter of Global Instability. Ternopil. Aston.

- Koziuk V. (2016). Independence of Central Banks in Commodity Economies. Visnyk of the National Bank of Ukraine, No. 235, pp. 6-25. https://doi.org/10.26531/vnbu2016.235.006

- Kydland F., Prescott E. (1977). Rules Rather than Discretion: The Inconsistency of Optimal Plans. Journal of Political Economy, Vol. 85, No. 3, pp. 473-492.

- Masciandro D., Quintyn M., Taylor M. (2008). Inside and Outside the Central Bank: Independence and Accountobility in Financial Supervision: Trends and Determinants. European Journal of Political Economy. Vol. 24, No. 4, pp. 833-848. https://doi.org/10.1016/j.ejpoleco.2008.07.005

- Orphanides A. (2013). Is Monetary Policy Overburdened? Working Paper, No. 435. BIS, pp. 1-39.

- Reinhart C., Rogoff K. (2013). Shifting Mandates: The Federal Reserve's First Centennial. NBER Working Paper, No. 18888 , NBER, pp. 1-14.

- Rossi S. (2013). Post-Crisis Challenges to Central Bank Independence. The LBMA/LPPM Precious Metals Conference. 30 September 2013, pp. 1-9.

- Schwartz A. (1995). Why Financial Stability Depends on Price Stability. Economic Affairs, Vol. 15. pp. 21-25. https://doi.org/10.1111/j.1468-0270.1995.tb00493.x

- Schwartz A. (2002). Asset Price Inflation and Monetary Policy. Working Paper, No. 9321, NBER, pp. 1-22.

- Smets F. (2014). Financial Stability and Monetary Policy: How Closely Interlinked? International Journal of Central Banking, Vol. 10, No. 2, pp. 263-300.

- Svensson L. (2012). Comment on Michael Woodford, "Inflation Targeting and Financial Stability". Sveriges Riksbank Economic Review, No. 1, pp. 33-39.

- Svensson L. (2016). Cost-Benefits Analysis of Leaning Against the Wind: Are Costs Larger Also with Less Effective Macroprudential Policy? Working Paper, No. 3, IMF, pp. 1-76.

- Ueda K., Valencia F. (2012). Central Bank Independence and Macro-prudential Regulation. Working Paper, No. 101, IMF, pp.1-22.

- Cecchetti S. (2013). Central Bank Independence - A Path Less Clear. Remarks at International Conference Held to Commemorate the 20th Anniversary of the Autonomy of the Bank of Mexico, Mexico City, 14 October 2013, pp. 1-6. 


\title{
BEHAVIORAL FINANCE: HISTORY AND FOUNDATIONS
}

\author{
Pavlo Illiashenko ${ }^{1}$ \\ Tallinn University of Technology, \\ School of Business and Governance \\ E-mail: pailli@ttu.ee
}

\begin{abstract}
Recent evidence suggests that ideology has the potential to affect academic research in economics and that exposure to a wide range of approaches may increase intellectual diversity, eventually leading to better decisions. Therefore, writing a literature review in behavioral finance, in principle, can bring benefits to a wide range of readers, especially since the field of behavioral finance itself has already grown into a complex web of related but distinct sub-fields and reached a stage when it can guide policy decisions. This review differs from the existent ones as it focuses on the history of the field and its psychological foundations. While the review of psychological foundations is necessary to appreciate the benefits of a behavioral approach and understand its limitations, even a brief historical detour may provide a compelling case against a naïve dichotomy between behavioral and classical finance.
\end{abstract}

JEL Codes: G02, B26, D03, D14

Keywords: behavioral finance, classical finance

\section{INTRODUCTION}

Federal Reserve research had been unable to find economies of scale in banking beyond a modest size [...] citing such evidence, I noted that "megabanks being formed by growth and consolidation are increasingly complex entities that create the potential for unusually large systemic risks in the national and international economy should they fail" [...]. Regrettably, we did little to address the problem.

Alan Greenspan (2010). The Crisis, Brookings Papers on Economic Activity.

I often wondered as the banks increase in size throughout the globe prior to the crash and since: Had bankers discovered economies of scale that FED research had missed?

Alan Greenspan (2014). The Map and the Territory 2.0: Risk, Human Nature, and the Future of Forecasting.

Reading Alan Greenspan's latest book in 2014, I stumbled upon the posed question. Indeed, had bankers discovered economies of scale that FED research had missed? I wondered if Greenspan ever considered a behavioral explanation (hubris hypothesis, Roll, 1986) for the wave of mergers and consolidations in the banking sector or an institutional explanation (Brewer and Jagtiani, 2013) that states that banks receive special treatment after growing over a too-big-to-fail threshold? And if not, was it because these explanations were rejected after thorough investigation or because real human beings overweight their prior beliefs and reluctantly accept ideas that contradict them, as most behavioral economists believe to be a quite accurate description of what we all do?

The questions are, obviously, rhetorical. Yet, as the law of the instrument (Kaplan, 1964) states that we tend to over-rely on familiar tools and ideas, the same way scholars in economics and finance may fail to approach important issues from multiple angles. The degree to which finance and economics in general suffer from a lack of diversity of ideas is a matter of discussion. However, the evidence indicates that ideology influences the results of academic research in economics and leads to sorting into fields, departments, and methodologies (Jelveh et al., 2015).

If an ideology and personal background affect academic views, then exposure to a wide range of approaches should increase intellectual diversity, which in turn should lead to better decisions. Therefore, writing a literature review in behavioral finance still makes sense even though the field lost its controversial status a long time ago (Thaler, 1999a) and nowadays is included in standard textbooks like Hens and Rieger (2016). Namely, I can see at least two reasons. 
First, behavioral finance has already grown into a complex web of related but distinct sub-fields of research and providing an overview of recent studies may bring some benefits to the otherwise deeply specialized researchers. Secondly, finance plays an enormous role in most domains of life at virtually any level of aggregation from individuals to governments. Thus, the range of potential readers of the literature review extends beyond one profession. For instance, it is my strong conviction that behavioral finance had reached a stage when it should guide related policy decisions.

Interestingly enough, there is no simple answer to what behavioral finance actually is. ${ }^{2}$ There are many ways to define the field and its boundaries, and they mostly depend on the personal perspective of a researcher. For example, to Eugen Fama, a pioneer and a vocal champion of the efficient market hypothesis, behavioral finance is a body of literature mostly preoccupied with attacks on market efficiency (Fama, 2014). On the other side of the spectrum, consider Richard Thaler, a founding father of behavioral finance who made a substantial effort to establish the field as a legitimate part of classical finance (Thaler, 2015 tells a thrilling history of behavioral economics and finance from the perspective of the author). He defines behavioral finance as simply open-minded finance (Thaler, 1993).

Behavioral finance may also be defined by the modifications it has made to a standard finance framework. Here is a catch-all description given by Statman (2014):

Behavioral finance substitutes normal people for the rational people in standard finance. It substitutes behavioral portfolio theory for mean-variance portfolio theory, and behavioral asset pricing models for the CAPM and other models where expected returns are determined only by risk. [...] Behavioral finance expands the domain of finance beyond portfolios, asset pricing, and market efficiency. It explores the behavior of investors and managers in direct and indirect ways, whether by examining brains in fMRIs or examining wants, errors, preferences, and behavior in questionnaires, experiments, and the field. [...] behavioral finance explores saving and spending behavior [...]. And it explores financial choices affected by culture, fairness, social responsibility, and other expressive and emotional wants.

Finally, behavioral finance is an umbrella-term for a set of research questions which were put together mainly by historical accident. Noah Smith, a Bloomberg View columnist and a former assistant professor of finance at Stony Brook University, identified ${ }^{3}$ six different streams of research in finance encompassed by behavioral finance. They range from finance based on informational frictions (starting with seminal works such as Grossman and Stiglitz, 1980; Milgrom and Stokey, 1982) to empirical research on the behavior of individual investors (mostly initiated by Brad Barber and Terry Odean).

The difference in definitions may reaffirm the idea that a researcher's background matters. However, any attempt to define behavioral finance will eventually succumb to the nature of economic agents.

Standard finance assumes that its models are populated by agents empowered with such superpowers as limitless cognitive skills and willpower, and on the other hand restrained to pursue only their self-interest. These three unbounded traits (rationality ${ }^{4}$, self-control, and self-interest) form the basis for a so-called Homo Economicus, which is a model used to approximate the behavior of real human beings in a way that can be operationalized for the sake of building economic models. The word "approximate" is crucial. Finance (and economics in general) does not claim that Homo Economicus is a one-to-one representation of real world Homo Sapiens, rather such a portrayal is close enough to reality so we can bear the benefits of the simplification.

Naturally, humans may make mistakes, but people will learn over time and, given sufficient incentives, they will think and try harder to make truly rational choices. And if all of this is not enough, the individual mistakes will still be canceled out in the process of aggregation. These are severe assumptions, but this has not stopped the profession from building itself around Homo Economicus.

Instead, behavioral finance highlights that humans behave quite differently from Homo Economicus by embracing findings from psychology and sociology. This difference, no matter how much it may appear trivial, nonetheless has important consequences since real human beings are inclined to make systematic and predictable mistakes referred to as behavioral biases.

Following Thaler and Sunstein (2008), I will label decision makers described in the models of classic finance as Econs while referring to decision makers as viewed by behavioral finance as Humans.

To illustrate the difference between Humans and Econs, consider the classic example known as the "Asian disease problem" (Tversky and Kahneman, 1985).

\footnotetext{
${ }^{2}$ I will not provide a definition of behavioral finance of my own, while sticking to as much a wide definition as possible throughout this article. It also worth mentioning that in principle such terms as finance, financial economics, classical finance, and standard finance may have a slightly different meaning in different contexts. Nevertheless, I will use them interchangeably, unless otherwise specified.

${ }^{3}$ http://noahpinionblog.blogspot.com/2014/02/behavioral-economics-vs-behavioral.html

${ }^{4}$ In this article, the term "rationality" means that an individual knows and follows his or her own preferences as well as the absence of systemic and predictable mistakes in the processing of information.
} 
Imagine that the U.S. is preparing for the outbreak of an unusual Asian disease, which is expected to kill 600 people. Two alternative programs to combat the disease have been proposed. Assume that the exact scientific estimate of the consequences of the programs is as follows. If Program A is adopted, 200 people will be saved. If Program B is adopted, there is a $1 / 3$ probability that 600 people will be saved, and a $2 / 3$ probability that no people will be saved. Which of the two programs would you favor?

A typical answer to such problem is Program A since the prospect saving 200 people with certainty appears to be more attractive than a risky prospect of equal expected value in Program B. However, the likely answer changes if options are stated differently but the expected values of programs remain the same (only the wording has changed): if Program $A$ is adopted 400 people will die, while if Program B is adopted there is a $1 / 3$ probability that nobody will die, and a $2 / 3$ probability that 600 people will die.

This time, the majority choice is reversed and most people chose Program B. Notice, however, that the only difference between the two conditions is that in the first case the outcome of Program A is described by the number of lives saved and in the second case by the number of lives lost.

Because Econs are focused on the expected value of the programs and have stable preferences, they have no reason to change their minds from one condition to another. On the other hand, Humans are prone to a so-called framing effect, a tendency to react to a particular choice in different ways depending on how the choice is presented. In the example described above, the framing effect leads to a reversal in preferences. In the first case, Humans act as if they are risk-averse and prefer certainty while in the second case, facing a certain loss of 400 lives they became risk-seeking and chose Program B.

It is worth mentioning that besides unbounded rationality, self-control, and self-interest, agents in finance and economics have two very specific additional characteristics. First, their thinking process is approximated by the method of constraint optimization, i.e., economic agents are concerned only with optimizing an objective function (e.g., utility function) with respect to some variables (different consumption goods) in the presence of constraints on those variables (budget constraint). Secondly, modern economics is largely based on the principle of methodological individualism, the idea that we can explain society-wide phenomena by the actions of individuals. In other words, we agree that society is nothing more than the sum of all economic agents (which all are Homo Economicus).

Since neither behavioral economics nor behavioral finance addresses these last two assumptions of human behavior, some scholars state that behavioral modifications of Homo Economicus do not solve the main problem of modern economics (unrealistic assumptions about human behavior and interaction). For instance, Berg and Gigerenzer (2010) call behavioral economics as simply "Neoclassical economics in disguise", meaning that a behavioral approach makes economic agents more realistic, but not realistic enough to take the conclusions of a behavioral economics model seriously. Furthermore, Gerd Gigerenzer proposes a total rethinking of our understanding of human decision-making that goes much further away from traditional economics than behavioral economics and finance (for review see Forbes et al., 2015).

The introduction of this "third" perspective should help readers to escape the false dichotomy between classical and behavioral finance, or neoclassical and behavioral economics in general. Since the behavioral approach is largely based on the same principles of maximization and methodological individualism, behavioral finance does not represent an alternative to a standard finance; rather it should be considered as a set of modifications allowing for more realism while keeping most of the simplicity and usability of Homo Economicus. The same way readers should be warned against the even more simplistic and incorrect dichotomy between "rational" and "irrational" behavior. On one hand, standard finance rests on a quite narrow definition of rationality that allows for many post-hoc non-optimal decisions such as participating in the stock market bubble and suffering severe losses in the process. On the other hand, behavioral finance does not state that people are "irrational", "crazy", or that human behavior is random and cannot be modeled with any sufficient precision. On the contrary, a behavioral approach highlights predictability and a systemic nature of human mistakes so they can be incorporated into a standard framework of classical finance and neoclassical economics.

There is plenty of excellent literature to review on the topic, including such classics as Barberis and Thaler (2003) and Shiller (2003), and more recent ones such as Hirshleifer (2015) and Frydman and Camerer (2016). This review, however, is different as it gives more space to the history of behavioral finance and reviews its psychological foundations.

The need to review the historical background and foundations of behavioral finance deserves additional clarification. Specifically, it is my strong conviction that history provides a compelling case against the naive dichotomy between behavioral and classical finance. Even a brief historical detour will show that the discussion about psychological assumptions of human behavior is only a small part of much larger philosophical and methodological debates in the social sciences and that the proponents of a radical version of Homo Economicus had never won the debate, but rather choose to ignore it.

As a review of the history of behavioral finance should guard the open-minded readers from popular myths and historical fictions (such as behavioral movement is a recent phenomenon), a review of the psychological foundations is necessary to appreciate the benefits of a behavioral approach as well as to understand its limitations. The latter is of immense importance 
since proponents of behavioral finance bear the risk of succumbing to the law of the instrument and take the behavioral approach too far, the same way as neoclassical economists did it in the second half of the XX century. As economic imperialism and neoliberalism as its ideological base eventually lead to undesired outcomes, ${ }^{5}$ the uncritical acceptance of the normative conclusion of behavioral finance and economics may, in the end, result in inefficient policies as well as create some undesired consequences.

This article is organized as follows. The first section presents a brief historical review of behavioral finance starting from the advent of decision theory by Blaise Pascal in XVII century and concluding with the modern landscape of the field as of 2016. The second section reviews the foundation of behavioral finance by dividing it into micro and macro sub-fields, similar to Merton Miller's distinction between micro-normative and macro-normative streams of research in finance (Miller, 2000). The review of micro behavioral finance aims to contrast the behavior of Humans and Econs in both broad and finance contexts, while the review of macro behavioral finance serves to illustrate that these differences have implications at the aggregate level.

\section{HISTORY OF BEHAVIORAL FINANCE}

The history of behavioral finance as a particular case of the extensive history of behavioral economics is usually told from the perspective of finance and covers only a recent period. This simplified account starts with the discoveries of market anomalies (empirical findings in contradiction with theories of standard finance) in the 1980s and continues with attempts to explain these anomalies with the foundational ideas of behavioral economics proposed by Daniel Kahneman and Amos Tversky.

Following this narrative to the present, one may notice a paradox of the simultaneous coexistence of both psychological (behavioral finance) and antipsychological (classical finance) ideas within finance. Indeed, proponents of traditional and behavioral finance still have their deep ideological divisions despite at least a 30-year-long debate, which, given that modern finance was born in the early 1950s, preoccupied almost half of the current lifespan of the field.

With the goal to understand this paradox, this article will focus on the long history of interaction between economics (as a progenitor of finance) and psychology before the second half of the XX century, where the story of modern behavioral finance starts with the story of modern behavioral economics.

Following Lewin (1996), I believe that by studying earlier episodes "... we learn that the debate over psychological assumptions is only a small piece of a much larger intellectual debate that concerns the relationship between economics and the other human sciences, most particularly, with sociology". It is my hope that an understanding of the historical background, as well as the repudiation of some historical misconceptions, will help to resolve the paradox and provide a more unified picture of behavioral finance.

As a proper history detour may require space for an entire article, this paper will focus only on a few significant episodes. Namely, I intended to show that (1) the debates over the psychological assumptions already started in the XVII and XVIII centuries and that the advent of expected utility theory (EUT) was a response to a behavioral critique of a rational approach toward decision-making; (2) the classical economists such as Adam Smith as well as early neoclassical economists were hardly a proponents of Homo Economicus; (3) the rise of the psychology-free economics in the late XIX to early XX century was in part influenced by the developments in hard sciences and in psychology itself; and (4) that the period of supposedly psychologyfree economics of the first half of the XX century was in truth full of debates over psychological assumptions of the behavior of economic agents.

\subsection{Pascal's Wager and the advent of expected utility theory}

As a predecessor to behavioral finance, behavioral economics has its origins in early decision theory of the XVII century (Heukelom, 2007). Following Blaise Pascal's ingenious idea (Pascal's Wager) that one should evaluate a decision by the expected value of its outcomes and his discussion of rational solutions to gambling problems with Pierre de Fermat (Samuelson, 1977), decision theory was mostly concerned with the formalization of human behavior and its explanation in mathematical terms.

While Pascal's Wager provided a start for a formal decision theory of rational choice under uncertainty, the Enlightenment mathematicians of probability made no distinction between the rational solution to a problem and how a person would behave (Heukelom, 2007). In other words, no distinction was made between normative (optimal decisions) and descriptive (actual decisions) models of decision-making. Following a long-standing intellectual tradition (in part reinforced by Descartes' false dichotomy of "animal" instincts versus "human" rationality), scholars of the time had an aspiration to unveil and formalize the idealistic decision-making of the rational mind (opposed to the flawed emotional soul).

Despite the apparent success of Pascal's revolution, the attempts to model human behavior in a rational and purely logical way ran into troubles at an early age. It soon became apparent that gambles could be constructed to show that the rational solution is clearly at odds with the real-life observations. 
The most famous and consequential of such contradictions, the St. Petersburg paradox, was formulated by Nicolaus Bernoulli in 1713. It follows from the observation that no rational person will agree to pay all his wealth for the opportunity to make a wager with the small probability of an infinite payoff (thus, the bet has an infinite expected value). Over the next three centuries, the paradox grew into an intellectual phenomenon and linked together such prominent figures as the Bernoulli brothers, Nicolaus and Daniel; the inventor of Cramer's rule for solving systems of equations, Gabriel Cramer; the famous explorer of Roman history, Edward Gibbon; Charles Darwin, Thomas Mann, John Maynard Keynes; Karl Menger, one of the leading mathematicians of the XX century; and Paul Samuelson (Samuelson, 1977).

Solutions to the St. Petersburg paradox can generally be divided into four groups: explanations of statistical nature, concerns over finite resources and counterparty risk, diminishing marginal utility, and what we today would call explanations of behavioral economics (Hayden and Platt, 2009).

The most famous and influential explanation of the paradox was given in 1738 by Daniel Bernoulli (Bernoulli, 1954). He proposed that people make decisions not on the basis of expected value, but decisions are instead made based on their expected utility. In other words, what matters is not the amount of money per se, but the pleasure (utility) that they provide to an individual. This way, using the solution to the St. Petersburg paradox, Bernoulli successfully introduced EUT as the basis for the study of rational decisions. The key element to the solution of the paradox was the formulation of diminishing marginal utility of wealth (an equal amount of additional money is more useful for a poor person than an already-wealthy person).

The leading alternative solution to the paradox was proposed in 1713 by Nicolaus Bernoulli himself, as he suggested that events with incredibly small probabilities should be regarded as impossible (Dehling, 1997). Hereby, the younger Bernoulli indirectly and somewhat unknowingly introduced the idea that people may not act in a purely rational matter as they will underweight small probabilities. This idea is in many ways similar to a probability weighting, which is one of the building blocks of the prospect theory - the modern behavioral alternative to the EUT developed by Daniel Kahneman and Amos Tversky in the 1970s.

\subsection{Classical and early neoclassical economists}

It is not uncommon to assume that the father of modern economics, Adam Smith, was also an inventor of Homo Economicus and the concept of the "invisible hand", an integral part of Homo Economicus and the basis for unlimited self-interest.

A closer look, however, provides us with a rather different picture. In their already quite famous paper, Nava Ashraf, Colin Camerer, and George Loewenstein picture Adam Smith as the first true behavioral economist on the basis of his earlier work "The Theory of Moral Sentiments" (Ashraf et al., 2005):

Adam Smith's actors [...] are driven by an internal struggle between their impulsive, fickle and indispensable passions, and the impartial spectator. They weigh out-of-pocket costs more than opportunity costs, have selfcontrol problems and are overconfident. They display erratic patterns of sympathy but are consistently concerned about fairness and justice. [...] In short, Adam Smith's world is not inhabited by dispassionate rational purely self-interested agents, but rather by multidimensional and realistic human beings.

In a similar style, Tomas Sedlacek explores the history of the "invisible hand" in his book Economics of Good and Evil and concludes that it has its roots in the Epic of Gilgamesh, Hebrew and Christian thought, and was explored by Aristophanes and Thomas Aquinas. More importantly, Sedlacek shows that the concept in its modern form originates in the writings of an AngloDutch philosopher, economist and satirist Bernard Mandeville (1670-1733), namely in his Fable of the Bees (1705). In this poem, Mandeville proposes that private vices contribute to public good and are therefore beneficial for society. This is in sharp contrast with Adam Smith's thinking of the benefits of virtue expressed in his The Theory of Moral Sentiments.

The same applies to the other supposed fathers of Homo Economicus such as Menger, Walras, Jevons, and Edgeworth. While it is true that Jevons, Walras, Edgeworth, and the other marginal utilitarians, in their quest to make the utilitarian approach more mathematical and be able to express utility as an explicit quantity, were inspired by the developments in hard sciences of the XIX century (Mirowski, 1992), they also considered utility to be of real psychological substance (Lewin, 1996). In other words, despite these scholars' perception of utility as a gravitational forcefield that directed the actions of humans (Lewin, 1996), they also were looking for the true psychological underpinnings of behavior and motivation.

Likewise, Angner and Loewenstein (2007) point out that the adaptation of the hedonistic principle (individuals seek to maximize pleasure and minimize pain) by early neoclassical economics allowed for both rational and irrational behavior. For instance, the assumption that people maximize pleasure was not in contradiction with mistaken anticipation of pleasure resulting from certain actions.

This pattern is universal and repeats itself constantly. Whenever we start to consider the work of economic historians, it appears that the search for the father of Homo Economicus in its modern sense leaves us with unexpected discoveries. It appears that the thinking of classical and early neoclassical economists was full of references to psychology and allowed for 
deviation from purely rational behavior. For instance, Alter (1982) revisits the views of the famous Austrian economist Carl Menger and concludes that the acknowledgment of uncertainty and the existence of the time dimension made him believe in the importance of psychological factors in the explanation of human behavior.

\subsection{Quest for psychology-free economics}

Despite the fact that major economists of the second half of the XIX century can hardly be regarded as proponents of modern Homo Economicus, the changes in their environment were slowly pushing for the creation of psychology-free economics. The main drivers in this process were the success of XIX century natural sciences with their mechanistic view of the world and the changes in psychology itself starting from the rise of psychophysicists in the 1850 s and followed by the rise of behaviorism in the early XX century.

First of all, the late XIX century advancements in physics and chemistry were instrumental in promoting the mechanistic view of society and even made such a view fashionable. As Roy Weintraub writes: ${ }^{6}$

The very term "social system" is a measure of the success of neoclassical economics, for the idea of a system, with its interacting components, its variables and parameters and constraints, is the language of mid-nineteenthcentury physics. This field of rational mechanics was the model for the neoclassical framework. Agents were like atoms; utility was like energy; utility maximization was like the minimization of potential energy, and so forth.

In other words, despite most economists of the period seeming to accept the complex psychological nature of human beings, the success of natural sciences created pressure to uncover similar purely mechanistic and universal laws of individual decision-making and economic interaction.

One of the earliest real possibilities to make economics into a more physics-like discipline came from the developing field of psychophysicists, quantitative investigation of the relationship between physical stimuli and the perceptions they produce. This so-called stimulus-response paradigm in the works of Gustav Fechner produced an inspiring finding for the economists. It turned out that the relationship between wealth and utility proposed by Daniel Bernoulli looks very similar to the relationship between stimulus and subjective sensation (known as the Weber-Fechner law). This finding, in turn, inspired marginalists like Jevons, and later Edgeworth, to reduce the complex notion of utility to a one-dimensional measurement scale of the individual perception of pleasure and pain (Heukelom, 2007), allowing for a major simplification of the complex human nature and reducing the need for psychological assumptions.

Then, in the late XIX century to the early XX century, psychology witnessed the rise of Freudianism with its focus on unconscious, unobservable motives. Because this development went against the mechanistic view of human nature, economists began to find comfort in the gaining popularity of ideas on behaviorism, as it was primarily concerned with observable behavior (Sent, 2004). In the end, it appears that the rise of behaviorism became the major escape route for economists from psychology and its assumptions of human nature. However, in truth, instead of rejecting psychology entirely (as many seem to believe), neoclassical economics simply chose to base itself on a particular vein of psychology (behaviorism). As a result, this means that the neoclassical economics of the XIX century still relies on the psychological ideas of the early XX century that were mostly rejected in the wake of a cognitive revolution in the 1950 s.

Finally, the economics of the late XIX century began to lose its aspiration to be a universal social science (Lewin, 1996) as it was prepared to hand over to others the study of social and institutional change in order to free pure economic science from such entanglements (Winch, 1973).

\subsection{Challenges to psychology-free economics}

It is hard to put the exact date on the birth of Homo Economicus. However, it is possible to argue that the most important advancements were made during a roughly 20-year period, from the early 1930s till the early 1950s. During that time, such scholars like Robbins, Hicks, Allen, Samuelson, von Neumann, Morgenstern, and others created the modern tools of microeconomics that we are still supposed to rely on when analyzing the behavior of rational economic agents.

Although the theory of rational choice was making noticeable progress in the first half of the XX century, its postulates were put under test immediately by the scientific community.

For instance, an experimental economics program was initiated by the Louis Thurstone experiments on individuals' actual indifference curves (graphical representation of the all possible combinations between two different economic goods which has equal utility to the consumer) in the early 1930s and continued by Stephen Rousseas and Albert Hart in the 1940s and Frederick Mosteller and Phillip Nogee in the 1950s. These early experiments concluded that the indifference curves indeed have some basis in reality and that it is possible to construct subjects' utility functions. However, the results are not so good as might be expected. 
More serious problems started to appear with experiments conducted under risks and uncertainty. For example, the famous hypothetical experiment proposed by Maurice Allais in 1953 (Allais paradox) showed that the theory of maximization of expected utility, which had been accepted for many decades, did not apply to certain empirically realistic decisions under risk and uncertainty.

Another line of testing the basic assumptions of Homo Economicus came from survey data. The famous Lester-Machlup Debate started with Lester's (1946) paper that used survey data to show that corporate managers do not use marginal analysis in their decision-making. The data clearly indicated that the behavior of real humans simply does not confirm the expectations of economists, as the former did not rely on explicit maximization and marginal analysis to guide their decision-making.

However, instead of taking the real-world data seriously and modifying the model of decision-making accordingly, economists appealed to an ingenious argument: it does not matter what people think they do as long as their actions can be approximated with the sufficient accuracy. First, Machlup (1946) came up with the analogy, stating that corporate managers behave the same way a car driver who acts as if he calculates all variables related to driving (e.g., speed, remaining distance, etc.) in a mathematically rigorous way. Then, Friedman (1953) took this defense to a new level by formulating the so-called "as-if" defense of economics:

Consider the problem of predicting the shots made by an expert billiard player. It seems not at all unreasonable that excellent predictions would be yielded by the hypothesis that the billiard player made his shots as if he knew the complicated mathematical formulas that would give the optimum directions of travel, could estimate accurately by eye the angles, etc., describing the location of the balls, could make lightning calculations from the formulas, and could then make the balls travel in the direction indicated by the formulas. Our confidence in this hypothesis is not based on the belief that billiard players, even expert ones, can or do go through the process described; it derives rather from the belief that, unless in some way or other they were capable of reaching essentially the same result, they would not in fact be expert billiard players.

In other words, proponents of Homo Economicus postulated that the unrealistic assumptions of human behavior do not matter until the theory allows for making reasonably accurate predictions. Psychological assumptions are irrelevant to the validation of theories, and the theories should be judged on the accuracy of predictions. And since the experimental evidence of the day was inconclusive, largely due to the weak experimental designs, most economists sided with Machlup and Friedman.

\subsection{Behavioral economics: the "old" and the "new"}

By the early 1950s, it became apparent that economics and other social sciences were moving in the separate ways. Armed with Friedman's idea of "as-if economics", the field embraced its psychology-free status, and the dissidents were welcomed to pursue a different career path.

Interestingly, during the next two decades, precisely, when economics decided to isolate itself from the other social sciences, psychology underwent a so-called cognitive revolution, which sought to undermine the dominance of behaviorism (Mirowski, 1992). While the former assumed that the only things that are real are the things one can see and observe (we cannot observe the mind at work, but we can see how people act, react, and behave), the latter provided new insights into the mechanics of the mind and focused on internal psychological processes (Sent, 2004).

Together with the slow accumulation of experimental evidence at odds with the predictions of the model of rational choice, the cognitive revolution allowed for a renewed interest in the psychological assumptions of human behavior. However, despite the works of prominent figures of this new movement such as Herbert Simon and George Katona, their efforts did not have much impact on mainstream economics (Nagatsu, 2015). One of the main reasons behind the limited recognition of these works (Esther-Mirjam Sent refers to this stream of research as "old" behavioral economics) was the lack of conclusive experimental evidence, as the experiments were confined to so-called "small world" situations, i.e., were highly abstract and hypothetical. Such experiments typically involve urns with poker chips of different colors on the basis of which subjects have to compute some probability distribution (Heukelom, 2007). Fortunately, all this changed with the rise of New Behavioral Economics.

Behavioral economics as we know it today (thus, "new" behavioral economics) originated in the early 1970s and was associated with (at that time) two relatively unknown cognitive psychologists, Amos Tversky and Daniel Kahneman, and their studies of decision-making under uncertainty.

In the 1960s, Amos Tversky was working on the theoretical exploration and development of EUT and the related problem of measurement, while Daniel Kahneman's research focus was on the errors of human perception given some external stimuli (Heukelom, 2007). For example, Kahneman was interested how subjective perception of a visual stimulus depends on cognitive load and distractions and found that if you give people simple math problems they would be less likely to perceive a weak visual stimulus which they have no trouble detecting when they are not engaged in such a task. This combination of Tversky's mathematical work on EUT and Kahneman's psychophysical emphasis on the difference between stimulus and perception was a natural fit for a new research agenda of decision-making in real-world situations (Heukelom, 2007). 
Kahneman and Tversky started with EUT predictions of how people should behave and began to document the systematic deviation from EUT in realistic decision-making settings. The former was important because economists were not interested in an alternative to EUT, while the latter solved the problem of the excessively unmaterialistic experimental setting of "old" behavioral economics (these two factors partially explain the non-impact of "old" behavioral economics onto mainstream economics). In other words, Kahneman and Tversky accepted the rules of mainstream economics and, by using its own instruments, began to uncover problems with EUT as a good descriptive theory.

\subsection{The birth of Behavioral Finance}

The rise of behavioral finance was hardly predicted beforehand (Thaler, 2015) as financial models populated with Econs were the most elegant and they had been applied to a real world with what at that time was considered as an enormous success. Also, because financial markets were seen as the most efficient markets of all, it was expected that individual errors would have negligent effect at the aggregate level. Nonetheless, in hindsight, it seems that financial decision-making is one of the least natural for Humans. Thus, there is room for behavioral mistakes in this domain. Finally, the availability of high quality data in finance eventually made these mistakes easy to uncover.

Similar to behavioral economics, behavioral finance needed two ingredients for its development: examples of deviation from predictions of normative theories and some ready-made explanations of such deviations. The latter was provided by ideas from behavioral economics, but the former required an approach different from the one used in behavioral economics where it is was enough to show the examples of behavior that do not conform to the model of Homo Economicus. One of distinct features of finance is that if people will not act as Econs, they will lose money and disappear from financial markets. Thus, individual mistakes cannot reject the assumptions of traditional finance. As a result, to show the importance of behavioral mistakes it was important to point to the existence of market anomalies, i.e., some unexpected market-wide phenomena contradicting the predictions of the existent theory. For behavioral finance to be born, researchers needed to find such market anomalies and successfully explain them with the help of insights from behavioral economics.

The exact date when it happened is a matter of disagreement and depends on personal perspective. Some point to the year of 1994 while others conclude that the beginnings lie in the late 1950s (Bikas et al., 2012). However, the cross-disciplinary consensus points rather to the year 1985 and the publication of De Bondt's and Thaler's (1985) paper on stock market overreaction.

De Bondt and Thaler expanded on already well-known value anomaly. However, they were the first to use a convincing behavioral explanation of the anomaly. It is also worth noting that 1985 saw the publication of two more seminal papers (Shefrin and Statman defined the now well-established "disposition effect", while Mehra and Prescott uncovered the so-called "equity premium puzzle"). Additionally, 1985 was a year when the behavioral approach attracted serious academic attention for the first time during a conference at the University of Chicago, where such heavyweights as Robert Lucas, Merton Miller, and Eugene Fama debated Daniel Kahneman, Amos Tversky, Richard Thaler, and Robert Shiller (Thaler, 2015).

Alternatively, if we want to highlight the importance of research on market anomalies as the origins of behavioral finance, then history also points to the Shiller (1981) paper showing that the volatility of a stock market is much greater than can be explained by rational factors. While Shiller's paper was not the first to explore market anomalies, it was the first to generate academia-wide discussion. In general, research on market anomalies has much deeper roots and can be traced back at least to the 1960s. For example, famous hedge fund manager Victor Niederhoffer, during his academic career at Berkeley in the the 1960s, published a series papers on anomalies in stock market behavior. In the late 1970s, Basu (1977) was the first to formulate and test the value anomaly, i.e., the positive relationship between such valuation metrics as price to earnings ratio and average stock returns, while Banz (1981) later described the related so-called size anomaly: the negative relationship between stock returns and the market capitalization of a firm.

In search of the starting point, those who view behavioral finance as a part of a research stream focused on problems with information processing (finance based on informational frictions) may refer to the Grossman and Stiglitz (1980) and Milgrom and Stokey (1982) papers on information and market efficiency. These first suggested that the prices of financial assets should be wrong to justify the cost of going out and finding new information. The second paper proposed that huge trade volumes in real-world markets may be a sign of some deviation from rationality because in rational markets everyone has almost the same information and thus the motive for trading is rather the second-guessing of the counterparty motives and not an efficient processing of relevant fundamental information.

Finally, if we want to highlight the psychological underpinnings of behavioral finance, then we may conclude that behavioral finance started with Slovic's (1972) paper summarizing psychological findings related to investment decision-making, such as the existence of cognitive limitations in processing information and biases in judgments of probability. 


\subsection{Modern Behavioral Finance}

Behavioral finance reached several significant milestones in the late 1990s and early 2000s. Thaler (1999a) proclaimed the end of behavioral finance in the sense that the field had already become a part of the mainstream. By that time, behavioral finance provided convincing behavioral explanations for many anomalies and proposed a range of behavioral models which had advantages in explaining real world phenomena. For example, Benartzi and Thaler (1995) used the concept of myopic loss aversion to address causes for a historically high equity risk premium (equity premium puzzle). Later, Shleifer and Vishny (1997) introduced the idea of limits to arbitrage in financial markets and basically predicted the situation that the successful and famous hedge fund LTCM found itself in during the 1998 Asian financial crisis, while Hong and Stein (1999) created models that reconciled short-term underreactions and long-term overreactions of stock markets. At the same time, Brad Barber and Terrence Odean started a new wave of research in behavioral finance by documenting behavioral mistakes of individual investors using the data from brokerage accounts. For example, in the seminal paper, Barber and Odean (2001) provide evidence that individual investors achieved sub-par investment results and explained this finding by proposing that overconfidence leads to excessive trading, noting that there is a clear gender difference in the attitude toward trading activity (men are more prone to excessive trading).

In 1999, Andrei Shleifer was awarded the John Bates Clark Medal of the American Economic Association, and in 2000, Matthew Rabin, another scholar advocating the behavioral approach, won a MacArthur Foundation "genius" award and was awarded the John Bates Clark medal in 2001. Also in 2000, Robert Shiller published his famous book Irrational Exuberance in which he correctly predicted the crash of the dotcom stock market bubble, and Andrei Shleifer published the seminal textbook Inefficient Markets: An Introduction to Behavioral Finance. While Shiller's book was instrumental in spreading ideas of behavioral finance to a wider audience, Shleifer also did what was required to compare the efficient market approach with the insights of behavioral finance. He described the role of noise traders (financial market participants whose behavior was different from Econs), arbitrageurs, and investors, and explained how factors such as risk aversion and agency problems could impose limits on arbitrage. Later, Brunnermeier and Nagel (2004), by looking at data on hedge funds' activity during the dotcom bubble, proved that supposedly "smart money" does not necessarily correct the disparity between fundamental and market prices, but rather will "ride the bubble" and confirm the models of noise traders.

Finally, in 2001 George Akerlof, Michael Spence, and Joseph Stiglitz shared the Nobel Prize "for their analyses of markets with asymmetric information", and a year later the Nobel Prize was shared by Daniel Kahneman "for having integrated insights from psychological research into economic science, especially concerning human judgment and decision-making under uncertainty".

In short, in the early 2000s, behavioral finance, and behavioral economics, in general, gained acceptance and respectability after many years of intensive discussions with supporters of the dogmatic neoclassical approach. As Thaler (2015) noted: "Not surprisingly, there have been numerous squabbles with traditionalists who defended the usual way of doing economics. Those squabbles were not always fun at the time but [...] the necessity of fighting those battles has made the field stronger".

At the same time, despite the apparent success of the behavioral approach to finance in the early 2000 s the critics were pointing out that behavioral economics, and behavioral finance in particular, still lacks a grand unifying theory of decisionmaking that can take the place of EUT. This quest for a grand unified theory was at that time predicted by many to become one of the central forces in behavioral finance research in the years to come.

However, it is apparent that the development of the field moved in a different direction: behavioral finance presents itself 10 to 15 years later as an even more diverse and scattered field than it used to be. Instead of unification, the field experienced increased specialization, while the behavioral approach became more widely used to tackle different questions, from the role of households' time preferences in accumulation of credit card debts (Meier and Sprenger, 2010) to the path dependence in corporate costs of borrowing (Dougal et al., 2015).

Additionally, behavioral finance became much more diverse in terms of accepted methods and sources of data. Now behavioral finance utilizes data from functional magnetic resonance imaging, genetic and neurobiological studies, and randomized field experiments; it applies linguistics analysis to identify deception (Larcker and Zakolyukina, 2012), relies on qualitative methods to understand behavioral biases (Sahi et al., 2013), and considers an evolutionary approach for the modeling of financial markets (Evstigneev et al., 2016).

\section{FOUNDATIONS OF BEHAVIORAL FINANCE}

Just like economics consists of microeconomics and macroeconomics, both finance and behavioral finance can be similarly divided into two somewhat separate parts.

Miller (2000) suggests that research in finance falls into two streams: micro-normative and macro-normative. The first vein is concerned with individual decision-making and is historically associated with the approach taken by Business Schools aiming to 
teach students to make high-quality financial decisions. The second approach is historically associated with the research done in Economic Departments with the main goal to derive the dynamic of asset prices from the behavior of individuals.

In the same style, Pompian (2012) proposes a similar approach to describe a variety of topics in behavioral finance. Micro behavioral finance documents behavioral biases of individual investors and its implications for decision-makers. It also tries to uncover the roots of behavioral biases and mechanisms by which they operate. Similarly to the macro-normative stream of research in finance, macro behavioral finance is interested in how the behavior of individual decision-makers determines and influences asset prices. However, unlike the former, macro behavioral finance does not assume that individuals behave like Econs, rather, it is based on the behavior of real humans described by micro behavioral finance.

Inspired by this distinction, this section starts with an account of the theoretical underpinnings of micro behavioral finance by examining the difference between Humans and Econs. Then, the section turns to the most important findings in the realm of macro behavioral finance, which are mostly related to the so-called financial market "anomalies" and the question of financial market efficiency.

\subsection{Micro Behavioral Finance}

Homo Economicus is a highly-specified model and this fact makes it easy to make a distinction between Econs (suggesting how economic agents behave) and Humans (empirical evidence on how real humans actually behave). In short, Econs should have the following three qualities.

First, Econs should process information efficiently and effortlessly translate it into actions, i.e., correctly retrieve information from their memory; correctly access the accuracy of the knowledge and skills they have; correctly infer new information from observations of their environment; be indifferent to the way information is presented; ignore non-relevant information; make correct probabilistic judgments; and possess the required self-control to execute the needed actions.

Secondly, Econs should have so-called standard preferences that are known to an individual, are stable in time, and do not change under the influence of irrelevant information. Interestingly, the examples of prosocial and other types of behavior contradicting the notion of unbounded self-interest do not constitute a threat to Homo Economicus, at least on the micro level. The theory of rational choice states that economic agents act rationally given their preferences. It means that if an individual investor trades securities on a stock exchange to satisfy his/her sensation seeking, he/she does not act irrationally since he/ she satisfies his/her preferences, whatever they might be (sensation seekers are looking for intense and novel experiences associated with risky behavior; Grinblatt and Keloharju, 2009 found that sensation seeking is associated with higher trading activity). The failure to account for the limits of self-interest (in the strict sense of pursuing only one's own monetary gain) may result in incorrect estimation of response to government or business actions. However, this problem has a rather technical nature and potentially can be dealt with through more or better data (the problem is rather how to measure prosocial preferences).

Finally, the model of Homo Economicus implies that people can and will learn from their mistakes and that the process of learning can be described by the so-called Bayesian updating. The latter means that humans have a prior probability estimate (probabilistic estimate given all available information) of the occurrence of some event and when the new relevant information becomes available, we produce a posterior probability estimate (new estimate) by applying the Bayesian rule of updating probabilities. In other words, people apply probabilistic thinking to most real-world situations, efficiently process information, and change their minds based on rules of probabilities estimation.

Behavioral studies have shown that all these propositions are far from the universal truth.

First, Humans make decisions based on the so-called dual process theory of decision-making and over-rely on quick intuitive shortcuts (heuristics) rather than on deliberate thinking, which in the end leads to a variety of behavioral biases. Secondly, real human preferences are better described by the prospect theory, rather than by EUT. Likewise, Humans are not necessarily aware of their preferences, and the preferences themselves may be unstable over time and depend on the way the choice is framed (depend on the way the situation is presented). Finally, there are a number of behavioral phenomena preventing Humans from learning from their own mistakes, and the process of learning is better described by the model of Reinforcement Learning rather than by Bayesian updating. Moreover, Humans experience emotions and those emotions can influence all three ingredients constituting Homo Economicus: processing of information, preferences, and learning.

Behavioral research was also successful in addressing the most often used objection to its findings, namely, the high-stakes argument (when the stakes are high enough, people will make decisions just like Econs). Reviewing the relevant literature, Camerer and Hogarth (1999) concluded that there is simply not enough evidence that Humans act more like Econs during high stakes situations rather than at low stakes. In addition, a recent study (Van Dolder et al., 2015) documented peoples' behavior during particular game shows where participants were making decisions with very substantial sums of money at stake and found no support for the argument that high stakes force Humans to act in accordance with the model of Homo Economicus. 
The rest of the sub-section examines these three sources of differences between Econs and Humans in more detail (biases that arise due to the dual process theory of decision-making, the difference in preferences, and limits to learn from own mistakes) and concludes with a discussion of the heterogeneity of behavioral biases, as well as the main factors behind it.

\subsubsection{Dual Process Theory of Decision-Making}

The Dual process theory of cognition proposes that we use two parallel systems of decision-making. The first system is automatic, effortless, heavily influenced by associations, intuitive, quickly jumps to conclusions, largely unconscious, and mostly based on heuristics (shortcuts or rules of thumb which "represent an adaptive mechanism that saves us time and effort while making daily decisions", Croskerry et al., 2012). The second system is deliberate, conscious, effortful, logical and slow. Most researchers refer to those two systems as System 1 and System 2 (Morewedge and Kahneman, 2010), however, following Haidt and Kesebir (2010) and Hirshleifer (2015), I will refer to them as intuitive and reasoning systems.

To illustrate the difference between the two systems, consider an example. Answer the question: how many people are living in the New York City? Notice that, no matter if you know the right answer of not, you still have an intuitive answer. It probably came to you at once and was based on simple heuristics: I know that a big city has several millions inhabitants, New York is among the biggest cities in the world, so it may have something close to 10 million people (the right answer is 8.5 million). This was an intuitive system at work. It is also reasonable to assume that your answer at least partially depended on the size of the city you live in, because the size of it, no matter how irrelevant it is, still may have influenced the guess of the intuitive system (this is an example of the "anchoring effect", which is discussed later in this section). Now consider a different question: what is the product of 57 and 28 ? Notice that your intuitive system was most likely silent this time. This was a question designed to be addressed by the reasoning system, while your intuition was not able to provide an easy guess.

The work of these two systems is not entirely separate, rather they may work in parallel, where the intuitive system generates impressions, guesses, and tentative judgments, which might be accepted, blocked, or corrected by the reasoning system (Morewedge and Kahneman, 2010). One of the most colorful and useful metaphors depicting this interaction was popularized by Haidt (2006): "Like a rider on the back of an elephant, the conscious, reasoning part of the mind has only limited control of what the elephant does".

There are two important details about this interaction between the intuitive and reasoning systems.

Firstly, the reasoning system requires a lot of cognitive resources and, thus, most of our decisions are made on autopilot. Lakoff and Johnson (1999) estimated that people spend about $95 \%$ of their time under the control of the intuitive system. It also means that most of the decisions produced by the intuitive system go unchecked by the reasoning system. The intuitive system is always involved in decision-making, i.e., the limbic system is consistently interfering with cognitive processes (Loewenstein et al., 2008; Rustichini, 2009) and medical conditions preventing the experience of emotions results in a worse quality of decision-making (Damasio, 2008).

Secondly, the intuitive system was well suited to the human ancestral environment, however, it provides poor guidance for decision-making in a modern complex world (Hirshleifer, 2015). Consequently, since the problems that our mind evolved to deal with are different from today's, heuristics developed by our ancestors are likely to generate systematic and predictable errors in decision-making (behavioral biases).

Despite the idea that our brain is not very well suited to a modern environment may seem highly speculative, there is growing evidence that behavioral biases indeed have evolutionary roots. For instance, Santos and Rosati (2015) review literature on the origins of decision-making and conclude that comparative studies of humans and nonhuman primates' decision-making support the notion of evolutionary roots of behavioral biases. Other studies reached the same conclusion by analyzing isolated behavioral phenomena. For example, Apicella et al. (2014) provide an evolutionary explanation for an endowment effect, while Moshe and Levy (2014) and Zhang et al. (2014) showed the evolutionary origins of risk aversion (both endowment effect and risk aversion are discussed later in this section).

The important conclusion is that the intuitive system has a predominant influence on our decision-making and its reliance on heuristics may lead to predictable and systematic mistakes in specific circumstances.

Literature usually highlights the four most important heuristics: availability, representativeness, anchoring and adjustment, and affect. The first three were introduced by Daniel Kahneman and Amos Tversky in the early 1970s and eventually helped them to formulate prospect theory (Kahneman and Tversky, 1979), which to this day remains the most successful alternative to the EUT.

The availability heuristic is the tendency to estimate the probability of an event based on how prevalent or familiar it appears in our lives (Pompian, 2012). While this is a sensible mental shortcut on its surface, it can result in mistaken estimates because not all past instances of this event are equally retrievable from memory. Thus, people tend to make judgments based on a limited sample of past occurrences, overweighting more recent or more vivid memories. For example, after witnessing a car 
accident, people will likely drive more carefully for some time afterwards despite the fact that traffic does not become riskier. Likewise, when investors overweight the last available and more vivid information, they tend to overreact to news which, in turn, helps to explain the positive autocorrelation of returns and momentum.

The extrapolation from past returns is also partially explained by the representativeness heuristic, which states that people judge the probability that an object $A$ belongs to a class $B$ by considering how much $A$ is similar to $B$, i.e., by relying on formed stereotypes. This leads to all sorts of probabilistic mistakes from sample size neglect (alternatively the law of small numbers) - the tendency to make inferences from too small samples to a conjunction fallacy - the mistaken belief that the conjoint occurrence of two independent events are more probable than the probability of either one occurring alone (famous "Linda problem").

These heuristics, together with self-attribution and hindsight bias (discussed later in this section), result in overconfidence and its correlates (overoptimism and wishful thinking). As a result, Humans display unrealistically positive views of their abilities and prospects and rely on too narrow a confidence interval when estimating probabilities (Alpert and Raiffa, 1982).

The anchoring and adjustment heuristic represents a tendency to place too much weight on the first piece of information available or offered (anchor) when making an estimate. People start with the anchor (no matter how irrelevant it may be) and make adjustments based on the newly received information. The heuristic may cause two sorts of problems. First, Humans are influenced by non-relevant information. For example, Ariely et al. (2003) presented experimental evidence that the last digits of a tax identification number (irrelevant anchor) may influence the willingness to pay for several consumer items (including wine, books, and computer accessories). Secondly, problems arise because the adjustments are usually insufficient and the final estimate remains too close to the initial starting point. For example, Cen et al. (2013) demonstrated that analysts make insufficient adjustments to their earnings forecasts even if such adjustments are well supported by new information.

Finally, Slovic et al. (2002) reformulated and popularized the affect heuristic which states that emotions provide guidance in the process of decision-making. Emotions and feelings help to weight possible outcomes, which simplifies the process of comparison and motivates decisions and actions. The affect heuristic helps to explain well-documented findings that sentiment (time-varying mood swings) can influence asset prices and macroeconomic outcomes. For instance, recent studies found that sentiment affects investors preferences for risk-taking as well as confidence in their own skills and abilities, thus emotions affect both preferences and beliefs (Kuhnen and Knutson, 2011; Bassi et al., 2013).

\subsubsection{Preferences: Humans vs. Econs}

If Humans behave like Econs, then preferences are known and independent from the way the situation is presented. However, empirical evidence rejects both of these assumptions.

In a creative paper titled Tom Sawyer and the construction of value, Ariely et al. (2006) provide evidence that in some situations people do not have a pre-existing sense regarding a particular experience. Subjects in this study were shown to be easily manipulated by non-normative cues to change their perception from good to bad even if they have tried a similar experience before.

Humans' preferences also depend on the way the situation is described (framing effect), i.e., people make different choices depending on how the choices are presented to them (for example, the "Asian disease problem", described in the introduction). The way we react to a difference in the representation of the problem is called mental accounting (Thaler, 1999b). For example, people treat gains and losses of the same magnitude differently (Kahneman and Tversky, 1979) and sometimes make a distinction between financial assets depending on how they frame them, as belonging to current wealth, current income, or future income (Shefrin and Thaler, 1988). The last example means that Humans treat one dollar in their left pocket differently from one dollar in their right pocket.

Preferences are also shown to be time-inconsistent. Unlike Econs, who applied a stable discount factor to value future payoff, Humans discount near term payoffs much more rapidly than payoffs they expect to receive in the distant future (Laibson, 1997), meaning that the value of the discount factor depends on the characteristics of the situation. Such a difference in approach to near term versus distant rewards is an example of failing to resist a temptation and related to a problem of limited self-control. Interestingly, as early as in the late 1970s and early 1980s, Thaler and Shefrin (1981) illustrated that people are generally aware of this problem and impose personal rules with the goal of increasing their savings. For example, authors describe a case of Christmas clubs, savings programs which were popular in the first half of the XX century in the United States. The design of the scheme was that customers deposit money during the year into a special account, and receive them back before Christmas. Even though such accounts paid no interest, they were nonetheless popular as a part of aa commitment strategy helping to address the problem of insufficient self-control.

The next big thing which distinguishes Humans and Econs is that Humans are loss averse, i.e., they prefer to avoid a loss to acquiring a gain of equal magnitude. In practice, it means that people will unlikely participate in a gamble with an expected value of zero because the negative emotions from the loss of 100 dollars are much more powerful than the positive emotions 
from winning 100 dollars. In general, the magnitude of loss aversion is domain and situation specific, but most estimates put the loss aversion coefficient into the range from 1.4 to 4.8 , meaning that loses on average are more than twice as powerful as gains (Abdellaoui et al., 2007).

Although it is rather unclear how we should perceive loss aversion, as a preference, a behavioral bias, or as an emotional reaction driven by fear, empirical studies have shown that loss aversion is a universal and important aspect of human behavior (Camerer, 2005). Loss aversion can help explain many behavioral phenomena, from the famous St. Petersburg paradox (Camerer, 2005) to the status quo bias, a tendency to take no actions and follow the chosen decision path (Samuelson and Zeckhauser, 1988). It also explains the endowment effect, a tendency to value things people own relatively more only because of the fact of ownership (Thaler, 1980). Loss aversion seems to be a very basic trait and may have evolutionary origins as it was found present in the behavior of capuchin monkeys (Chen et al., 2006).

The combination of loss aversion and short evaluation horizons produce myopic loss aversion. The latter helps understand relatively high stock market returns (compared to such safe assets as government bonds) over the last century that cannot be explained by the relative riskiness of securities alone (equity premium puzzle). Instead of focusing their attention on stock market returns over the long run, investors focus on short-time price fluctuations. As a result, such investors observe more frequent "paper" losses (negative price changes) and since they are loss averse, investors demand relatively higher compensation (a higher equity premium).

Loss aversion also constitutes one of the main building blocks in the prospect theory (Kahneman and Tversky, 1979), the theory of choice under risk and uncertainty which to this day remains the sole alternative to the standard framework of the EUT.

Prospect theory states that individuals value outcomes of choices they consider to make in relative terms, comparing them to a reference point. Rather than consider the expected value of some risky option, individuals instead will make a decision based on the potential value of gains and losses resulting from such a risky option. First of all, since Humans are loss-averse, they unlikely take a risk if the pleasure they expect to receive from a gain will be lower than the pain they will experience in the case of loss. Secondly, people will exhibit more risk aversion (less tendency to take on risks) if there is a high chance of gain, while they will act in a more risk seeking manner facing the greater probability of loss. It is usually said that Humans are risk-averse in gains, but risk-seeking in losses. Finally, prospect theory considers mistakes people make when they perceive probabilities, namely, it accounts for a tendency to overweight small probabilities and underweight the large ones.

In a seminal review, Barberis (2013) documents a wide list of applications of the prospect theory for the analysis of realworld problems, especially in finance and insurance since prospect theory models decision-making under risk and uncertainty. For example, prospect theory helps explain a robust and widespread finding - the disposition effect, a tendency of individual investors to realize their profits quickly (sell securities which went up in price after they were bought), but hold losing positions for too long (Shefrin and Statman, 1985; Talpsepp, 2011; Li and Yang, 2013). Prospect theory was also successfully used to enrich standard models of consumer choice (Köszegi and Rabin, 2009; Pagel, 2012), understand business strategy for price setting (Heidhues and Kőszegi, 2012), and explain the intriguing finding of Camerer et al. (1997) that the daily labor supply of New York City cab drivers negatively correlates with the average hourly wage on that day (Crawford and Meng, 2011).

The next important distinction between Humans and Econs in terms of their preferences concerns their motives for making financial decisions. While Econs make investments with the goal to receive utilitarian benefits (increase in wealth), Humans also focus on expressive and emotional benefits of their financial decisions (Statman, 2014). Expressive benefits communicate to others our values, tastes, and status, while emotional benefits represent how our decisions make us feel. For example, by analyzing data from retail brokerage accounts in China, Hong et al. (2014) showed that status concerns may explain a number of stylized facts that characterize the behavior of retail stock market investors, including excessive trading and preferences for stocks with small market capitalization.

If Humans are concerned only with utilitarian benefits, there are still some important differences from the behavior predicted by the model of Homo Economicus. In theory, investors desire high returns with low risk, while the standard deviation of returns constitutes a good proxy for risk. However, the development of psychological risk-return models following Weber and Milliman (1997) and corresponding empirical evidence suggest that Humans perceive risk in a subjective manner, i.e., the same level of objective risk (captured by the standard deviation of returns) may be perceived differently by different people. At the same time, recent studies challenge an even more fundamental assumption that the returns themselves are the most important parameter that matters to investors. Grosshans and Zeisberger (2016) demonstrate that investor satisfaction with an investment depends heavily on the price trajectory by which the final return is achieved. For instance, investors in this study were mostly satisfied when the price path of an investment was first negative before starting to yield positive results.

Finally, except aversion to risk and losses, Humans also tend to avoid ambiguity (ambiguity aversion) and prefer the familiar (preference for the familiar). These effects help to explain limited stock market participation, under-diversification, home bias (failure to diversify stock market portfolio with foreign stocks), and excessive holdings of stock in their own company (Guidolin and Rinaldi, 2013). 


\subsubsection{Limits to learning from one's own mistakes}

Finally, there are several factors preventing Humans from learning from their mistakes and adjusting behavior in the face of non-optimal decision-making. This notion has some parallels with the idea of efficient markets. If there are no constraints (limits to arbitrage), then markets should be efficient. However, in the presence of constraints, markets may be much less efficient than is suggested by the efficient market hypothesis $(\mathrm{EMH})$.

When it comes to learning, Humans face the following constraints. First, people are generally unaware of the role the intuitive system plays in their decision-making, with which the addition of self-attribution, hindsight, and confirmation biases limits the power of feedback we otherwise should receive from our decisions. Secondly, feeling regret, cognitive dissonance, the sunk cost fallacy, status quo biases, and inertia reduce the chance of accepting one's own mistakes and reduce motivation to change the behavior accordingly.

Now let's consider these constraints in more detail.

From the start, we underestimate how flawed and susceptible to behavioral biases our behavior is (Scopelliti et al., 2015). Humans also possess a general tendency to attribute successes to their skills and effort, while failures are attributed to factors beyond their control (self-attribution). Recently, Hoffmann and Post (2014) tested this proposition empirically by combining survey data with matched trading records of a large Dutch discount broker and found that individual investors indeed attributed their recent higher positive returns to their skills. Such a combination of unawareness and attribution of failures to external factors severely limits Humans' ability to identify mistakes to be learned from.

The related finding of Baron and Hershey (1988) suggests that we evaluate decisions by their outcomes and not by the quality of the decision-making process. The latter means that if a bad investment decision had led to a positive outcome by chance alone, the investor will likely view that decision as worth repeating in the future. This finding is related to the concept of reinforcement learning, a Humans' tendency to extrapolate from own direct experience rather than analyze and reflect on all the available data. In other words, economic agents update their understanding of the value of taking a particular action based on the outcome they had received from taking that action previously (Sutton and Barto, 1998).

Additionally, the combination of availability heuristics, overconfidence, and hindsight bias (a tendency to overestimate predictability of certain outcomes after they occurred, also known as the "I-knew-it-all-along" effect) provide Humans with a biased assessment of their track record in predicting a wide range of phenomena, from major geopolitical surprises (Fischhoff and Beyth, 1975) to volatility estimates (Biais and Weber, 2009).

In a related research, Choi et al. (2004) found that cognitive dissonance and the sunk cost fallacy (the decision to stick to the current course of action because of already incurred costs that cannot be recovered) can induce inertia and prevents investors from updating their retirement portfolios in response to changing circumstances.

\subsubsection{Variety of behavioral biases and their causes}

The list of cognitive biases and heuristics on Wikipedia contains about 177 items. Such a high number may suggest that researchers lack a single unified theory of decision-making. Consequentially, decision-making mistakes made by Humans are explained by parallel, complementary, and sometimes contradictory ideas. Speaking of debiasing ${ }^{7}$ strategies, Larrick (2004) suggested that behavioral biases have multiple determinants, and it is highly unlikely that we can find simple causes and establish one-to-one bias to debiasing strategy correspondences.

For instance, 25 years ago, Arkes (1991) suggested that most behavioral biases have only a few general causes and divided them into three categories: strategy-based, association-based, and psychophysically-based errors. Since then, empirical and theoretical works showed that isolated behavioral bias can result from an interplay of different factors (Nickerson, 1998) and some biases are not unitary, but rather represent a collection of different effects and vice versa. For example, availability and representativeness heuristics, in fact, constitute a single heuristic which Kahneman and Frederick (2002) called attribution substitution (however, the tradition to distinguish between the two stuck in both research and practice). Later, Krueger and Funder (2004) produced a list of the 42 most important cognitive biases from the perspective of psychological research, while Carter et al. (2007) list 76 decision biases in business and management and divided them into nine categories.

Despite most empirical studies focusing on one behavioral phenomenon or at a small sample of the population, there is growing evidence that certain groups of individuals are more prone to exhibit behavioral biases than others. Behavioral biases are also to some extent correlated with each other and with other skills and behaviors, like planning and problem-solving abilities, social engagement, alcohol and drug use, and juvenile delinquency (Parker and Fischhoff, 2005).

For instance, using brokerage account data from China, Chen et al. (2007) found that more than $40 \%$ of individual and $58 \%$ of institutional investors show evidence of more than one behavioral bias. While analyzing Swedish data, Anderson (2007, 2013) 
documented that a low-income, less wealthy, less educated, and less sophisticated investor is more prone to have a less diversified portfolio, trades relatively more, and achieves worse trading results.

In addition, there is also evidence that gender, age, experience, and other factors help to explain some heterogeneity in the manifestation of behavioral biases. However, it is important to keep in mind that the associations with most factors are quite complex and sometimes non-linear, while the explanatory power of many factors may be low and not rather stable. For instance, Kaustia and Luotonen (2016) analyzed factors driving stock market participation and could explain only $30 \%$ of the variation in the participation decision and about a third of this explanatory power were captured by institutional factors, while behavioral, cultural, and other recently identified factors explain less than a fifth of the variation.

Among standard individual level explanatory variables, gender is shown to be a robust predictor of overconfidence, since Barber and Odean (2001) proposed in now one of the most cited papers in behavioral finance that men achieve relatively worse trading results because of overtrading, which in turn is caused by a relatively higher level of overconfidence.

On the other hand, the relationship between behavioral biases and age is less straightforward. Korniotis' and Kumar's (2011) study based on U.S. discount brokerage data revealed that investors' cognitive skills and, consequently, investment outcomes decline with age and this negative effect is not fully compensated for by the greater experience of older investors. Alternatively, Li et al. (2013) collected a list of standard cognitive measures for economically important decision-making traits and reached the opposite conclusion, namely, that intelligence and experience gained by older participants compensate for the lower levels of fluid intelligence, especially in the case of temporal discounting (older people are more patient).

Whatever experience helps investors to overcome the decline of their cognitive skills, experience by itself is shown to reduce the influence of behavioral biases (Kaustia et al., 2008). Interestingly, personal experience also affects financial decisionmaking. Multiple recent studies documented that living through such traumatic experiences as exposure to a civil war, natural disasters (such as Hurricane Katrina), and the Great Depression of the 1930s affects risk-taking behavior, while living through a period of high inflation results in a tendency to have higher inflationary expectations (Frydman and Camerer, 2016).

On the contrary, positive personal experience may indirectly increase risk-taking, for instance, by encouraging participation in a particular kind of investment activity. Kaustia and Knüpfer (2008) investigated the link between investors' past experience and their tendency to subscribe to initial public offerings. Analyzing the behavior of retail investors in 57 Finnish IPOs occurring from 1995 to 2000, the authors concluded that earning a positive return from the first IPO participation substantially increase the probability that such investors will subscribe to future IPO offerings.

Not surprisingly, education is an important factor influencing financial decisions. Christiansen et al. (2008) concluded that individuals holding a university degree in economics have a higher tendency to participate in the stock market, while Liivamägi et al. (2014) found that higher education (economics, business administration, or in information technology) associates with higher risk-adjusted investment results. Additionally, education is found to reduce the influence of some behavioral biases, from self-attribution and anchoring biases (Nguyen and Schuessler, 2012) to the disposition effect (Vaarmets et al., 2016), as well as influence investors' trading activity (Liivamägi, 2016). Naturally, being a smart person also helps as Grinblatt et al. (2012) showed that high-IQ investors are more likely to hold more diversified portfolios and earn higher Sharpe ratios.

Some other factors that might explain heterogeneity in both rational and biased financial decision-making include genetics (Cesarini et al., 2010; Cronqvist and Siegel, 2014), personality traits (Bucciol and Zarri, 2015; Oehler et al., 2016), culture (Chang and Lin, 2015), and experiencing emotions (Kaplanski et al., 2015). Interestingly, a series of studies examining emotional states of financial market participants at work concluded that poor financial performance is a result of having too much or too little emotion, rather than simply experiencing them (Lo et al., 2005; Coates and Herbert, 2008; Liu et al., 2016).

Finally, since behavioral biases are susceptible to environmental clues and framing of the situation, manipulation of seemingly irrelevant factors may influence financial decisions. For example, Bazley et al. (2016) showed that using a red color (compared to black or blue) to communicate financial losses makes investors relatively more risk-averse and more pessimistic about future returns. This susceptibility to the environment is the foundation of one of three major debiasing strategies (along with training and incentives).

\subsection{Macro Behavioral Finance}

It has long been known that people make mistakes and may enter financial transactions for all the wrong reasons. However, before some scholars were even ready to give up the elegant and simple world of efficient markets in favor of much more complex and messier reality populated by Humans, the behavioral approach was required to overcome a set of (at that time) convincing counterarguments.

When behavioral finance started to take shape as a distinct research field, Thaler (1986) listed four standard objections economists used to offer against taking research in early behavioral economics seriously. Aside from the already discussed mistaken beliefs that people will learn from their mistakes and will act rationally facing high stakes, the list included another 
pair of counterarguments. The first stated that individual errors will cancel each other out in aggregation, while the second proposed that arbitrage and competition will eliminate the effects of irrational agents on the market level.

The need to answer these objections embedded in the idea of efficient markets was crucial to the success of behavioral finance and defined the sub-field of behavioral macro finance as we know it today. Behavioral finance responded to the first argument by discovering and documenting market anomalies, empirical facts that were in a sharp contrast with EMH. The response to the second macro argument was addressed with the development of theories of noise traders and limits to arbitrage, which is essentially an explanation of why market anomalies exist in the first place.

For convenience, I will distinguish between the three related but different components of EHM while documenting the most known financial market anomalies, and then discuss the concepts of limited arbitrage and noise traders. These three components are: "no free lunch", "all available information", and the "price is right".

\subsubsection{No free lunch}

The "no free lunch" component of EMH states that it is impossible to beat the market on a risk-adjusted basis and this view is largely supported by empirical evidence (Rubinstein, 2001; Jones and Wermers, 2011). Therefore, the rise of active management over recent decades seems to contradict the efficient market hypothesis. Interestingly, even John Cochrane, who is hardly a proponent of behavioral finance, noted that the persistence of active management at very high fees remains a puzzle (Cochrane, 2013).

Yet Greenwood and Scharfstein (2012), reflecting on the rise of modern finance, concluded that the net effect of active asset management is rather positive for American society because at least in the 1980s and 1990s it resulted in increased diversification and household participation in the stock market. However, they also note that the growth of asset management after 1997 was rather not beneficial for a society and potentially caused large distortions in the allocation of talent. Along similar lines, Gennaioli et al. (2014) argue that professional money managers reinforce distortions in the allocation of limited financial resources rather than arbitrage them away. The latter does not mean that financial advisers and money managers are totally counterproductive. In some sense, they still provide societal benefits by helping otherwise distrustful and loss averse individuals to participate in the financial markets.

\subsubsection{All available information}

The second part of EMH reflects the idea that all available information is already taken into account and reflected in current prices. Consequently, this means that the market processes information efficiently even if some individuals are biased and that no public information is useful in predicting asset prices (according to the semi-strong form EMH).

Therefore, the limited attention of individuals and their reading habits should have no effect on asset prices. However, it seems that the stock market is not fully efficient in processing information as it reacts to the same information multiple times when releases of financial information (such as earnings announcements) occur at the same time (Fedyk and Hodson, 2015). Consider a classic case of the biotechnology firm EntreMed described by Huberman and Regev (2001). The stock price of this company went up over 300\% on 4 May 1998, a day after the New York Times published a front-page story in its Sunday edition about EntreMed and recent developments in cancer treatment research. The rationality of the otherwise usual stock market reaction was undermined by the fact this article contained virtually the same information that was already published a few months before in the journal Nature and the Times.

The EMH implies that the stock price and, correspondingly, the value of the company should not be influenced by choice of the ticker symbol under which company stock is traded. However, Head et. al. (2009) found that companies with meaningful tickers such as SLOT and ODDS, in the case of casinos, perform better than similar companies with regular tickers. Utilizing the unique feature of the Chinese stock market, namely, that tickers have a numeric form (for example, Bank of China stock is traded in Shanghai under the ticker "601988") and the prevalence of numerical superstition beliefs in China (digits 6,8,9 are considered lucky because their pronunciations sound are similar to positive words such as "longevity" and "prosper", while 4 is associated with the word "death" and considered unlucky), Hirshleifer et al. (2016) found that superstition affects stock market returns. Newly listed Chinese companies with lucky tickers are traded at a premium of over $20 \%$, which dissipates within three years after the IPO leading to underperformance of these companies. Interestingly, company managers are usually aware of such inefficiencies and eager to exploit them for their own or in the company's interest, which in literature is referred as "catering".

Then, there is a large body of literature documenting the existence of some predictability in asset prices, especially in the aftermath of large price movements. Stock prices move in the same direction in the short run (positive autocorrelation of returns, sometimes referred as momentum), while in the long run stocks tend to do the opposite (negative autocorrelation of returns, sometimes referred as reversal).

The academic interest in this topic started to gain widespread attention after De Bondt and Thaler (1985) showed that a stock market portfolio constructed of past losers (stocks that experienced a decline in price over a recent period) substantially 
outperformed a portfolio of past winners over the next three years. In the world of EMH, such a finding would be impossible because the information about stocks' past performance is publicly available, already reflected in market prices and useless for prediction.

DeBondt and Thaler explained their finding by proposing the overreaction hypothesis. Investors tend to overreact to current information and become excessively optimistic (pessimistic) after a series of good (bad) news. In other words, in an uncertain world, investors overweight the last available information and their recent experience. Such overreaction leads to a growing difference in fundamental and market prices, while it disappears with the passing of time and arrival of more recent information.

In the complementary line of inquiry, Jegadeesh and Titman (1993) proposed underreaction hypothesis to explain the tendency of stock prices to slowly incorporate new information, which gives rise to the positive autocorrelation of returns. The hypothesis states that investors are behaving conservatively and overweight their prior beliefs, which leads to underreaction to news and causes what is known as post-earnings announcement drift, the tendency of a stock price to move in the direction of an earnings surprise for some time after an earnings announcement. While underreaction hypothesis is mostly dealing with market reaction to information, momentum is a more general phenomenon and can also be explained by the effects of reinforcement learning and representativeness heuristic. For instance, investors are shown to naïvely extrapolate future returns from the past in all kinds of research setups from experimental markets and surveys to field experiments (Hirshleifer, 2015).

Both overreaction and underreaction can occur at the same time. Investigating the connection between stock market moves and major world events, Niederhoffer (1971) reported that stocks exhibit short-term price continuations and at the same time show a tendency to overact to major negative news as the death or serious illness of a world leader. Later, with the advent of behavioral arguments, several theoretical models were proposed to explain both momentum and reversals. Daniel et al. (1998) suggested that overconfident investors put too much weight on private information (information they already have), which leads to overreaction, but they underweight public information (news) because of self-attribution bias, causing underreaction. Hong and Stein (1999) in turn made a more basic distinction and built their model on the interaction of two groups of traders: news watchers and momentum traders. The former react to private and slowly diffusing public information concerning company fundamentals, while the latter exploit momentum in stock prices created by the action of news watchers. The model also stresses that information diffuses quite slowly among investors and, consequently, both phenomena are likely to occur in the stock of small companies receiving relatively little attention from analysts. Later, Barberis and Shleifer (2003) show how a trader who switches between different trading styles depending on their relative performance can cause stock price over- and underreaction. More recently, Vayanos and Woolley (2013) extended the idea of Barberis and Shleifer and proposed that mutual fund flows can explain momentum and reversals and make both strategies profitable to exploit.

Besides behavioral explanations, scholars propose a number of possible explanations for observed predictability in asset markets ranging from the dominant role of the market microstructure to changes in investors' perception of risk. Reviewing relevant studies, Amini et al. (2013) concluded that despite this field of research being highly fragmented in terms of different methodological approaches and different proposed explanations, predictable patterns in asset prices are robust to nonbehavioral explanations and the effect has not disappeared or declined over time. Interestingly, Amini et al. (2013) note that the patterns of predictable behavior in asset prices are unlikely to yield abnormal returns for those intended to exploit such predictability (because of trading costs, price impact of trades, and other factors).

\subsubsection{Price is right}

The third element of efficient market hypothesis is the most important and at the same time is the most difficult to test empirically. As Baker and Wurgler (2011) put it, violations of EHM are not that important if they lead only to transfers of wealth among investors, from less to more rational. However, the problem becomes one of paramount importance if mispricing leads to the misallocation of limited financial resources and resulting deadweight loss for the economy.

Given the gravity of the question, it may be surprising that researchers still have no conclusive answer if EMH is true and prices reflect fundamentals. This state of affairs was explained by Fama's (1991) emphasis on the observation that market efficiency per se is not testable because of a joint hypothesis problem: to be able to compare market prices with fundamental values we need a theory explaining what these fundamental values are. Indeed, if the test of a price-is-right component of $\mathrm{EMH}$ indicates that prices are not right, it is impossible to conclude that markets are inefficient because the result may be driven by the failure of the asset pricing model used to provide true fundamental values of tested assets.

And indeed, despite the capital asset price model (CAPM) being rejected by Fama and French (1992), neither the shift of attention to purely empirical asset price models (such as the Fama-French three-factor model) nor the development of behavioral alternatives (such as Shefrin and Statman, 2000) have led to satisfying results and few are satisfied with the current state of asset pricing models (Statman, 2014). While predictions of CAPM simply have no basis in reality (e.g., Frazzini and Pedersen (2014) recently show that high-beta stocks underperform low-beta stocks which are the opposite of CAPM prediction), empirical asset pricing model becomes a field of factor mining. For example, Harvey et al. (2015) document over 300 factors used in prior research to explain the cross-section of expected returns and argue that most of the claimed findings are likely to be false because of the use of too low t-statistic to identify significance. 
Fortunately, researchers found indirect ways to solve the problem of joint hypothesis testing. Over the years, behavioral finance has documented multiple cases of mispricing of securities, while laboratory experiments and the idea of limits to arbitrage shed a light on the driving forces behind such mispricing.

A special case of the more general thesis of "price is right" states that two identical financial assets should have equal prices. However, the now famous analysis of the price behavior of twin shares of Royal Dutch/Shell and Unilever NV/PLC revealed that even if the true fundamental relative value of two securities is unambiguously known and fixed, the ratio of market prices of such securities may deviate from its fundamental level for a prolonged period. Similarly, researchers discovered that the prices of closed-end funds may substantially deviate from funds' net asset values despite the fact that the two prices should be equal (for review, see Lamont and Thaler, 2003). Since such cases of mispricing received their first major attention in the early 1990s, analogous cases were documented all around the world and asset classes, including the market for derivatives in China (Xiong and Yu, 2011) and the U.S. bond market (Fleckenstein et al., 2014).

The next obvious example of violations of EMH is the existence of bubbles, situations when asset prices increase far above their fundamental value and eventually crash back. Despite financial bubbles being an essential part of human history (Kindleberger and Aliber, 2005) along with financial crises (Reinhart and Rogoff, 2008), the academic view of this phenomenon substantially differs from the common perception. Fama (2014) points out that bubble literature suffers from ex-post selection bias, meaning that financial bubbles are easy to identify after the fact, but almost impossible to predict in advance, and most of the successful prediction of financial bubbles are simply a result of cherry picking stories of success. In other words, despite recent advances in econometric methods, the identification of asset price bubbles is still beyond our reach and most findings are not robust (Gürkaynak, 2008).

On the other hand, researchers were able to create robust asset price bubbles in laboratory experiments. Following the seminal work of Smith et al. (1988), the existence of bubbles in experimental financial markets was created a countless number of times and experimental asset markets research already reached the level when it may be carried on with a standardized open source software (Palan, 2015). Despite the fundamental (intrinsic) value of the particular asset being known to experimental subjects, prices tend to peak well above the fundamental value before the bubble starts to burst. Naturally, the size of a bubble negatively depends on the cognitive skills and experience of market participants (Palan, 2013). The other robust finding is that the possibility of short selling of assets does not prevent bubbles in experimental markets (Haruvy and Noussair, 2006). The latter, however, is not equivalent to the statement that financial markets are indifferent to short-selling restrictions. On the contrary, the restriction of short selling practices is shown to have no positive effect on the mitigation of market panic but has a negative effect on market liquidity (Kim et al., 2016).

\subsubsection{Noise traders and limits to arbitrage}

To explain the existence of financial market anomalies, it is essential to take two steps. First, we must assume that the behavior of some market participants systemically deviates from predictions of a rational model of decision-making. Secondly, the other group of market participants should find themselves in a situation when there are some constraints in the way to exploit mispricing to their own benefit. In other words, for anomalies to exist, rational agents should interact with a group of noise traders in a world with limits to arbitrage.

The concept of noise traders was first proposed in a Fischer Black (1986) address to an American Finance Association meeting. Black defined noise traders as those who make their decision based on noise as if it was information, meaning if a person makes a trade not on the basis of the rational analysis of relevant information that is useful to predict future fundamentals (such as earnings), then such a person is a noise trader. By this definition, Black made a suggestion to early scholars of behavioral finance - critics of EMH had to show that noise traders influence market prices, which Black himself hardly expected since he also stated in the address that "[...] almost all markets are efficient most of the time".

The idea that arbitrage in financial markets may have its limits was well known and such constraints to arbitrage as restrictions on short selling was shown to cause mispricing. For instance, Miller (1977) theoretically demonstrated that restriction of short-selling can develop into a situation when a price reflects only one side of a wide range of views since pessimists cannot express their opinion by shorting the stock. What was lacking in this and other early models was an explanation as to why some investors are willing to buy and hold an overpriced asset, especially if most investors are rational by their nature, and, most importantly, the model provides no answer to Friedman's (1953) critique that irrational investors will lose money to arbitrageurs and eventually disappear from the marketplace.

The first model to address these limitations was developed in the early 1990s by Bradford De Long, Andrei Shleifer, Lawrence Summers, and Robert Waldmann (De Long et al., 1990). The major innovation was to show that the existence of noise traders poses a risk for arbitrageurs since the sentiment of the first group may become even more extreme over time (risk was previously shown to be a constraint that can limit arbitrage opportunities). If arbitrageurs are risk-averse and have short term horizons, then the ability of noise traders to earn positive returns for a long time by bearing more risk will eventually lead to persistence of mispricing. While this model contained a number of important innovations, the main contribution was to show that noise traders and limits to arbitrage taken together create a world much different than predicted by EMH and that noise traders cannot be dismissed with Friedman's argument. 
Later, with several important works of other authors, this model became a major building block in literature dedicated to the problem of limits to arbitrage. In a seminal paper, Shleifer and Vishny (1997) expanded on idea of limits of arbitrage, Hirshleifer et al. (2006) show that the actions of noise traders can induce self-validating feedback into fundamentals which allow them to earn higher profits than is available for arbitrageurs, while Hong and Stein (2007) explain how heterogeneity of opinions lead to changes in sentiment which was exogenous in the model of De Long et al. (1990).

In probably the most well-known article in behavioral macro finance, Shleifer and Vishny (1997) stressed the importance of capital constraint (capital is much less available in the real-world than in the case of textbook arbitrage) and highlighted the agency problem. Since arbitrageurs are professional money managers raising capital from endowments, banks, wealthy individuals, and other investors, they are affected by capital inflows and outflows. If investors, who provide capital, suffer from loss aversion and extrapolate future returns from the recent past, then arbitrageurs run a constant risk that investors will start to redeem their money at the worst possible moment, when market prices move against the arbitrageur.

Besides the notion that noise traders interact with rational agents (smart money) in the world of limits of arbitrage, another series of relevant findings suggest that many market participants hardly behave as Econs either. For instance, behavioral finance challenged a belief that security analysts present an additional rational force that helps financial markets achieve efficiency. Since an early finding by De Bondt and Thaler (1990) that analysts show signs of overreaction, i.e., that their forecasts are too extreme to be considered rational, additional evidence had confirmed that analysts indeed behave much more like Humans rather than "smart money". In general, security analysts were shown to be overoptimistic and having a conflict of interest (Richardson et al., 2004; Mola, 2013), as well as attempting to ride market sentiment rather than correct the market toward fundamental prices (Corredor et al., 2013) and also to be influenced by their personality traits (Jiang et al., 2016) and social environment (König, 2016).

That is not to say that all market participants are noise traders and that limits to arbitrage completely prevent correction of mispricing. Akbas et al. (2015) compared money inflows into mutual funds (dumb money) and to hedge funds (smart money) and the consequent dynamics of some proxy measures of market mispricing and concluded that money inflows to hedge funds contribute to the correction of mispricing.

\section{CONCLUSION}

This review of the history of behavioral finance and its foundations is intended to serve as an extensive introduction to the field for novice readers, as well as to affirm several broad ideas.

A closer look at the history of the field reveals that the psychology-free economics of the 1950s-1970s appears to be an interlude in the long lasting and complex relationship between psychology and other social sciences on one hand, and economics and finance on the other. It also seems that neither economics nor finance were ever truly psychology-free and, instead of rejecting psychology, economics was rather defined by it. Homo Economicus also appears to be a product of the intellectual environment of late the XIX to early XX centuries with characteristic dominance of mechanistic and deterministic views of the world. However, as Dow (2003) points out, many sources of this inspiration are long gone, as many predominant views in the fields of theoretical physics, psychology, and even mathematics all underwent substantial changes.

Another lesson of history indicates that the development of behavioral economics and behavioral finance was defined by their striving to prove themselves worthy of inclusion into the mainstream. This need to wage a constant war against the predominant and even orthodox approach has left its mark on both behavioral approaches as it developed as a "negative science", with the main goal of rejecting explicit and implicit hypothesis proposed by neoclassical economics and standard finance.

Finally, the overwhelming evidence against Homo Economicus as a realistic description of real humans as well as a compelling case against the efficient market hypothesis does not mean that behavioral finance holds the keys to all important answers. For instance, as the discussion of the variety of behavioral biases and their causes illustrates, we still do not know how exactly such a basic trait as age affects our propensity to make systemic and predictable mistakes.

Likewise, as a part of the mainstream, behavioral economics and finance (at least at this stage) leave out many important issues such as methodological individualism or complexity. By including Humans in its models, behavioral finance certainly improves our understanding of the real world. However neither behavioral economics nor behavioral finance can be used as a substitute for an inclusive interdisciplinary approach to important real-world problems. 


\section{References}

- Abdellaoui M., Bleichrodt H., Paraschiv C. (2007). Loss Aversion Under Prospect Theory: A Parameter-Free Measurement. Management Science, No. 53, Vol. 10, pp. 1659-1674. https://doi.org/10.1287/mnsc.1070.0711

- Akbas F., Armstrong W.J., Sorescu S., Subrahmanyam A. (2015). Smart money, dumb money, and capital market anomalies. Journal of Financial Economics, No. 118, Vol. 2, pp. 355-382. https://doi.org/10.1016/j.jfineco.2015.07.003

- Alpert M., Raiffa H. (1982). A progress report on the training of probability assessors. In D. Kahneman, P. Slovic \& A. Tversky (eds.), Judgment Under Uncertainty: Heuristics and Biases. Cambridge University Press, Cambridge.

- Alter M. (1982). Carl Menger and Homo Oeconomicus: Some Thoughts on Austrian Theory and Methodology. Journal of Economic Issues, Vol. 16, No. 1, pp. 149-160. http://dx.doi.org/10.1080/00213624.1982.11503966

- Amini S., Gebka B., Hudson R. S., Keasey K. (2013). A review of the international literature on the short term predictability of stock prices conditional on large prior price changes: Microstructure, behavioral and risk related explanations. International Review of Financial Analysis, Vol. 26, pp. 1-17. https://doi.org/10.1016/j.irfa.2012.04.002

- Anderson A. (2007). All Guts, No Glory: Trading and Diversification Among Online Investors. European Financial Management, Vol. 13, No. 3, pp. 448-471.

- Anderson A. (2013). Trading and Under-Diversification. Review of Finance, Vol. 17, No. 5, pp. $1699-1741$. https://doi.org/10.1093/rof/rfs044

- Angner E., Loewenstein G. (2006). Behavioral Economics. Handbook of the Philosophy of Science: Philosophy of Economics. Elsevier, Amsterdam.

- Apicella C. L., Azevedo E. M., Christakis N. A., Fowler J. H. (2014). Evolutionary Origins of the Endowment Effect: Evidence From Hunter-Gatherers. American Economic Review, Vol. 104, No. 6, pp. 1793-1805. https://doi.org/10.1257/aer.104.6.1793

- Ariely D., Loewenstein G., Prelec D. (2003). “Coherent Arbitrariness”: Stable Demand Curves Without Stable Preferences. Quarterly Journal of Economics, Vol. 118, No. 1, pp. 73-106. https://doi.org/10.1162/00335530360535153

- Ariely D., Loewenstein G., Prelec D. (2006). Tom Sawyer and the construction of value. Journal of Economic Behavior \& Organization, Vol. 60, No. 1, pp. 1-10.

- Arkes H. R. (1991). Costs and benefits of judgment error: Implications for debiasing. Psychological Bulletin, Vol. 110. No. 3, pp. 486-498.

- Ashraf N., Camerer C. F., Loewenstein G. (2005). Adam Smith, Behavioral Economist. Journal of Economic Perspectives, Vol. 19, No. 3, pp. 131-145. https://doi.org/10.1257/089533005774357897

- Baker M., Wurgler J. (2011). Behavioral Corporate Finance: An Updated Survey. NBER Working Paper No. 17333. Available at: http://www.nber.org/papers/w17333

- Banz R. W. (1981). The relationship between return and market value of common stocks. Journal of Financial Economics, Vol. 9, No. 1, pp. 3-18.

- Barber B. M., Odean T. (2001). Boys will be Boys: Gender, Overconfidence, and Common Stock Investment. Quarterly Journal of Economics, Vol. 116, No. 1, pp. 261-292. https://doi.org/10.1162/003355301556400

- Barberis N., Shleifer A. (2003). Style investing. Journal of Financial Economics, Vol. 68. No. 2, pp. $161-199$. https://doi.org/10.1016/S0304-405X(03)00064-3

- Barberis N., Thaler R. (2003). A survey of behavioral finance. Handbook of the Economics of Finance, pp. 1053-1128.

- Barberis N. C. (2013). Thirty Years of Prospect Theory in Economics: A Review and Assessment. Journal of Economic Perspectives, Vol. 27, No. 1, pp. 173-195. https://doi.org/10.1257/jep.27.1.173

- Baron J., Hershey J. C. (1988). Outcome bias in decision evaluation. Journal of Personality and Social Psychology, Vol. 54, No. 4, pp. 569-579. http://dx.doi.org/10.1037/0022-3514.54.4.569

- Bassi A., Colacito R., Fulghieri P. (2013). 'O Sole Mio: An Experimental Analysis of Weather and Risk Attitudes in Financial Decisions. Review of Financial Studies, Vol. 26, No. 7, pp. 1824-1852. https://doi.org/10.1093/rfs/hht004

- Basu S. (1977). Investment Performance of Common Stocks in Relation to Their Price-Earnings Ratios: A Test of the Efficient Market Hypothesis. Journal of Finance, Vol. 32, No. 3, pp. 663-682. https://doi.org/10.1111/j.1540-6261.1977.tb01979.x

- Bazley W. J., Cronqvist H., Mormann M. (2016). In the Red: How Color Affects Investors and Financial Markets. Unpublished manuscript. Avaliable at: https://goo.gl/Bb4T1Q 
- Benartzi S., Thaler R.H. (1995). Myopic loss aversion and the equity premium puzzle. Quarterly Journal of Economics, Vol. 110, No. 1, pp. 73-92. https://doi.org/10.2307/2118511

- Berg N., Gigerenzer G. (2010). As-if behavioral economics: Neoclassical economics in disguise? History of Economic Ideas, pp. 133-165.

- Biais B., Weber M. (2009). Hindsight bias, risk perception, and investment performance. Management Science, Vol. 55, No. 6, pp. 1018-1029.

- Bikas E., Jurevičienè D., Dubinskas P., Novickyte L. (2013). Behavioural finance: The emergence and development trends. Procedia-social and behavioral sciences, No. 82, pp. 870-876. https://doi.org/10.1016/j.sbspro.2013.06.363

- Black F. (1986). Noise. The journal of Finance, Vol. 41, No. 3, pp. 528-543.

https://doi.org/10.1111/j.1540-6261.1986.tb04513.x

- Brewer E., Jagtiani J. (2013). How much did banks pay to become too-big-to-fail and to become systemically important? Journal of Financial Services Research, Vol. 43, No. 1, pp. 1-35.

- Brunnermeier M., Nagel S. (2004). Hedge Funds and the Technology Bubble. The Journal of Finance, Vol. 59, No. 5, pp. 2013-2040.

- Bucciol A., Cavasso B., Zarri L. (2015). Social status and personality traits. Journal of Economic Psychology, No. 51, pp. 245260. https://doi.org/10.1016/j.joep.2015.10.002

- Camerer C. (2005). Three cheers-psychological, theoretical, empirical-for loss aversion. Journal of Marketing Research, Vol. 42, No. 2, pp. 129-133. https://doi.org/10.1509/jmkr.42.2.129.62286

- Camerer C., Babcock L., Loewenstein G., Thaler R. (1997). Labor supply of New York city cabdrivers: One day at a time. Quarterly Journal of Economics, Vol. 112, No. 2, pp. 407-441. https://doi.org/10.1162/003355397555244

- Camerer C.F., Hogarth R.M., Budescu D.V., Eckel C. (1999). The effects of financial incentives in experiments: A review and capital-labor-production framework. In Elicitation of Preferences, pp. 7-48. Springer, Berlin. https://doi.org/10.1007/978-94-017-1406-8_2

- Carter C.R., Kaufmann L., Michel A. (2007). Behavioral supply management: a taxonomy of judgment and decisionmaking biases. International Journal of Physical Distribution \& Logistics Management, Vol. 37, No. 8, pp. $631-669$. https://doi.org/10.1108/09600030710825694

- Cen L., Hilary G., Wei K. J. (2013). The role of anchoring bias in the equity market: Evidence from analysts' earnings forecasts and stock returns. Journal of Financial and Quantitative Analysis, Vol. 48, No. 01, pp. 47-76. https://doi.org/10.1017/S0022109012000609

- Cesarini D., Johannesson M., Lichtenstein P., Sandewall Ö., Wallace B. (2010). Genetic variation in financial decision-making. Journal of Finance, Vol. 65, No. 5, pp. 1725-1754. https://doi.org/10.1111/j.1540-6261.2010.01592.x

- Chang C.-H., Lin S.-J. (2015). The effects of national culture and behavioral pitfalls on investors' decision-making: Herding behavior in international stock markets. International Review of Economics \& Finance, No. 37, pp. $380-392$. https://doi.org/10.1016/j.iref.2014.12.010

- Chen G., Kim K.A., Nofsinger J.R., Rui O.M. (2007). Trading performance, disposition effect, overconfidence, representativeness bias, and experience of emerging market investors. Journal of Behavioral Decision Making, Vol. 20, No. 4, pp. 425-451. https://doi.org/10.1002/bdm.561

- Chen M.K., Lakshminarayanan V., Santos L. R. (2006). How basic are behavioral biases? Evidence from capuchin monkey trading behavior. Journal of Political Economy, Vol. 114, No. 3, pp. 517-537. https://doi.org/10.1086/503550

- Choi J.J., Laibson D., Madrian B.C., Metrick A. (2004). For better or for worse: Default effects and 401 (k) savings behavior. In Perspectives on the Economics of Aging, pp. 81-126. University of Chicago Press, Chicago. https://doi.org/10.7208/chicago/9780226903286.003.0003

- Christiansen C., Joensen J.S., Rangvid J. (2008). Are economists more likely to hold stocks? Review of Finance, Vol. 12, No. 3, pp. 465-496.

- Coates J. M., Herbert J. (2008). Endogenous steroids and financial risk taking on a London trading floor. Proceedings of the national academy of sciences, Vol. 105, No. 16, pp. 6167-6172. https://doi.org/10.1073/pnas.0704025105

- Cochrane J. (2013). Is Finance too Big? The Grumpy Economist, 19. Available at: http://faculty.chicagobooth.edu/john. cochrane/research/papers/size_of_finance.pdf 
- Corredor P., Ferrer E., Santamaria R. (2013). Value of analysts' consensus recommendations and investor sentiment. Journal of Behavioral Finance, Vol. 14, No. 3, pp. 213-229. https://doi.org/10.1080/15427560.2013.819805

- Crawford V.P., Meng J. (2011). New York city cab drivers' labor supply revisited: Reference-dependent preferences with rational expectations targets for hours and income. American Economic Review, Vol. 101, No. 5, pp. 1912-1932.

- Cronqvist H., Siegel S. (2014). The genetics of investment biases. Journal of Financial Economics, Vol. 113, No. 2, pp. 215234. https://doi.org/10.1016/j.jfineco.2014.04.004

- Croskerry P., Singhal G., Mamede S. (2013). Cognitive debiasing 1: origins of bias and theory of debiasing. BMJ quality \& safety, Vol. 22, No. 2, pp. 58-64. https://doi.org/10.1136/bmjqs-2012-001712

- Damasio A. (2008). Descartes' Error: Emotion, Reason and the Human Brain. Random House, New York.

- Daniel K., Hirshleifer D., Subrahmanyam A. (1998). Investor psychology and security market under-and overreactions. Journal of Finance, Vol. 53, No. 6, pp. 1839-1885. https://doi.org/10.1111/0022-1082.00077

- De Bondt W.F., Thaler R.H. (1990). Do security analysts overreact? American Economic Review, Vol. 80, No. 2, pp. 52-57.

- De Bondt W.F., Thaler, R. (1985). Does the stock market overreact? Journal of Finance, Vol. 40, No. 3, pp. $793-805$.

- De Long J.B., Shleifer A., Summers L.H., Waldmann, R.J. (1990). Noise trader risk in financial markets. Journal of political Economy, Vol. 98, No. 4, pp. 703-738. https://doi.org/10.1086/261703

- Dehling H.G. (1997). Daniel Bernoulli and the St. Petersburg paradox. Nieuw archief voor wiskunde, Vol. 15, pp. 223-228.

- DeLong J., Shleifer A., Summers L. H., Waldmann R. (1991). The survival of noise traders in financial markets. Journal of Business, Vol. 64, No. 1, pp. 1-19.

- Dougal C., Engelberg J., Parsons C. A., Van Wesep E. D. (2015). Anchoring on credit spreads. Journal of Finance, Vol. 70, No. 3, pp. 1039-1080. https://doi.org/10.1111/jofi.12248

- Dow S.C. (2003). Understanding the relationship between mathematics and economics. Journal of Post Keynesian Economics, Vol. 25, No. 4, pp. 547-560.

- Evstigneev I., Hens, T., Schenk-Hoppé K.R. (2016). Evolutionary behavioral finance. In The Handbook of Post Crisis Financial Modeling. Springer, Berlin. https://doi.org/10.1007/978-1-137-49449-8_9

- Fama E.F. (1991). Efficient capital markets II. Journal of Finance, Vol. 46, No. 5, pp. $1575-1617$. https://doi.org/10.1111/j.1540-6261.1991.tb04636.x

- Fama E.F. (2014). Two pillars of asset pricing. American Economic Review, Vol. 104, No. 6, pp. $1467-1485$. https://doi.org/10.1257/aer.104.6.1467

- Fama E.F., French K.R. (1992). The cross-section of expected stock returns. Journal of Finance, Vol. 47, No. 2, pp. 427-465.

- Fedyk A., Hodson J. (2015). When can the market identify stale news? Available at SSRN: https://ssrn.com/abstract=2433234

- Fischhoff B., Beyth R. (1975). I knew it would happen: Remembered probabilities of once-future things. Organizational Behavior and Human Performance, Vol. 13, No. 1, pp. 1-16. https://doi.org/10.1016/0030-5073(75)90002-1

- Fleckenstein M., Longstaff F.A., Lustig H. (2014). The tips-treasury bond puzzle. Journal of Finance, Vol. 69, No. 5, pp. 21512197. https://doi.org/10.1111/jofi.12032

- Forbes W., Hudson R., Skerratt L., Soufian, M. (2015). Which heuristics can aid financial-decision-making? International Review of Financial Analysis, Vol., 42, pp. 199-210.

- Frazzini A., Pedersen L.H. (2014). Betting against beta. Journal of Financial Economics, Vol. 111, No. 1, pp. 1-25. https://doi.org/10.1016/j.jfineco.2013.10.005

- Friedman M. (1953). The methodology of positive economics. In Friedman M., editor, Essays in Positive Economics, pp. 3-43. University of Chicago Press, Chicago.

- Frydman C., Camerer C.F. (2016). The psychology and neuroscience of financial decision making. Trends in Cognitive Sciences, Vol. 20, No. 9, pp. 661-675. https://doi.org/10.1016/j.tics.2016.07.003

- Gennaioli N., Shleifer A., Vishny R. (2015). Money doctors. Journal of Finance, Vol. 70, No. 1, pp. 91-114. https://doi.org/10.1111/jofi.12188 
- Greenwood R.M., Scharfstein D.S. (2012). The growth of modern finance. Available at SSRN: https://ssrn.com/abstract=2162179

- Grinblatt M., Keloharju M. (2009). Sensation seeking, overconfidence, and trading activity. Journal of Finance, Vol. 64, No. 2, pp. 549-578. https://doi.org/10.1111/j.1540-6261.2009.01443.x

- Grinblatt M., Keloharju M., Linnainmaa J.T. (2012). IQ, trading behavior, and performance. Journal of Financial Economics, Vol. 104, No. 2, pp. 339-362. https://doi.org/10.1016/j.jfineco.2011.05.016

- Grosshans D., Zeisberger S. (2016). All's well that ends well? on the importance of how returns are achieved. Available at SSRN: https://ssrn.com/abstract=2579636

- Grossman S.J., Stiglitz J.E. (1980). On the impossibility of informationally efficient markets. American Economic Review, Vol. 70, No. 3, pp. 393-408.

- Guidolin M., Rinaldi F. (2013). Ambiguity in asset pricing and portfolio choice: A review of the literature. Theory and Decision, Vol. 74, No. 2, pp. 183-217. https://doi.org/10.1007/s11238-012-9343-2

- Gürkaynak R.S. (2008). Econometric tests of asset price bubbles: taking stock. Journal of Economic Surveys, Vol. 22, No. 1, pp. 166-186. https://doi.org/10.1111/j.1467-6419.2007.00530.x

- Haidt J. (2006). The happiness hypothesis: Finding modern truth in ancient wisdom. Basic Books, New York.

- Haidt J., Kesebir S. (2010). Morality. In Handbook of social psychology, 5-th Edition, John Wiley \& Sons, Hoboken, pp. 797832.

- Haruvy E., Noussair C.N. (2006). The effect of short selling on bubbles and crashes in experimental spot asset markets. Journal of Finance, Vol. 61, No. 3, pp. 1119-1157.

- Harvey C.R., Liu Y., Zhu H. (2015). ... and the Cross-Section of Expected Returns. Review of Financial Studies, Vol. 29, No. 1, pp. 5-68.

- Hayden B.Y., Platt M.L. (2009). The mean, the median, and the St. Petersburg paradox. Judgment and Decision Making, Vol. 4, No. 4, pp. 256-272.

- Head A., Smith G., Wilson J. (2009). Would a stock by any other ticker smell as sweet? Quarterly Review of Economics and Finance, Vol. 49, No. 2, pp. 551-561.

- Heidhues P., Koszegi B. (2014). Regular prices and sales. Theoretical Economics, Vol. 9, No. 1, pp. $217-251$. https://doi.org/10.3982/TE1274

- Hens T., Rieger M.O. (2016). Financial Economics. Springer, Berlin.

- Heukelom F. (2007). Kahneman and Tversky and the origin of behavioral economics. Discussion Paper No. 07-003/1, Tinbergen Institute. https://doi.org/10.2139/ssrn.956887

- Hirshleifer D. (2015). Behavioral finance. Annual Review of Financial Economics, No. 7, pp. 133-159. https://doi.org/10.1146/ annurev-financial-092214-043752

- Hirshleifer D., Jian M., Zhang H. (2016). Superstition and financial decision making. Management Science. https://doi.org/10.1287/mnsc.2016.2584

- Hirshleifer D., Subrahmanyam A., Titman S. (2006). Feedback and the success of irrational investors. Journal of Financial Economics, Vol. 81, No. 2, pp. 311-338. https://doi.org/10.1016/j.jfineco.2005.05.006

- Hoffmann A.O., Post T. (2014). Self-attribution bias in consumer financial decision-making: How investment returns affect individuals belief in skill. Journal of Behavioral and Experimental Economics, No. 52, pp. 23-28. https://doi.org/10.1016/j. socec.2014.05.005

- Hong H., Jiang W., Wang N., Zhao B. (2014). Trading for status. Review of Financial Studies, Vol. 27, No. 11, pp. $3171-3212$ https://doi.org/10.1093/rfs/hhu048

- Hong H., Stein J.C. (1999). A unified theory of underreaction, momentum trading, and overreaction in asset markets. Journal of Finance, Vol. 54, No. 6, pp. 2143-2184.

- Hong H., Stein J.C. (2007). Disagreement and the stock market. Journal of Economic Perspectives, Vol. 21, No. 2, pp. 109128. https://doi.org/10.1257/jep.21.2.109 
- Huberman G., Regev T. (2001). Contagious speculation and a cure for cancer: A nonevent that made stock prices soar. Journal of Finance, Vol. 56, No. 1, pp. 387-396. https://doi.org/10.1111/0022-1082.00330

- Jegadeesh N., Titman S. (1993). Returns to buying winners and selling losers: Implications for stock market efficiency. Journal of Finance, Vol. 48, No. 1, pp. 65-91. https://doi.org/10.1111/j.1540-6261.1993.tb04702.x

- Jelveh Z., Kogut B., Naidu S. (2015). Political language in economics. Columbia Business School Research Paper No. 14-57.

- Jiang D., Kumar A., Law K.K. (2016). Political contributions and analyst behavior. Review of Accounting Studies, Vol. 21, No. 1, pp. 37-88. https://doi.org/10.1007/s11142-015-9344-9

- Jones R.C., Wermers R. (2011). Active management in mostly efficient markets. Financial Analysts Journal, Vol. 67, No. 6, pp. 29-45. https://doi.org/10.2469/faj.v67.n6.5

- Kahneman D., Frederick S. (2002). Representativeness revisited: Attribute substitution in intuitive judgment. Heuristics and biases: The psychology of intuitive judgment, pp. 49-81. https://doi.org/10.1017/СВ09780511808098.004

- Kahneman D., Tversky A. (1979). Prospect theory: An analysis of decision under risk. Econometrica: Journal of the Econometric Society, Vol. 47, No. 2, pp. 263-292. https://doi.org/10.2307/1914185

- Kaplan A. (1964). The Conduct of Inquiry: Methodology for Behavirol Science. Chandler Publishing Company, San Francisco.

- Kaplanski G., Levy H., Veld C., Veld-Merkoulova Y. (2015). Do happy people make optimistic investors? Journal of Financial and Quantitative Analysis, Vol. 50, No. 1-2, pp. 145-168.

- Kaustia M., Alho E., Puttonen V. (2008). How much does expertise reduce behavioral biases? The case of anchoring effects in stock return estimates. Financial Management, Vol. 37, No. 3, pp. 391-412. https://doi.org/10.1111/j.1755-053X.2008.00018.x

- Kaustia M., Knüpfer S. (2008). Do Investors Overweight Personal Experience? Evidence from IPO ubscriptions. Journal of Finance, Vol. 63, No. 6, pp. 2679-2702. https://doi.org/10.1111/j.1540-6261.2008.01411.x

- Kaustia M., Luotonen N. (2016). What drives the heterogeneity in portfolio choice? The role of institutional, traditional, and behavioral factors. Available at SSRN: https://ssrn.com/abstract=2845963

- Kim J., Kim J-S., Yoo S.S. (2016). Regulatory overkill? Short-sales ban in Korea. International Journal of Managerial Finance, Vol. 12, No. 5, pp. 673-699. https://doi.org/10.1108/IJMF-12-2014-0191

- Kindleberger C., Aliber R.M. (2005). Panics, and crashes: A history of financial crises. John Wiley \& Sons, Hoboken.

- König F. (2016). Analyst behavior: The geography of social interaction. Journal of Behavioral Finance, 17, No. 3, pp. 201-216 https://doi.org/10.1080/15427560.2016.1171223

- Korniotis G.M., Kumar A. (2011). Do older investors make better investment decisions? Review of Economics and Statistics, Vol. 93, No. 1, pp. 244-265.

- Kőszegi B., Rabin M. (2009). Reference-dependent consumption plans. American Economic Review, Vol. 99, No. 3, pp. 909936. https://doi.org/10.1257/aer.99.3.909

- Krueger J.I., Funder D.C. (2004). Towards a balanced social psychology: Causes, consequences, and cures for the problemseeking approach to social behavior and cognition. Behavioral and Brain Sciences, Vol. 27, No. 3, pp. 328-376.

- Kuhnen C.M., Knutson B. (2011). The Influence of Affect on Beliefs, Preferences, and Financial Decisions. Journal of Financial and Quantitative Analysis, Vol. 46, No. 3, pp. 605-626. https://doi.org/10.1017/S0022109011000123

- Laibson D. (1997). Golden Eggs and Hyperbolic Discounting. Quarterly Journal of Economics, Vol. 112, No. 2, pp. $443-478$ https://doi.org/10.1162/003355397555253

- Lakoff G., Johnson M. (1999). Philosophy in the flesh: The embodied mind and its challenge to western thought. Basic books, New York.

- Lamont O.A., Thaler R.H. (2003). Anomalies: The law of one price in financial markets. Journal of Economic Perspectives, Vol. 17, No. 4, pp. 191-202. https://doi.org/10.1257/089533003772034952

- Larcker D.F., Zakolyukina A.A. (2012). Detecting deceptive discussions in conference calls. Journal of Accounting Research, Vol. 50, No. 2, pp. 495-540. https://doi.org/10.1111/j.1475-679X.2012.00450.x

- Larrick R.P. (2004). Debiasing. In D. J. Koehler \& N. Harvey (Eds.), Blackwell Handbook of Judgment and Decision Making. Blackwell Publishing Ltd, Hoboken. https://doi.org/10.1002/9780470752937.ch16 
- Lester R.A. (1946). Shortcomings of marginal analysis for wage-employment problems. American Economic Review, Vol. 36, No. 1, pp. 63-82.

- Levy M. (2015). An evolutionary explanation for risk aversion. Journal of Economic Psychology, No. 46, pp. 51-61. https://doi.org/10.1016/j.joep.2014.12.001

- Lewin S.B. (1996). Economics and psychology: Lessons for our own day from the early twentieth century. Journal of Economic Literature, Vol. 34, No. 3, pp. 1293-1323.

- Li Y., Baldassi M., Johnson E.J., Weber E.U. (2013). Complementary cognitive capabilities, economic decision making, and aging. Psychology and aging, Vol. 28, No. 3, pp. 595-613.

- Li Y., Yang L. (2013). Prospect theory, the disposition effect, and asset prices. Journal of Financial Economics, Vol. 107, No. 3, pp. 715-739.

- Liivamägi K. (2016). Investor Education and Trading Activity on the Stock Market. Baltic Journal of Economics, Vol. 16, No. 2, pp. 114-131. https://doi.org/10.1080/1406099X.2016.1189058

- Liivamägi K., Vaarmets T., Talpsepp T. (2014). Masters of the Stock Market. Working Paper. TUT Economic Research Series, TUTECON Working Paper, No. 7, pp. 1-25.

- Liu B., Govindan R., Uzzi B. (2016). Do emotions expressed online correlate with actual changes in decision-making? The case of stock day traders. PloS one, Vol. 11, No. 1.

- Lo A. W., Repin D.V., Steenbarger B. N. (2005). Fear and greed in financial markets: A clinical study of day-traders. Working Paper, No. 11243, NBER.

- Loewenstein G., Rick S., Cohen J.D. (2008). Neuroeconomics. Annual Review of Psychology, No. 59, pp. 647-672. https://doi.org/10.1146/annurev.psych.59.103006.093710

- Machlup F. (1946). Marginal analysis and empirical research. American Economic Review, Vol. 36, No. 4, pp. 519-554.

- Mehra R., Prescott E.C. (1985). The equity premium: A puzzle. Journal of monetary Economics, Vol. 15, No. 2, pp. $145-161$. https://doi.org/10.1016/0304-3932(85)90061-3

- Meier S., Sprenger C. (2010). Present-biased preferences and credit card borrowing. American Economic Journal: Applied Economics, Vol. 2, No. 1, pp. 193-210.

- Milgrom P., Stokey N. (1982). Information, trade and common knowledge. Journal of Economic Theory, Vol. 26, No. 1, pp. 17-27. https://doi.org/10.1016/0022-0531(82)90046-1

- Miller E.M. (1977). Risk, uncertainty, and divergence of opinion. Journal of finance, Vol. 32, No. 4, pp. 1151-1168. https://doi.org/10.1111/j.1540-6261.1977.tb03317.x

- Miller M.H. (2000). The history of finance: an eyewitness account. Journal of Applied Corporate Finance, Vol. 13, No. 2, pp. 8-14. https://doi.org/10.1111/j.1745-6622.2000.tb00050.x

- Mirowski P. (1992). Against mechanism: protecting economics from science. Rowman \& Littlefield Publishers, Lanham.

- Mola S. (2013). Framing the initiation of analyst coverage on IPOs. Journal of Behavioral Finance, Vol. 14, No. 1, pp. 25-41. https://doi.org/10.1080/15427560.2013.759578

- Morewedge C.K., Kahneman D. (2010). Associative processes in intuitive judgment. Trends in cognitive sciences, Vol. 14, No. 10, pp. 435-440. https://doi.org/10.1016/j.tics.2010.07.004

- Nagatsu M. (2015). Behavioral Economics, History of. International Encyclopedia of the Social \& Behavioral Sciences, Edition: 2nd, pp. 443-449. https://doi.org/10.1016/B978-0-08-097086-8.03053-1

- Nguyen T., Schuessler A. (2012). Investment decisions and socio-demographic characteristics - empirical evidence from Germany. International Journal of Economics and Finance, Vol. 4, No. 9, pp. 1-12.

- Nickerson R.S. (1998). Confirmation bias: A ubiquitous phenomenon in many guises. Review of General Psychology, Vol. 2, No. 2, pp. 175-220. https://doi.org/10.1037/1089-2680.2.2.175

- Niederhoffer V. (1971). The analysis of world events and stock prices. Journal of Business, Vol. 44, No. 2, pp. $193-219$. https://doi.org/10.1086/295352

- Oehler A., Wedlich F., Wendt S., Horn M. (2016). Does personality drive price bubbles? Available at SSRN: https://ssrn.com/abstract=2807401 
- Pagel M. (2013). Expectations-based reference-dependent life-cycle consumption. Available at SSRN: https://ssrn.com/ abstract $=2268254$

- Palan S. (2013). A review of bubbles and crashes in experimental asset markets. Journal of Economic Surveys, Vol. 27, No. 3, pp. 570-588. https://doi.org/10.1111/joes.12023

- Palan S. (2015). GIMS-Software for asset market experiments. Journal of Behavioral and Experimental Finance, No. 5, pp. 1-14. https://doi.org/10.1016/j.jbef.2015.02.001

- Parker A.M., Fischhoff B. (2005). Decision-making competence: External validation through an individual-differences approach. Journal of Behavioral Decision Making, Vol. 18, No. 1, pp. 1-27.

- Persky J. (1995). Retrospectives: The ethology of Homo Economicus. Journal of Economic Perspectives, Vol. 9, No. 2, pp. 221-231. https://doi.org/10.1257/jep.9.2.221

- Pompian M. (2012). Behavioral Finance and Investor Types: Managing Behavior to Make Better Investment Decisions. John Wiley \& Sons, Hoboken. https://doi.org/10.1002/9781119202417

- Reinhart C., Rogoff K. (2013). Shifting Mandates: The Federal Reserve's First Centennial. Working Paper, No. 18888, NBER, pp. 1-14. https://doi.org/10.3386/w18888

- Reinhart C.M., Rogoff K.S. (2008). This time is different: A panoramic view of eight centuries of financial crises. Working Paper, No. 13882, NBER.

- Richardson S., Teoh S.H., Wysocki P.D. (2004). The walk-down to beatable analyst forecasts: The role of equity issuance and insider trading incentives. Contemporary accounting research, Vol. 21, No. 4, pp. 885-924. https://doi.org/10.1506/KHNWPJYL-ADUB-ORP6

- Roll R. (1986). The hubris hypothesis of corporate takeovers. Journal of Business, Vol. 2, No. 1, pp. 197-216. https://doi. $\operatorname{org} / 10.1086 / 296325$

- Rubinstein M. (2001). Rational markets: yes or no? The affirmative case. Financial Analysts Journal, Vol. 57, No. 3, pp. 15-29. https://doi.org/10.2469/faj.v57.n3.2447

- Rustichini A. (2009). Neuroeconomics: what have we found, and what should we search for. Current opinion in neurobiology, Vol. 19, No. 6, pp. 672-677. https://doi.org/10.1016/j.conb.2009.09.012

- Sahi S.K., Arora A.P., Dhameja N. (2013). An exploratory inquiry into the psychological biases in financial investment behavior. Journal of Behavioral Finance, Vol. 14, No. 2, pp. 94-103. https://doi.org/10.1080/15427560.2013.790387

- Samuelson P.A. (1977). St. Petersburg paradoxes: Defanged, dissected, and historically described. Journal of Economic Literature, Vol. 15, No. 1, pp. 24-55.

- Samuelson W., Zeckhauser R. (1988). Status quo bias in decision making. Journal of risk and uncertainty, Vol. 1, No. 1, pp. 7-59. https://doi.org/10.1007/BF00055564

- Santos L.R., Rosati A.G. (2015). The evolutionary roots of human decision making. Annual review of psychology, No. 66, pp. 321-347. https://doi.org/10.1146/annurev-psych-010814-015310

-Scopelliti I., Morewedge C.K., McCormickE., Min H.L., LebrechtS., Kassam K.S. (2015). Bias blind spot:Structure, measurement, and consequences. Management Science, Vol. 61, No. 10, pp. 2468-2486. https://doi.org/10.1287/mnsc.2014.2096

- Sent E.-M. (2004). Behavioral economics: how psychology made its (limited) way back into economics. History of Political Economy, Vol. 36, No. 4, pp. 735-760.

- Shefrin H., Statman M. (1985). The disposition to sell winners too early and ride losers too long: Theory and evidence. Journal of finance, Vol. 40, No. 3, pp. 777-790. https://doi.org/10.1111/j.1540-6261.1985.tb05002.x

- Shefrin H., Statman M. (2000). Behavioral portfolio theory. Journal of Financial and Quantitative Analysis, Vol. 35, No. 02, pp. 127-151. https://doi.org/10.2307/2676187

- Shefrin H.M., Thaler R.H. (1988). The behavioral life-cycle hypothesis. Economic Inquiry, Vol. 26, No. 4, pp. 609-643. https://doi.org/10.1111/j.1465-7295.1988.tb01520.x

- Shiller R. (1981a). Do stock prices move too much to be justified by subsequent changes in dividends? American Economic Review, Vol. 71, No. 3, pp. 421-436.

- Shiller R.J. (2003). From efficient markets theory to behavioral finance. Journal of Economic Perspectives, Vol. 17, No. 1, pp. 83-104. https://doi.org/10.1257/089533003321164967 
- Shleifer A., Vishny R.W. (1997). The limits of arbitrage. Journal of Finance, Vol. 52, No. 1, pp. 35-55. https://doi. org/10.1111/j.1540-6261.1997.tb03807.x

- Slovic P. (1972). Psychological study of human judgment: Implications for investment decision making. Journal of Finance, Vol. 27, No. 4, pp. 779-799. https://doi.org/10.1111/j.1540-6261.1972.tb01311.x

- Slovic P., Finucane M., Peters E., MacGregor D.G. (2002). Rational actors or rational fools: Implications of the affect heuristic for behavioral economics. Journal of Socio-Economics, Vol. 31, No. 4, pp. 329-342. https://doi.org/10.1016/S10535357(02)00174-9

- Smith V.L., Suchanek G.L., Williams A.W. (1988). Bubbles, Crashes, and Endogenous Expectations in Experimental Spot Asset Markets. Econometrica: Journal of the Econometric Society, Vol. 56, No. 5, pp. 1119-1151. https://doi.org/10.2307/1911361

- Statman M. (2014). Behavioral finance: Finance with normal people. Borsa Istanbul Review, Vol. 14, No. 2, pp. 65-73. https://doi.org/10.1016/j.bir.2014.03.001

- Sutton R.S., Barto A.G. (1998). Reinforcement learning: An introduction. 1. MIT press, Cambridge.

- Talpsepp T. (2011). Reverse disposition effect of foreign investors. Journal of Behavioral Finance, Vol. 12, No. 4, pp. 183-200 https://doi.org/10.1080/15427560.2011.606387

- Thaler R. (1980). Toward a positive theory of consumer choice. Journal of Economic Behavior \& Organization, Vol. 1, No. 1, pp. 39-60. https://doi.org/10.1016/0167-2681(80)90051-7

- Thaler R.H. (1986). The psychology and economics conference handbook: Comments on Simon, on Einhorn and Hogarth, and on Tversky and Kahneman. Journal of Business, Vol. 59, No. 4, pp. 279-284. https://doi.org/10.1086/296366

- Thaler R.H. (1993). Advances in Behavioral Finance, Vol. 1. Russell Sage foundation, New York.

- Thaler R.H. (1999 a). The end of behavioral finance. Financial Analysts Journal, Vol. 55, No. 6, pp. 12-17.

- Thaler R.H. (1999 b). Mental accounting matters. Journal of Behavioral decision making, Vol. 12, No. 3, pp. $183-206$.

- Thaler R.H. (2015). Misbehaving: The making of behavioral economics. WW Norton \& Company, New York.

- Thaler R.H., Benartzi S. (2004). Save more tomorrow: Using behavioral economics to increase employee saving. Journal of political Economy, Vol. 112, No. 1, pp. 164-187. https://doi.org/10.1086/380085

- Thaler R.H., Shefrin H.M. (1981). An economic theory of self-control. Journal of political Economy, Vol. 89, No. 2, pp. 392-406. https://doi.org/10.1086/260971

- Thaler R.H., Sunstein, C.R. (2008). Nudge: Improving decisions about health, wealth, and happiness. Yale University Press, New Haven.

- Tversky A., Kahneman D. (1985). The framing of decisions and the psychology of choice. In Environmental Impact Assessment, Technology Assessment, and Risk Analysis, Springer, Berlin, pp. 107-129. https://doi.org/10.1007/978-3-642-70634-9_6

- Vaarmets T., Liivamägi K., Talpsepp T. (2015). How does learning and education help to overcome the disposition effect? Available at SSRN: https://ssrn.com/abstract=2721460

- Van Dolder D., Van den Assem M.J., Camerer C., Thaler R. H. (2015). Standing United or Falling Divided? High Stakes Bargaining in a TV Game Show. American Economic Review, Papers and Proceedings, Vol. 105, No. 5, pp. $402-407$. https://doi.org/10.1257/aer.p20151017

- Vayanos D., Woolley P. (2013). An institutional theory of momentum and reversal. Review of Financial Studies, Vol. 26, No. 5, pp. 1087-1145. https://doi.org/10.1093/rfs/hht014

- Weber E.U., Milliman R.A. (1997). Perceived risk attitudes: Relating risk perception to risky choice. Management Science, Vol. 43, No. 2, pp. 123-144.

- Winch D. (1972). Marginalism and the boundaries of economic science. History of Political Economy, Vol. 4, No. 2, pp. 325-343. https://doi.org/10.1215/00182702-4-2-325

- Xiong W., Yu J. (2011). The Chinese warrants bubble. American Economic Review, Vol. 101, No. 6, pp. 2723-2753.

- Zhang R., Brennan T.J., Lo A.W. (2014). The origin of risk aversion. Proceedings of the National Academy of Sciences, Vol. 111, No. 50, pp. 17777-17782. https://doi.org/10.1073/pnas.1406755111 


\title{
STOCK-FLOW CONSISTENT MODELING OF DEFAULT EVENTS SEQUENCE IN A CLOSED ECONOMY
}

\author{
Ihor Voloshyn ${ }^{1}$ \\ National Bank of Ukraine \\ Email: Ihor_Voloshyn@bank.gov.ua
}

\begin{abstract}
By sequentially examining the full chain of events starting from the default of firms through the fire-sale of goods towards the write-offs of bad loans, we develop a new matrix of financial transactions. This matrix is incorporated into the transactions-flows matrix of the closed economy consisting of households, firms, and banks. On the basis of the balance sheet and transactionsflows matrices, this study further constructs a stock-flow consistent model of the closed economy. We also provide the results of a numerical simulation and argue that our model allows studying how such key parameters as the probability of default, the rate of fire-sales (new injected parameter), the recovery rate, and interest rates on loans and deposits affect the performance of banks and firms, observing economic dynamics in time.
\end{abstract}

\section{JEL Codes: E16, E17, E21, E23, G21}

Keywords: closed economy, stock-flow consistent framework, probability of default, fire-sales, write-offs

\section{INTRODUCTION}

Goodhart (2008) wrote that "although many formal macroeconomic models (implicitly) employ an assumption of a defaultfree system in their so-called transversality assumption, it is not, alas, a characteristic of the real world. Indeed, the probability of default (PD) is a key concept in any analysis of financial fragility... If economic theory and formal models are to provide analytical support and guidance for issues relating to financial fragility, they must make the modeling of default a central feature of their work".

White (2010) stated that "the prevailing macroeconomic frameworks simply allowed no room for crises of the sort we are currently experiencing... Absent an analytical framework that included the possibility of crises and deep economic slumps, it is not surprising that the crisis was not commonly anticipated. Nor is it surprising that no policy efforts were made to prevent the crisis from happening".

After them, Caiani et al. (2016) argue that "the crisis cast serious doubts on the plausibility of standard macroeconomic models ... and their ability to provide effective policy advices to prevent the occurrence of large-scale economic turmoils, and to tackle their consequences".

All this suggests the need for the development of alternative approaches to macroeconomic modeling in order to incorporate the possibility of default into the core of the analysis (Goodhart et al., 2008, 2011; Caiani et al., 2016; Stellian \& Buitrago, 2014).

This study aims to track the full sequence of events in a closed economy as a whole and to develop a corresponding nonequilibrium, dynamic mathematical model. To avoid accounting errors and unacceptable implications that may be unnoticed, and therefore ignored, we will methodologically draw on the stock-flow consistent (SFC) approach (Godley, 1996). It should be noted that the resulting mathematical model can be used in various macroeconomic models not necessarily based on the SFC framework, for instance, into Dynamic System Models (Yamaguchi, 2013).

The remainder of the paper is organized as follows. A brief review of the literature about macroeconomic models incorporating defaults events sequence in an economy is given in Section II. Section III presents the mathematical model of an economy with firms' defaults based on the stock-flow consistent framework. Model dynamics are studied in Section IV in which we report the simulation results. Section V concludes.

\footnotetext{
${ }^{1}$ Acknowledgments. The author is very grateful to an anonymous reviewer for valuable comments and fruitful suggestions for improving the paper.
} 


\section{BRIEF LITERATURE REVIEW}

In response to the recent world crisis, various economic schools have developed new macroeconomic models that incorporate defaults into the economy. Thus, the dynamic stochastic general equilibrium (DSGE) model developed by Benes et al. (2014) makes a connection between defaults on loans and macroeconomic variables. Their model allows simulating productivity growth, changes in the riskiness of bank borrowers, deviations of asset prices, shocks to bank equity, etc. Authors argued that "excessively large and risky loans can impair balance sheets and sow the seeds of a financial crisis". The aim of their work was to investigate "an optimal equilibrium phenomenon resulting from the interactions between loan contracts, endogenous loan losses and regulation". But, the question of how the rate of fire-sales affects the coverage of losses remains unexplored. Additionally, real economical processes are non-equilibrium.

The Agent-Based model "usually assumes that new firms enter the market to replace defaulted ones with a given stock of capital and liquid assets. This assumption is implicitly imposing an exogenous positive shock on the model dynamics which counteracts the negative endogenous shock related to the firm's default" (Caiani et al., 2016).

Combining the Agent-Based and Stock Flow Consistent approaches (AB-SFC), Caiani et al. (2016) suggested a model that takes into consideration the defaults of economical agents. They considered more fully the chain of events caused by defaults including the fire-sales of assets to recover the bad loans of firms. For simplicity reasons, they assumed that defaulted firms and banks to be bailed in by households and depositors in order to maintain the number of firms and banks constant. Dynamics of inventories has not been investigated.

Another scientific school led by Godley and Lavoie (2007) proposed a macroeconomic model with defaults under the stockflow consistent framework. Two special matrices of a balance sheet and transactions based on the quadruple entry principle allow careful consideration of the impact of defaults on both stocks and flows. However, they did not consider the events of fire-sale of assets. Also, the rate of fire-sales is a key indicator as to how quickly banks can recover losses on bad loans due to firms' defaults. This crucial chain determines the redistribution of income and losses between sectors of the economy.

\section{MODEL OF ECONOMY WITH DEFAULT OF FIRMS}

We consider a closed cashless economy that consists of households, production firms that may go into default, and banks.

In order not to obscure the view of idea with a number of details, we proposed the next assumptions. Firms have no fixed capital. The only means of production is labor. Both firms and banks have no equities. Therefore, they pay out no dividends to households. Households take no loans. Only the households consume goods produced by firms. Since this economy does not include government, both banks and firms do not pay taxes.

To start production, the firms borrow loans from banks, hire workers of households, and pay them wage bill. Further, firms produce goods and sell them to households. Thus, workers of households spend their wages to buy goods. Firms pay interest on their good (performing) loans to banks and receive interest on their deposits from banks. Households receive interest on their deposits from banks (Graziani, 2003; Keen, 2010; Voloshyn I. and Voloshyn M., 2016).

In view of the above-described model, the stylized balance sheet of the economy developed by Godley and Lavoie (2007) looks like:

Table 1. The stylized balance sheet of the economy (Godley and Lavoie, 2007)

\begin{tabular}{|c|c|c|c|c|}
\hline & Households & Firms & Banks & $\Sigma$ \\
\hline Inventories & & $+\mathrm{IN}$ & $+\mathrm{IN}$ \\
\hline Deposits & $+\mathrm{D}_{\mathrm{h}}$ & $+\mathrm{D}_{\mathrm{f}}$ & $-\mathrm{D}_{\mathrm{h}}-\mathrm{D}_{\mathrm{f}}$ & $\mathbf{0}$ \\
\hline Loans & & $-\mathrm{L}_{\mathrm{f}}$ & $\mathrm{L}_{\mathrm{f}}$ & $\mathbf{0}$ \\
\hline Net wealth & $-\mathrm{V}_{\mathrm{h}}$ & $-\mathrm{V}_{\mathrm{f}}$ & $-\mathrm{V}_{\mathrm{b}}$ & $-\mathrm{IN}$ \\
\hline$\Sigma$ & $\mathbf{0}$ & $\mathbf{0}$ & $\mathbf{0}$ & $\mathbf{0}$ \\
\hline
\end{tabular}

It is remarkable that the balance sheet matrix in Table 1 effectively integrates three stand-alone balance sheets of households, firms, and banks. 
In Table 1 we use the next notations:

\begin{tabular}{|c|c|}
\hline$D_{f}$ & Deposits held by firms \\
\hline$D_{h}$ & Deposits held by households \\
\hline IN & Stock of inventories at cost \\
\hline$L_{f}$ & Loans supplied by banks to firms \\
\hline$V_{b}$ & Net wealth of banks \\
\hline$V_{f}$ & Net wealth of firms \\
\hline$V_{h}$ & Net wealth of households \\
\hline
\end{tabular}

Note that according to Godley and Lavoie (2007): "All the columns and all the rows that deal with financial assets or liabilities must sum to zero. The only row that may not sum to zero is the row dealing with inventories accumulated by the firms... All assets appear with a plus sign in the balance sheet matrix while liabilities, including net worth, are assigned a negative sign".

In Table 1 we have seven unknown variables which we should find.

\section{Financial transactions related to defaulting firms}

Further, we consider a sequence of events starting from defaults of firms through fire-sales of produced goods towards write-offs of bad loans and coverage of credit losses of banks on bad loans. Thus, we will distinguish normal and fire-sales of goods. Recall that Godley's and Lavoie's model (2007) takes into consideration only events of firms' defaults.

So, some firms make mistaken decisions about what kind of goods should be produced. As a result, the produced goods turn out not in demand and must be fire-sold at a price far lower cost. In its turn, these firms cannot repay their loans and go into default. The loans become non-performing or briefly bad. Herewith, at the moment of default, the balance sheet of defaulted firms takes the next form:

$$
I N_{b}=L_{b},
$$

where $I N_{b}$ is the stock of goods produced by defaulted firms, $L_{b}$ stands for stock of bad (non-performing) loans held by them. Thus, at the moment of default, the stock of inventories of defaulted firms is exactly equal to the stock of their bad loans. Here we assume that the defaulted firms spent all their deposits to produce goods. Firstly, the rationale for this is that the amount of unused deposits is usually substantially less than the value of inventories. Secondly, this assumption leads to a maximal estimate of time of covering losses on bad loans through fire-sales. Therefore, the less the deposits, the longer the time for the fire-sale of inventories. Also, it is easy to demonstrate that the presence of an unused deposit does not change the financial result of firms from their defaults. It remains null. However, it requires significantly complicating the model by dividing all the firms between operating and defaulted ones.

We do not distinguish whether the sale of goods is voluntary or enforced, whether the goods are pledged or not. These are only procedural aspects. Nevertheless, we assume that the defaulted firms fire-sell the goods voluntarily in order to repay their loans and in this way to partly cover credit losses of banks on their bad loans.

Thus, firms incur fire-sale losses but at the same time gain a benefit from write-offs by banks of their bad loans. Indeed, in accordance with Shubik and Wilson (1977): "The advantage of default is that it enables the borrower not to repay all that he owes". Whereas, the banks do incur merely credit losses on bad loans of defaulted firms.

Write-offs by banks of bad loans are considered to be equivalent to repurchase by defaulted firms of their bad loans with a discount. The result of that is booked as firms' income.

It should be noted that households gain a benefit from the fact that they buy goods at a price far below cost.

The financial transactions related to the aforementioned sequence starting from fire-sales of goods towards coverage of banks' losses on bad loans are presented in Table 2.

As shown in Table 2, in the long run, the firms barely contract their total assets on the value (-WO) of written-off bad loans and have zero results in profit and loss.

Recall that the firms in the model have no equities. Thus, they have no losses as a result of default. Borrowing is a risk-free deal for firms but not for banks.

It should be noted that the fact that the cost of firms' default is zero may keep banks from lending (Shubik and Wilson, 1977). 
Table 2. The financial transactions starting from fire-sales of goods towards coverage of banks' losses on bad loans (view from the defaulted firms' side)

\begin{tabular}{|c|c|c|c|c|}
\hline & \multicolumn{4}{|c|}{ Changes in the stocks of } \\
\hline & $\begin{array}{l}\text { inventories } \\
(+I N)\end{array}$ & $\begin{array}{l}\text { deposits of firms } \\
\left(+D_{f}\right)\end{array}$ & $\begin{array}{l}\text { bad loans } \\
\qquad\left(+L_{b}\right)\end{array}$ & $\begin{array}{c}\text { firms profits } \\
\left(+F_{f}\right)\end{array}$ \\
\hline $\begin{array}{l}\text { Fire-sales } \\
\text { of goods produced } \\
\text { by defaulted firms }\end{array}$ & $\begin{array}{l}- \text { WO } \\
\text { sold goods } \\
\text { at cost }\end{array}$ & $\begin{array}{l}\quad+C_{f} \\
\text { fire-sales } \\
\text { revenue }\end{array}$ & & $\begin{array}{c}-\left(W O-C_{f}\right) \\
\text { losses on } \\
\text { fire-sales }\end{array}$ \\
\hline In total & $-w o$ & $+C_{f}$ & & $-\left(W O-C_{f}\right)$ \\
\hline $\begin{array}{l}\text { Write-offs } \\
\text { of bad loans }\end{array}$ & & & $\begin{array}{l}\text {-WO } \\
\text { written-off } \\
\text { bad loans }\end{array}$ & $\begin{array}{l}+ \text { WO } \\
\text { benefit from } \\
\text { write-offs }\end{array}$ \\
\hline $\begin{array}{c}\text { Transfer } \\
\text { of fire-sales revenue } \\
\text { to banks }\end{array}$ & & $\begin{array}{l}-C_{f} \\
\text { transfer of fire-sales } \\
\text { revenue to banks }\end{array}$ & & $\begin{array}{c}-C_{f} \\
\text { expenditures } \\
\text { of firms }\end{array}$ \\
\hline In total & & $-C_{f}$ & $-w o$ & $+\left(W O-C_{f}\right)$ \\
\hline$\Sigma$ & $-w o$ & 0 & $-w o$ & 0 \\
\hline
\end{tabular}

\section{Transactions-flows matrix of the economy}

Taking into account the above, we present in Table 3 the transactions-flows matrix modified by the author as compared with the original matrix developed by Godley and Lavoie (2007). Again, in accordance with Godley and Lavoie (2007):

- "The coherence of the transactions flow matrix is built on the rule that each row and each column must sum to zero.

- The zero-sum rule for each column represents the budget constraint of each sector.

- Any transaction involving an incoming flow, the proceeds of a sale or the receipts of some monetary flow, thus takes a positive sign; a transaction involving an outgoing flow must take a negative sign".

Note that the columns entitled as "current" and "capital" in the transactions-flows matrix define the equalities for increments of profits and balance sheets correspondingly of firms and banks.

In the long run, we built a model where "the system as a whole is closed in the sense that every flow and every stock variable is logically integrated into the accounting to such a degree that the value of any one item is implied by the values of all the others taken together; this follows from the fact that every row and every column sums to zero" (Godley and Lavoie, 2007).

\section{Table 3. Modified transactions-flows matrix of the economy}

\begin{tabular}{|c|c|c|c|c|c|c|c|}
\hline & & \multirow{2}{*}{ Households } & \multicolumn{2}{|c|}{ Firms } & \multicolumn{2}{|c|}{ Banks } & \\
\hline & & & Current & Capital & Current & Capital & $\Sigma$ \\
\hline Consumption & $\begin{array}{c}\text { normal sales } \\
\text { fire-sales }\end{array}$ & $\begin{array}{l}-C_{n} \\
-C_{f}\end{array}$ & $\begin{array}{l}+C_{n} \\
+C_{f}\end{array}$ & & & & $\begin{array}{l}0 \\
0\end{array}$ \\
\hline $\begin{array}{c}\text { Transfer } \\
\text { of fire-sales revenue } \\
\text { to banks }\end{array}$ & & & $-C_{f}$ & & $+C_{f}$ & & 0 \\
\hline $\begin{array}{l}\text { Inventory } \\
\text { accumulation }\end{array}$ & & & $+\Delta I N$ & $-\Delta I N$ & & & 0 \\
\hline Wage bill & & $+W B$ & $-W B$ & & & & 0 \\
\hline Profits & & & $-F_{f}$ & $+F_{f}$ & $-F_{b}$ & $+F_{b}$ & 0 \\
\hline
\end{tabular}




\begin{tabular}{|c|c|c|c|c|c|c|c|}
\hline Interests on & $\begin{array}{l}\text { loans } \\
\text { deposits }\end{array}$ & $+I D_{h}$ & $\begin{array}{l}-I L \\
+I D_{f}\end{array}$ & & $\begin{array}{c}+I L \\
-I D_{f} \\
-I D_{h}\end{array}$ & & $\begin{array}{l}0 \\
0 \\
0\end{array}$ \\
\hline $\begin{array}{l}\text { Change } \\
\text { in the stocks of }\end{array}$ & $\begin{array}{l}\text { loans } \\
\text { deposits }\end{array}$ & $-\Delta D_{h}$ & & $\begin{array}{l}+\Delta L_{f} \\
-\Delta D_{f}\end{array}$ & & $\begin{array}{l}-\Delta L_{f} \\
+\Delta D_{h} \\
+\Delta D_{f}\end{array}$ & $\begin{array}{l}0 \\
0 \\
0\end{array}$ \\
\hline $\begin{array}{l}\text { Write-offs } \\
\text { of bad loans }\end{array}$ & & & $+W O$ & & $-W O$ & & 0 \\
\hline$\Sigma$ & & 0 & 0 & 0 & 0 & 0 & 0 \\
\hline
\end{tabular}

In the Table 2 and 3 we use the next notations:

\begin{tabular}{|c|c|}
\hline$F_{b}$ & Profits of banks \\
\hline$F_{f}$ & Profits of production firms \\
\hline$I D_{h}$ & Interests on deposits held by households \\
\hline$I D_{f}$ & Interests on deposits held by firms \\
\hline$I L$ & Interests on loans held by firms \\
\hline WB & Wage bill \\
\hline WO & Write-offs of bad loans of defaulted firms \\
\hline
\end{tabular}

\section{Mathematical model of the economy with firms' defaults}

Using both the balance sheet and the transaction-flow matrices (Tables 1 and 3) allows formulating the following mathematical model of the economy. Note that all the variables of the model are considered to depend on time, unless otherwise stipulated.

The differential equation for inventories takes the next form:

$$
\begin{aligned}
& \frac{d I N}{d t}=\quad W B-\frac{C_{n}}{1+\rho}-W O \\
& \begin{array}{cccc}
\text { Flows of: } & \begin{array}{c}
\text { produced } \\
\text { goods }
\end{array} & \begin{array}{c}
\text { normal } \\
\text { sold goods }
\end{array} & \begin{array}{c}
\text { fire-sold } \\
\text { goods }
\end{array} \\
& \text { at cost } & \text { at cost } & \text { at cost }
\end{array}
\end{aligned}
$$

where $\rho$ is price markup (Kalecki, 1971), $t$ stands for time, $\frac{d}{d t}$ is the first derivative with respect to time $t$.

We present inventories $I N$ as sum of stocks of goods being produced by means of good and bad loans:

$$
I N=I N_{g}+I N_{b},
$$

where $I N_{g}$ is the stock of goods produced by non-defaulted firms.

Taking into account (1) the stock $I N_{g}$ of goods produced by non-defaulted firms is equal to:

$$
I N_{g}=I N-L_{b} .
$$

The firms' deposits are governed by the next equation:

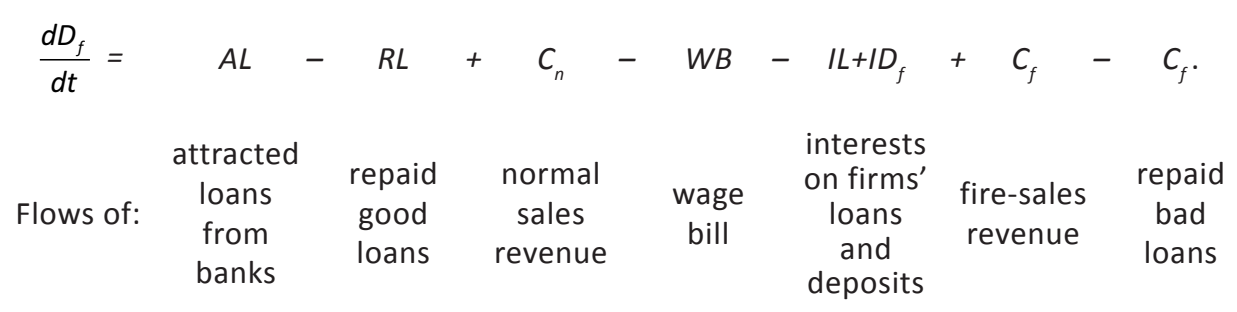


The households' deposits are ruled by the next equation:

$$
\begin{aligned}
& \frac{d D_{h}}{d t}=W B-C_{n}-C_{f}+I D_{h} . \\
& \text { consumption: } \\
& \text { Flows of: } \begin{array}{cccc}
\text { received } & \begin{array}{c}
\text { bought } \\
\text { wages } \\
\text { market } \\
\text { price }
\end{array} & \begin{array}{c}
\text { bought } \\
\text { goods at } \\
\text { fire-sale } \\
\text { price }
\end{array} & \begin{array}{c}
\text { interests } \\
\text { on }
\end{array} \\
& & \text { deposits }
\end{array}
\end{aligned}
$$

We present firms' loans as sum of good (performing) and bad (non-performing) loans:

$$
L_{f}=L_{g}+L_{b}
$$

These loans are governed by the next equations:

$$
\begin{aligned}
& \frac{d L_{g}}{d t}=\quad A L-R L-D L \text {, }
\end{aligned}
$$

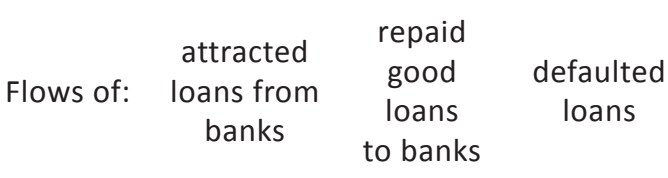

$$
\begin{aligned}
& \frac{d L_{b}}{d t}=\quad D L \quad-\quad W O . \\
& \text { Flows of: defaulted written-off }
\end{aligned}
$$

The derivatives of net wealth of households, firms, and banks are equal to their profits correspondingly. So, net wealth of households, firms, and banks are governed by the next equations:

$$
\begin{aligned}
& \frac{d V_{h}}{d t} \equiv F_{h}=\quad \frac{d D_{h}}{d t}, \\
& \text { Derivative derivative } \\
& \text { of net wealth of of deposits } \\
& \text { households of households } \\
& \frac{d V_{f}}{d t} \equiv F_{f}=\quad \frac{C_{n} \times \rho}{1+\rho} \quad-\quad I L+I D_{f}, \\
& \text { net income from interests } \\
& \text { Flows of: normal sales on loans } \\
& \text { at market price and deposits } \\
& \frac{d V_{b}}{d t} \equiv F_{b}=\quad+I L-I D_{f}-I D_{h}-\left(W O-C_{f}\right) . \\
& \text { interests losses } \\
& \text { Flows of: on loans on bad loans } \\
& \text { and deposits cut upon recovery }
\end{aligned}
$$

Into the bargain, we employ the next equation for market prices on goods (Kalecki, 1971) that are based on the cost-plus concept:

$$
p=(1+\rho) \times u c,
$$

where $\rho$ is price markup, uc is unit cost of goods. 
Equation (11) is used to convert the value of sold goods at market price into a cost price and vice versa, for instance, in order to calculate a change in inventories.

All given equations (1-10) meet both stocks and flows balances (Tables 1 and 3).

\section{Equations linking flows and stocks}

Following Keen (2010), we use the next generic equation relating the flow and stock:

Flow $=$ Rate of turnover $\times$ Stock,

where "Rate of turnover" gives the fundamental frequency of financial operation.

The collection of equations defining flows is presented in Table 4.

\section{Table 4. Equations linking flows and stocks}

\begin{tabular}{|c|c|c|}
\hline Flows & Description & Formulas \\
\hline$A L$ & Attracted firms' loans from banks & $\beta \times\left(N-L_{f}\right)$ \\
\hline$C_{f}$ & Fire-sales consumption / repayment of bad loans & $R \times W O$ \\
\hline$C_{n}$ & Normal consumption & $V_{n} \times(1+\rho) \times I N_{g}$ \\
\hline$D L$ & Defaulted loans & $p d \times L_{g}$ \\
\hline IL & Payment of interest on loans & $r_{L} \times L_{g}$ \\
\hline$I D_{f}$ & Payment of interest on firms' deposits & $r_{D} \times D_{f}$ \\
\hline$I D_{h}$ & Payment of interest on households' deposits & $r_{D} \times D_{h}$ \\
\hline$R L$ & Repayment of good loans (Keen, 2010) & $\phi_{L} \times L_{g}$ \\
\hline$W B$ & Payment of wages by firms to households (Keen, 2010) & $\phi_{D} \times D_{f}$ \\
\hline wo & Write-offs of bad loans & $V_{w o} \times L_{b}$ \\
\hline
\end{tabular}

In Table 5 we picked out notations used in the model. Presented there are the values of the model's parameters used for numerical simulation too.

Table 5. Notations and values of model's parameters

\begin{tabular}{|c|c|c|}
\hline Parameters & Description & Values \\
\hline \multicolumn{3}{|c|}{ Latin symbols } \\
\hline$N$ & Total value of loans which can be granted by banks & 100 \\
\hline pd & Probability of default of firms & $0.05 / y r$ \\
\hline$R$ & Recovery rate of bad loans & $50 \%$ \\
\hline$r_{D}$ & Annual interest rate on deposits & $15 \%$ \\
\hline$r_{L}$ & Annual interest rate on loans & $16 \%$ \\
\hline \multicolumn{3}{|c|}{ Greek symbols } \\
\hline$\beta$ & Rate of issue of loans by banks to firms & $3 / 4 y r$ \\
\hline$v_{n}$ & Rate of normal sale of goods / normal consumption & $26 / y r$ \\
\hline$r_{\text {wo }}$ & Rate of write-offs of bad loans & $1 / 7 y r$ \\
\hline$\rho$ & Price markup & $5 \%$ \\
\hline$\phi_{D}$ & Rate of payment of wages & $2 / y r$ \\
\hline$\varphi_{\mathrm{L}}$ & Rate of repayment of good loans & $1 / 7 y r$ \\
\hline
\end{tabular}


According to Keen (2010), the rate-parameters designated by the Greek symbols in Table 5 are inverse to periods of turnover. For instance, rate $\varphi_{L}$ of repayment of good loans equaled $1 / 7 \mathrm{yr}$ means that firms repay their loans every 7 years. The value of 26 for $\gamma_{n}$ corresponds to normal consumption by households having a fundamental frequency of 1 / 26th of a year, or two weeks, and so on.

\section{NUMERICAL SIMULATION}

To simulate work of the economy, we used the values of the model's parameters given in Table 5. Some results of simulation are presented on Figures 1-3.

\section{Figure 1. Dynamics of good and bad loans, and firms' deposits (developed by author)}

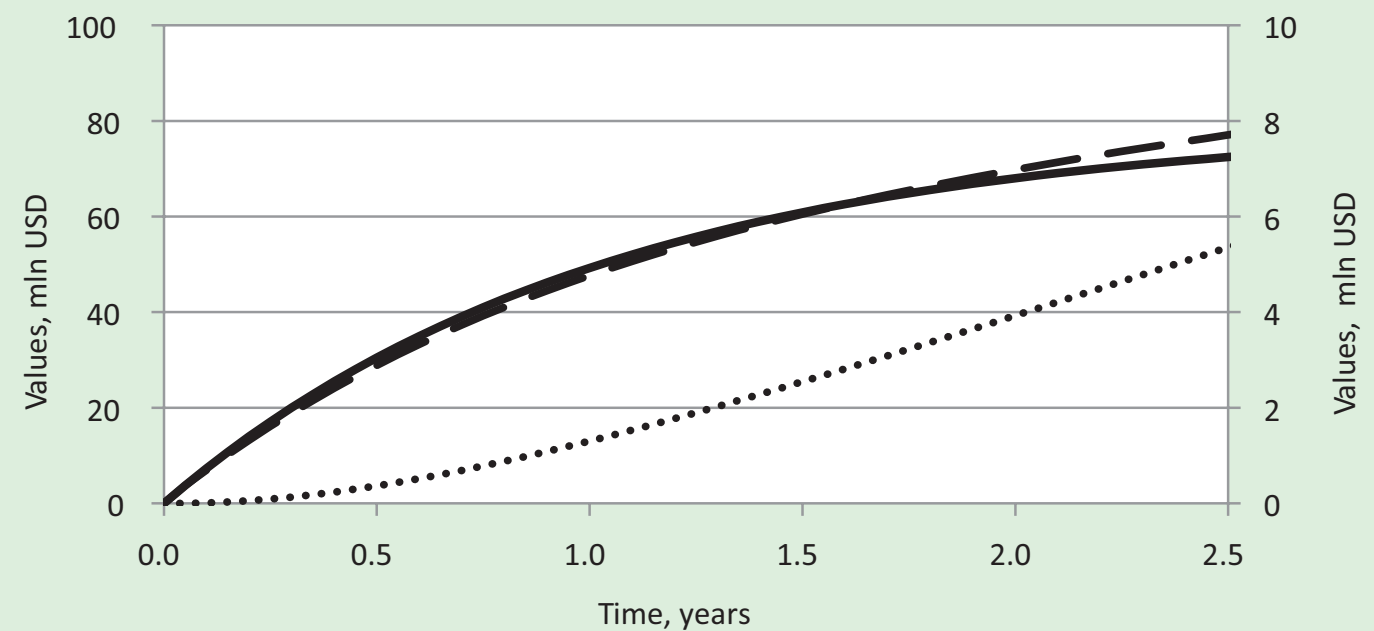

Good loans (left) $\quad$ - $\quad$ Firms' deposits (left) $\quad \ldots .$. Bad loans (right)

Figure 2. Dynamics of good and bad inventories of firms (developed by author)

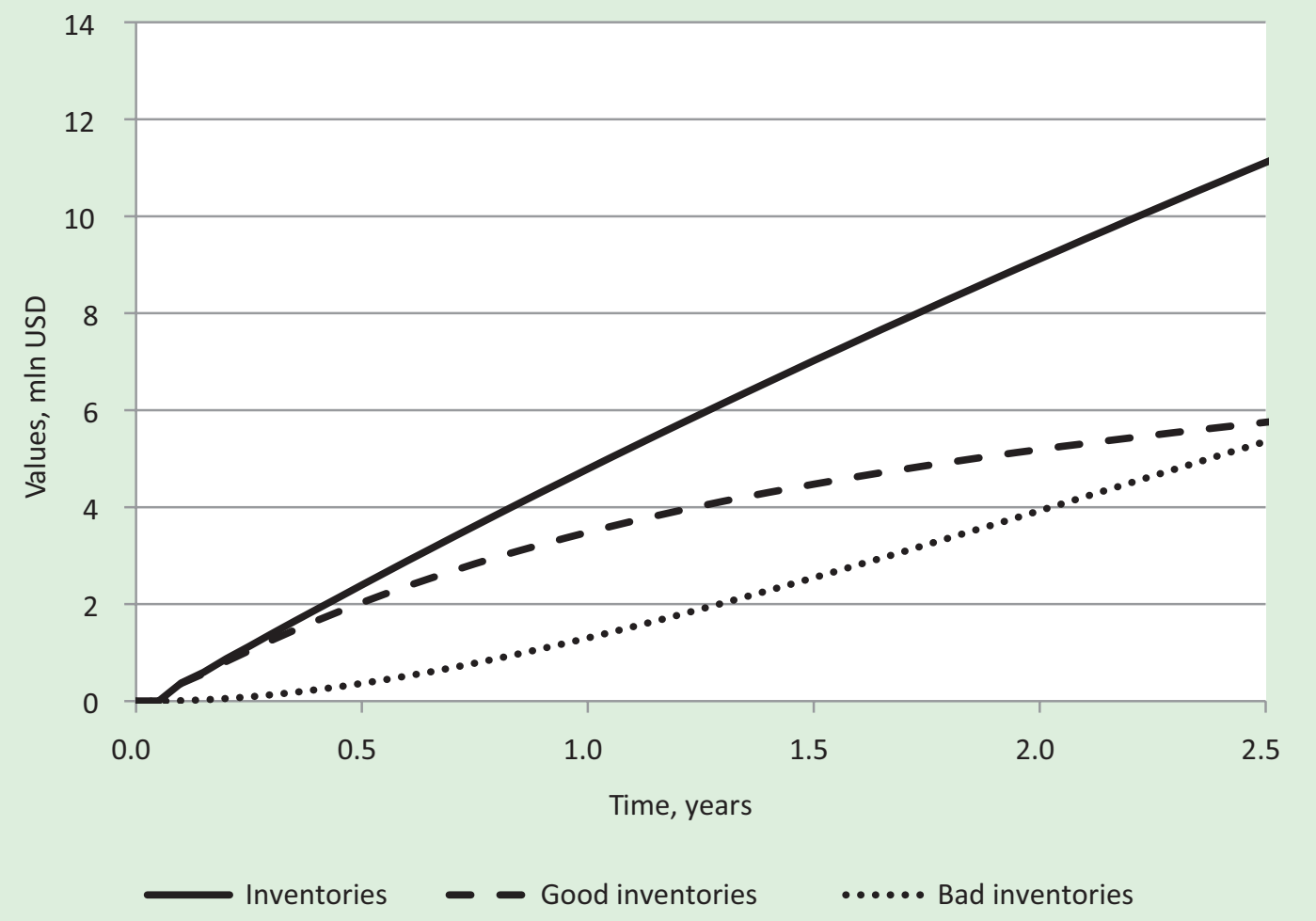


As shown in Figures 1 and 2, the defaulted firms are not in time to fire-sale goods under the model's parameters. Consequently, both the bad loans and the bad inventories are accumulated on aggregated balance sheets of firms.

\section{Figure 3. Dynamics of net wealth of households, firms, and banks (developed by author)}

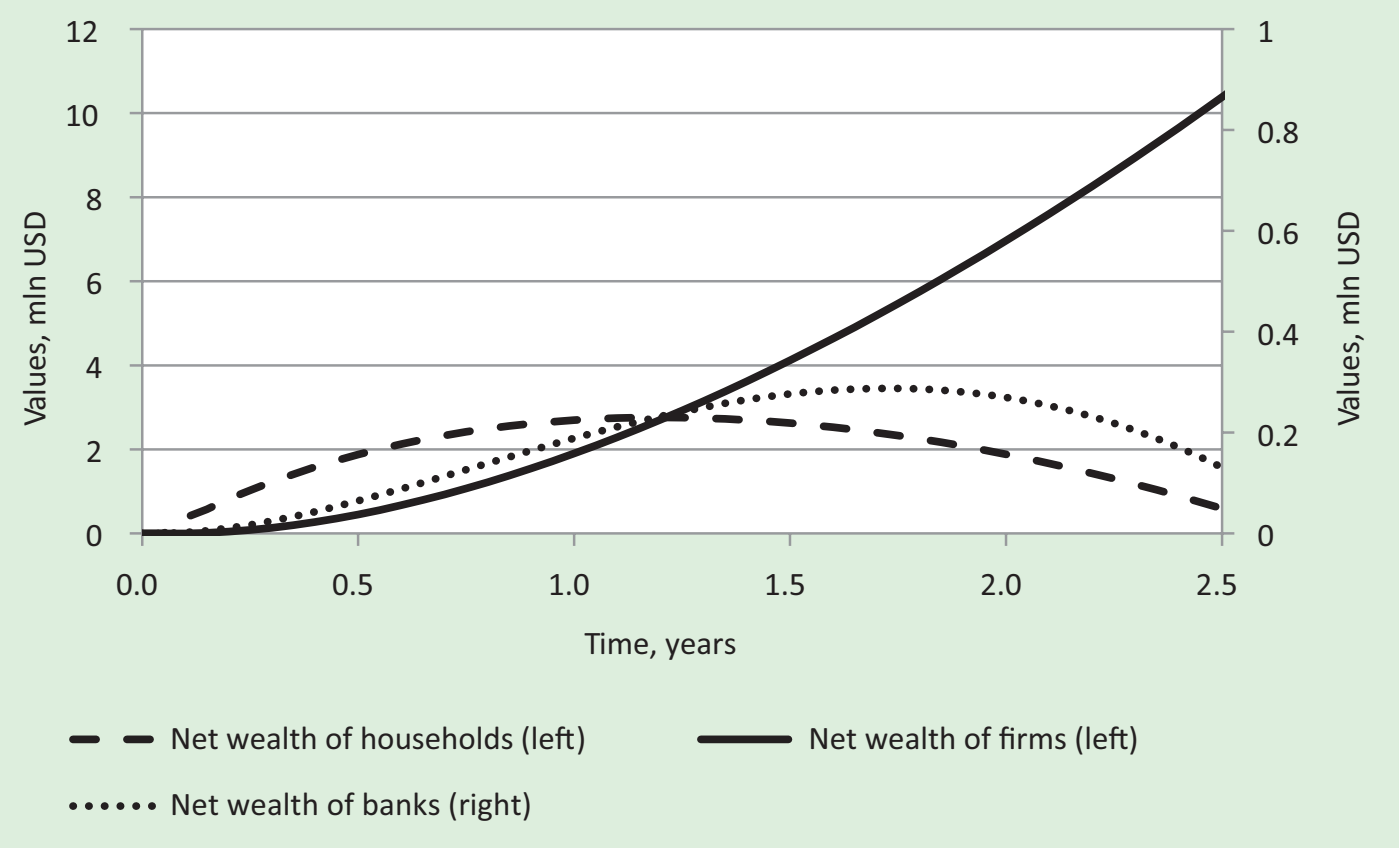

The net wealth of firms rises since the cost of default is zero, while both the net wealth of banks and households at the beginning runs high and then falls. The reasons for such behavior of the net wealth of banks and households are significantly different. The net wealth of banks begins to fall due to accumulation of credit losses on bad loans. Whereas, the net wealth of households does begin to fall due to profit paradox (Voloshyn I. and Voloshyn M., 2016), when workers of households have insufficient money in order to buy out all produced goods due to the existence of a price markup.

The balance sheet matrix of the economy at time $t=0.7$ years is presented in Table 6 .

Table 6. The balance sheet matrix of the economy at time $t=0.7$ years

\begin{tabular}{|c|c|c|c|c|}
\hline & Households & Firms & Banks & $\Sigma$ \\
\hline Inventories & & +3.37 & & +3.37 \\
\hline Deposits & +2.33 & +37.33 & -39.66 & $\mathbf{0}$ \\
\hline Loans & & -39.78 & +39.78 & $\mathbf{0}$ \\
\hline Net wealth & -2.33 & -0.92 & -0.12 & -3.37 \\
\hline$\Sigma$ & 0 & 0 & 0 & 0 \\
\hline
\end{tabular}

\section{CONCLUSIONS AND DIRECTIONS FOR FURTHER INVESTIGATION}

Sequentially examining the full chain of events starting from the default of firms through the fire-sale of goods towards writeoffs of bad loans, a new matrix of financial transactions was developed. As a result, there was an understanding of how firms' defaults affect all economic agents. It was shown that if firms have no equities, the cost of default of those firms equals zero. Indeed, firms suffer from losses on fire-sales but at the same time, they have a benefit from write-offs of their loans. Whereas, banks incur only the losses on bad loans. According to Shubik and Wilson (1977), this situation may restrain lending to the economy.

The considered matrix of financial transactions was incorporated into the transactions-flows matrix of a closed economy consisting of households, firms, and banks. The matrix obtained significantly differs from Godley's and Lavoie's matrix that the 
flows caused by write-offs of bad loans were taken to flows of incomes and expenses, not to the flows generated by changes in operating assets and liabilities.

A hallmark of the flow model is to use the assumption that normal and fire-sales consumptions depend on the rate of sales of inventories of non-defaulted and defaulted firms, respectively. While Keen's model assumes that consumption depends on the stock of deposits (Keen, 2010).

On the basis of the balance sheet and transactions-flows matrices, a mathematical model of the economy was developed. The stock-flow consistent framework used allows us to be sure that nothing will be lost neither in stocks nor in flows. Our model is rich enough to release the taken assumptions in order to bring the model closer to reality.

The model allows studying how key parameters such as the probability of default, the rate of fire-sales (newly injected parameter), recovery rate, and interest rates on loans and deposits affect the performance of banks and firms, observing economic dynamics in time. It should be noted that the mathematical model can be used in various macroeconomic models not necessarily based on the SFC framework.

Numerical simulation of the model was carried out. Under the chosen parameters of the models, the net wealth of firms rises due to the cost of default being zero, while both the net wealth of banks and households at the beginning run high and then fall. The reasons for such behavior of the net wealth are significantly different. The net wealth of banks begins to fall due to the accumulation of credit losses. Whereas, the net wealth of households begins to fall due to profit paradox (Keen, 2010), when workers of households have insufficient money in order to buy out all produced goods due to the existence of a price markup.

For further investigation, we are planning to explore the relationship between defaults of both firms and banks. In this case, we will consider that the probability of default depends on the structure of the aggregated balance sheet of firms. We will presume that interest rates on loans will be set by banks on a risk-based rule.

\section{References}

- Benes J., Kumhof M. Laxton D. (2014). Financial Crises in DSGE Models: A Prototype Model. Working Paper Series, Vol. 14, No. 57-59, IMF.

- Caiani A., Godin A., Caverzasi E., Gallegati M., Kinsella S., Stiglitz J.E. (2016). Agent Based-Stock Flow Consistent Macroeconomics: Towards a Benchmark Model. Journal of Economic Dynamics and Control, No. 69, pp. 375-408. https://doi.org/10.1016/i.jedc.2016.06.001

- Godley W. (1996). Money, finance and national income determination: An integrated approach. Working Paper, No. 167, The Levy Economics Institute of Bard College.

- Godley W., Lavoie M. (2007). Monetary Economics. An Integrated Approach to Credit, Money, Income, Production and Wealth. UK: Palgrave Macmillan. https://doi.org/10.1057/9780230626546

- Goodhart C.A.E. (2008). Money and Default. In Mathew Forstater and L. Randall Wray (eds.), Keynes for the Twenty-First Century: The continuing relevance of the General Theory. New York: Palgrave Macmillan, pp. 213-223.

- Goodhart C.A.E., Tsomocos D.P. (2011). The Role of Default in Macroeconomics, IMES Discussion Paper Series, No. 2011E-23, pp. 1-25.

- Graziani A. (2003). The Monetary Theory of Production. Cambridge, UK: Cambridge University Press, p. 176. https://doi. org/10.1017/CBO9780511493546

- Kalecki M. (1971). Selected Essays on the Dynamics of the Capitalist Economy. - Cambridge: Cambridge University Press, pp. 35-42.

- Keen S. (2010). Solving the Paradox of Monetary Profits. Economics: The Open-Access, Open-Assessment E-Journal, Vol. 4, No. 31.

- Shubik M., Wilson C. (1976). A Theory of Money and Financial Institutions. Part 30 (revised). The Optimal Bankruptcy Rule in a Trading Economy Using Fiat Money. Zeitschrift fur Nationalokonomie, Vol. 37, No. 3-4, pp. 337-354.

- Stellian R., Buitrago J.P.D. (2014). Business Bankruptcy: An Agent-Based Model, A Monetary Analysis. Seminario 372.

- Voloshyn I., Voloshyn M. (2016). The Model of Closed Economy with Full Consumption of Products. Working Paper, https://doi.org/10.13140/rg.2.1.2918.0403 
- White W.R. (2010). The Mayekawa Lecture: Some Alternative Perspectives on Macroeconomic Theory and Some Policy Implications. Monetary and Economic Studies, No. 28, Institute for Monetary and Economic Studies, Bank of Japan, pp. 35-58.

- Yamaguchi K. (2013). Money and Macroeconomic Dynamics. Accounting System Dynamics Approach. Edition 2.0. - Japan: Japan Futures Research Center. 